NBER WORKING PAPER SERIES

\title{
AGGREGATE IMPLICATIONS OF INNOVATION POLICY
}

\author{
Andrew Atkeson \\ Ariel T. Burstein \\ Working Paper 17493 \\ http://www.nber.org/papers/w17493 \\ NATIONAL BUREAU OF ECONOMIC RESEARCH \\ 1050 Massachusetts Avenue \\ Cambridge, MA 02138 \\ October 2011, Revised June 2018
}

We thank Manolis Hatzikonstantinou and Liyan Shi for research assistance, and Ufuk Akcigit, Costas Arkolakis, Francisco Buera, Arnaud Costinot, Chad Jones, Pete Klenow, Rasmus Lentz, Ellen McGrattan, Juan Pablo Nicolini, Pedro Teles, Aleh Tsyvinski, Ivan Werning, and four anonymous referees for very useful comments. We thank the National Science Foundation (Award Number 0961992) for research support. The views expressed herein are those of the authors and not necessarily those of the Federal Reserve Bank of Minneapolis, the Federal Reserve System, or National Bureau of Economic Research.

NBER working papers are circulated for discussion and comment purposes. They have not been peer-reviewed or been subject to the review by the NBER Board of Directors that accompanies official NBER publications.

(C) 2011 by Andrew Atkeson and Ariel T. Burstein. All rights reserved. Short sections of text, not to exceed two paragraphs, may be quoted without explicit permission provided that full credit, including ( $)$ notice, is given to the source. 
Aggregate Implications of Innovation Policy

Andrew Atkeson and Ariel T. Burstein

NBER Working Paper No. 17493

October 2011, Revised June 2018

JEL No. E6,O11,O3

\begin{abstract}
$\underline{\text { ABSTRACT }}$
We examine the quantitative impact of policy-induced changes in innovative investment by firms on growth in aggregate productivity and output in a model that nests several of the canonical models in the literature. We isolate two statistics, the impact elasticity of aggregate productivity growth with respect to an increase in aggregate innovative investment and the degree of intertemporal knowledge spillovers in research, that play a key role in shaping the model's predicted dynamic response of aggregate productivity, output, and welfare to a policy-induced change in the innovation intensity of the economy. Given estimates of these statistics, we find that there is only modest scope for increasing aggregate productivity and output over a 20-year horizon with uniform subsidies to firms' investments in innovation of a reasonable magnitude, but the welfare gains from such a subsidy may be substantial.
\end{abstract}

Andrew Atkeson

Bunche Hall 9381

Department of Economics

UCLA

Box 951477

Los Angeles, CA 90095-1477

and NBER

andy@atkeson.net

Ariel T. Burstein

Department of Economics

Bunche Hall 8365

Box 951477

UCLA

Los Angeles, CA 90095-1477

and NBER

arielb@econ.ucla.edu 


\section{Introduction}

Firms' investments in innovation are large relative to GDP and are likely an important factor in accounting for economic growth over time. ${ }^{1}$ Many OECD countries use taxes and subsidies to encourage these investments in the hope of stimulating economic growth. ${ }^{2}$ But what impact should we expect changes in firms' investments in innovation induced by changes in innovation subsidies to have on aggregate productivity and output at various time horizons? What are the welfare implications of subsidy-induced changes in firms' investments in innovation? And what would be the fiscal cost of such subsidies?

We examine these questions in a model that nests some of the canonical models of the interaction of firms' investments in innovation and aggregate productivity growth that have been developed over the past several decades. Our first contribution is to frame the quantitative answers to these questions in terms of two sufficient statistics that apply across a broad class of models in the literature. Our second contribution is to measure, under certain restrictions, one of these sufficient statistics, drawing on both available estimates in the literature and our own measurements.

Equipped with estimates of these statistics, we find that there is only modest scope for increasing aggregate productivity and output over a 20-year horizon with uniform subsidies to firms' investments in innovation of a reasonable magnitude (the fiscal cost of the subsidies we consider are on the order of $1 \%$ of aggregate output annually). The magnitude of the model-implied movements in aggregate productivity and output that result over a 20-year horizon from such an increase in innovation subsidies would be difficult to distinguish from normal business cycle fluctuations in these variables. In contrast, we find that the welfare gains from this change in subsidies may be substantial because changes in innovation subsidies can have a large cumulative impact on aggregate productivity and output over very long horizons.

We conduct our assessment of the aggregate implications of innovation policies in a framework that allows for consistent comparisons of the quantitative predictions of a range of models. The model we use extends the model of firm dynamics in Garcia-

\footnotetext{
${ }^{1}$ There is a wide range of estimates of the scale of firms' investments in innovation. In the US national income and product accounts as revised in 2013, investments in intellectual property products in the nonfinancial corporate sector were $6.1 \%$ of value added in that sector averaged over the period 1990-2014 (see Section 6 for additional details). Of that amount, roughly half was private research and development. Corrado et al. (2009) propose a broader measure of firms' investments in innovation, which includes nonscientific R\&D, brand equity, firm-specific resources, and business investment in computerized information. These broader investments in innovation accounted for roughly $13 \%$ of nonfarm output in the United States in 2005.

${ }^{2}$ See, for example, Bloom et al. (2002) and Chapter 5 of the OECD's 2009 report “Economic Policy Reform: Going for Growth," http://www.oecd.org/eco/growth/economicpolicyreformsgoingforgrowth2009.htm.
} 
Macia et al. (2016). This model includes innovation by entering firms and innovations by incumbent firms to acquire products new to the firm (either new to society or "stolen" from other firms) and to improve firms' existing products as drivers of firm dynamics and aggregate productivity growth. We extend this model to include a description of the technologies linking firms' innovative investments and the arrival of those innovations that are left unmodeled in their paper. We make assumptions that allow for enough aggregation of investments across firms to permit us to characterize the model's transition dynamics analytically and to make use of aggregate data in our measurement. ${ }^{3}$

With these assumptions, our model nests the aggregate model of Jones (2002), NeoSchumpeterian models based on the quality ladder framework which emphasize the role of business stealing by innovators - such as those described in Grossman and Helpman (1991b), Aghion and Howitt (1992), Klette and Kortum (2004), and Acemoglu and Cao (2015) - and models based on the expanding varieties framework of Romer (1990) which emphasize the role of new product creation by innovators - such as those described in Grossman and Helpman (1991a), Luttmer (2007), Atkeson and Burstein (2010), and Luttmer (2011). As described in Aghion et al. (2014), these are influential models that link micro data on firm dynamics to incumbent and entrant firms' investments in innovation and, in the aggregate, to economic growth in a tractable manner. ${ }^{4}$

To make our first contribution, we develop simple analytical results characterizing the cumulative impulse responses of the logarithm of aggregate productivity and output with respect to a policy-induced change in the innovation intensity of the economy as measured by the ratio of firms' spending on innovation relative to output. Given other standard parameters, the dynamics of aggregate productivity and output can be summarized, up to a first-order approximation, by two sufficient statistics: the impact elasticity of aggregate productivity growth with respect to an increase in aggregate real innovative investment, which we denote by $\Theta$, and the degree of intertemporal knowledge spillovers in research, which we denote by $\phi$. Not only do these sufficient statistics determine the model's positive implications for the dynamics of aggregate productivity and output in response to a

\footnotetext{
${ }^{3}$ Our model is related to the model in Akcigit and Kerr (2010), in which firms engage in the three types of innovative investment that we consider. They focus on the extent to which the intensity of incumbent firms' investments in innovation scales with their size, whereas we focus on characterizing the dynamics of aggregate productivity and welfare in response to changes in innovation policy. Ferraro et al. (2017) present numerical results on the aggregate impact of various tax policies in an endogenous growth model in which incumbent firms (which are identical in equilibrium) invest to improve their own products and entering firms invest to add new products.

${ }^{4}$ Our framework does not nest some recent models discussed in the literature, including Lentz and Mortensen (2008), Akcigit and Kerr (2010), the second model considered in Luttmer (2011), Lentz and Mortensen (2016), and Peters (2016). As we discuss in Appendix D, the transition dynamics in these models are substantially less tractable than in our model.
} 
policy-induced change in the allocation of labor to research, but they also play a key role in determining the model's normative implications for the welfare impact of changes in innovation policy. We also present analytical results for the fiscal cost in the long run of innovation subsidies required to implement a given permanent change in the innovation intensity of the economy.

To make our second contribution, we use our model to measure one of these sufficient statistics - the impact elasticity $\Theta$ of aggregate productivity growth with respect to a policy-induced change in aggregate real innovative investment. Under certain restrictions, in response to a proportional change in innovation subsidies for all types of innovative investment by firms, the elasticity $\Theta$ is bounded above by the ratio of the contribution of the innovative investments of entering firms to trend productivity growth, relative to the fraction of aggregate expenditure on innovative investment undertaken by entering firms.

In our quantitative analysis, to measure the bound on the impact elasticity $\Theta$, we use estimates of the contribution of innovative investments of entering firms to trend productivity growth presented in Akcigit and Kerr (2010) and Garcia-Macia et al. (2016). We also develop a simple method for using data on firm dynamics and the value of intangible capital in firms to infer the (unmeasured) share of aggregate innovative investment undertaken by entering firms. Our measurement of the value of intangible capital in firms in this step of the analysis follows the work of Hall (2003), McGrattan and Prescott (2005), and others. Finally, we rely on the work of Jones (2002), Fernald and Jones (2014), and Bloom et al. (2017) for estimates of intertemporal knowledge spillovers $\phi$.

While in our measurement we focus on the impact of proportional changes in innovation subsidies for all types of innovation by firms, we also derive analytical results regarding the impact on the dynamics of aggregate productivity and output of more general changes in innovation policies that might favor one type of innovative investment by firms over another. These results highlight how it might be possible to use innovation policies to achieve a large increase in aggregate productivity and output in the near term if one could find a policy that induced a reallocation of innovative investment away from investments that make a small contribution to aggregate productivity growth toward those that do. ${ }^{5}$ Using these results for practical analysis of more general changes in policies requires measurement of incumbent firms' elasticity of innovative investment

\footnotetext{
${ }^{5}$ These results are related to a recent literature examining the possibility that growth could be stimulated by using policies to reallocate innovative investment across firms without increasing aggregate real innovative investment (see, for example, Acemoglu et al. 2013, Lentz and Mortensen 2016, and Peters 2016). One challenge for this research is to find reliable metrics for evaluating which firms should be doing relatively more innovation spending and which should be doing less.
} 
with respect to specific policy changes.

Finally, our paper is related to a very large literature that uses a straightforward extension of the standard growth model to measure the contribution of firms' investments in intangible capital to the growth of aggregate productivity and output. ${ }^{6}$ One feature that distinguishes our framework from this prior literature is that, in our model, there is no obvious aggregate intangible capital stock. More important, our model allows for a large gap between the social and private returns to firms' investments in innovation. This gap between private and social returns to innovation arises from external increasing returns at the aggregate level of the economy (from love for variety), business stealing in firms' innovations, and intertemporal technological spillovers across firms as current innovative investments affect the cost of future innovation. These features of our modeling framework require us to develop new methods for measurement.

The paper is organized as follows. In Section 2, we introduce a simple version of the model that includes only innovative investment by entering firms. In Section 3, we introduce our two sufficient statistics and use them to characterize analytically, up to a first-order approximation, our model's positive and normative implications for the equilibrium dynamics of aggregate productivity and output resulting from a policy-induced change in the investments in innovation by entering firms, as well as the fiscal cost of the subsidies required to induce a given change in innovative investments. In Section 4, we introduce innovative investment by incumbent firms into the model, and in Section 5 we present the assumptions needed to extend our analytical result from Section 3 to our full model. In Section 6, we outline the procedure and data we use to conduct our measurement. In Section 7, we present our quantitative results. In Section 8, we conclude. In Appendix A we give a full definition of equilibrium in our model, in Appendix B we provide all proofs, in Appendix $C$ we provide a complete description of our measurement procedure, and in Appendices D and E, we discuss a number of model variations.

\section{Model}

In this section we describe the environment and then present equilibrium conditions that we use when deriving our analytic results in Section 3. We provide a full definition of equilibrium in Appendix A. In this section we focus on a simplified version of the model

\footnotetext{
${ }^{6}$ See, for example, Kendrick (1994), Griliches (1992), McGrattan and Prescott (2005), and Corrado and Hulten (2014). The Bureau of Economic Analysis uses these standard growth accounting methods to incorporate a measure of the stock of intangible capital induced by firms' investments in innovation in the fixed assets accounts for the United States and to assess the contribution of firms' accumulation of intangible capital to economic growth.
} 
in which only entering firms engage in innovative investment. After developing our analytical results in this simplified framework, in Sections 4 and 5 we provide conditions under which these results extend to a version of the model in which both entering and incumbent firms engage in innovative activities.

\subsection{Environment}

Time is discrete and labeled $t=0,1,2, \ldots$. There are two final goods, the first of which we call the consumption good and the second of which we call the research good.

Output of the consumption good, denoted by $Y_{t}$, is used for two purposes: as consumption by the representative household, $C_{t}$, and as gross investment in physical (tangible) capital $K_{t+1}$. The resource constraint for the final consumption good is given by

$$
Y_{t}=C_{t}+K_{t+1}-\left(1-d_{k}\right) K_{t}
$$

where $K_{t}$ denotes the aggregate physical capital stock and $d_{k}$ denotes the depreciation rate of physical capital. In what follows, we refer to $Y_{t}$ as aggregate output.

The representative household has preferences over consumption per capita $C_{t} / L_{t}$ given by

$$
\sum_{t=0}^{\infty} \frac{\beta^{t}}{1-\gamma} L_{t}\left(C_{t} / L_{t}\right)^{1-\gamma},
$$

with $\beta \leq 1$ and $\gamma>0$. Here, $L_{t}$ denotes the population (each of which supplies inelastically one unit of labor) which grows at an exogenous rate $\bar{g}_{L}$.

The consumption good The consumption good $Y_{t}$ is produced as a constant elasticity of substitution (CES) aggregate of the output of a continuum of differentiated intermediate goods. At each date $t$, the technology with which any particular intermediate good can be produced is summarized by its productivity index $z$. Production of an intermediate good with productivity index $z$ is carried out with physical capital, $k$, and labor, $l$, according to

$$
y_{t}(z)=z k_{t}(z)^{\alpha} l_{t}(z)^{1-\alpha}
$$

where $0<\alpha<1$. To simplify our notation, we assume that the support of $z$ is a countable grid with elements $z_{n}=\exp (n \Delta)$ for integers $n$. For each intermediate good that can be produced at time $t$, we refer to the technology with the highest value of $z$ on this grid available for producing this good as the frontier technology for producing this good. 
Aggregate output is then given by the CES aggregator

$$
Y_{t}=\left[\sum_{z} y_{t}(z)^{(\rho-1) / \rho} M_{t}(z)\right]^{\rho /(\rho-1)}
$$

with $\rho>1$. Here, $y_{t}(z)$ denotes the output of each intermediate good with productivity index $z$, and $M_{t}(z)$ is the measure of intermediate goods with frontier technology indexed by $z$ at time $t^{7}$

We let $L_{p t}=\sum_{z} l_{t}(z) M_{t}(z)$ denote the aggregate amount of labor engaged in current production of intermediate goods at time $t$. The resource constraint for physical capital requires that $K_{t}=\sum_{z} k_{t}(z) M_{t}(z)$.

We assume that in each period $t$, physical capital and labor are freely mobile across intermediate goods producing firms and that the markup $\mu \geq 1$ of price over marginal cost charged by intermediate goods producers is constant across intermediate goods and over time. ${ }^{8}$ In equilibrium, aggregate output can be written as

$$
Y_{t}=Z_{t}\left(K_{t}\right)^{\alpha}\left(L_{p t}\right)^{1-\alpha}
$$

where $Z_{t}$ is given by

$$
Z_{t}=\left[\sum_{z} z^{\rho-1} M_{t}(z)\right]^{1 /(\rho-1)}
$$

Hence, we refer to $Z_{t}$ as aggregate productivity at time $t .{ }^{9}$ We refer to $M_{t}=\sum_{z} M_{t}(z)$ as the total measure of products available, and to the ratio $Z_{t}^{\rho-1} / M_{t}$ as the average productivity index of existing intermediate goods (specifically, the average of $z^{\rho-1}$ across intermediate

\footnotetext{
${ }^{7}$ Under the assumption of a CES aggregator, the productivity index $z$ for intermediate goods can be reinterpreted as a measure of product quality (so that firms innovate to improve the quality of products rather than to increase their productivity), without changing the results in this paper. We require $\rho>1$ for two reasons: first, to allow for growth in the measure of intermediate goods and, second, to give incumbents incentives to invest in innovation to improve their own goods in this economy with constant markups.

${ }^{8}$ As is standard, with Bertrand competition and limit pricing, the gross markup $\mu$ charged by the incumbent producer of each product is the minimum of the monopoly markup, $\rho /(\rho-1)$, and the technology gap between the leader with productivity index $z$ and any potential second most productive producer of the good, with productivity index $z / \bar{\mu}$ (with $\bar{\mu}>1$ ), which potentially depends on the patent system. That is $\mu=\min \left\{\frac{\rho}{\rho-1}, \bar{\mu}\right\}$.

${ }^{9}$ In general, this model-based measure of aggregate productivity, $Z_{t}$, does not correspond to measured total factor productivity (TFP), which is given by TFP $P_{t}=G D P_{t} /\left(K_{t}^{\tilde{\alpha}} L_{t}^{1-\tilde{\alpha}}\right)$, where the definition of GDP depends on the measurement standard for expenditures on innovative investment being used (e.g., the definition of output of the final consumption good $Y_{t}$ in equation (1) corresponds to the pre-2013 measurement of GDP, which did not include expenditures on innovative investment), and $1-\tilde{\alpha}$ denotes the share of labor compensation in measured GDP. Our analytic comparative statics can be used to construct alternative measures of TFP and GDP.
} 
goods).

Let

$$
s_{t}(z) \equiv\left(\frac{z}{Z_{t}}\right)^{\rho-1}
$$

We refer to the term $s_{t}(z)$ as the size of an intermediate good with index $z$ at time $t$ since in equilibrium this term is equal to the share of revenues and inputs allocated to an intermediate good with productivity index $z$.

The research good The second final good in this economy, which we call the research good, is the input used for innovative investment by firms. Production of the research good is carried out using research labor $L_{r t}=L_{t}-L_{p t}$. Output of the research good is given by ${ }^{10}$

$$
Y_{r t}=A_{r t} Z_{t}^{\phi-1} L_{r t}
$$

Here, $A_{r t}$ represents the stock of freely available scientific progress, which grows at an exogenous rate $\bar{g}_{A_{r}}{ }^{11}$ The term $Z_{t}^{\phi-1}$ with $\phi \leq 1$ reflects intertemporal knowledge spillovers in the production of the research good, as in the model of Jones (2002). Using the language of Bloom et al. (2017), $A_{r t} Z_{t}^{\phi-1}$ denotes the productivity with which research labor $L_{r t}$ translates into a real flow of "ideas" $Y_{r t}$ available to be applied to innovative investment. Exogenous scientific progress drives up research productivity over time. If $\phi<1$, then increases in the level of aggregate productivity $Z_{t}$ reduce research productivity in the sense that "ideas become harder to find." Because the impact of advances in $Z_{t}$ on research productivity is external to any particular firm, we call it a "spillover." The parameter $\phi$ indexes the extent of this spillover.

An intermediate goods producing firm in our model is an organization that owns the exclusive rights to use the frontier technology for producing one or more intermediate goods. Aggregate productivity in our model grows as a result of innovations by intermediate goods producing firms that increase the average productivity index $z$ of frontier

\footnotetext{
${ }^{10}$ Here, for simplicity, we assume that the research good is produced entirely with labor. In Appendix E.2 we consider an extension in which research production uses both labor and the consumption good, as in the lab-equipment model of Rivera-Batiz and Romer (1991).

${ }^{11}$ It is common in the theoretical literature on economic growth with innovating firms to assume that all productivity growth is driven entirely by firms' expenditures on R\&D (Griliches 1979, p. 93). As noted in Corrado et al. (2011), this view ignores the productivity-enhancing effects of investments by actors other than business firms. We capture all of these other productivity-enhancing effects with $A_{r}$. Relatedly, Akcigit et al. (2013) consider a growth model that distinguishes between basic and applied research and introduces a public research sector. As we discuss below, the only role served by the exogenous growth of scientific progress $A_{r t}$ in our analysis is that, by adjusting the parameter $\bar{g}_{A_{r}}$, we can target a given baseline growth rate of output in the balanced growth path as we vary the parameter $\phi$ (for a given growth rate of population, $\left.\bar{g}_{L}\right)$.
} 
technologies available for existing intermediate goods and increase the total measure of intermediate goods available. These innovations arrive at rates determined by the investments in innovation undertaken by these firms.

We refer to those firms producing intermediate goods at $t$ that also produced at $t-1$ as incumbent firms. We refer to those firms at $t$ that are new (and hence did not produce intermediate goods at $t-1$ ) as entering firms. In our first simplified presentation of our model, we assume that only entering firms engage in innovative investment. For incumbent firms, there are no innovations on the products that they produce. In addition, an exogenous fraction $\delta_{0}$ of the products produced by incumbent firms exit each period. In Section 4, we extend our model to consider the aggregate implications of innovative investment when such investment is undertaken by both incumbent and entering firms.

\subsection{Innovative investment by entering firms}

Entering firms purchase units of the research good to invest in obtaining the frontier technology to produce an intermediate good that is new to that entering firm. Let $M_{e t+1}$ denote the measure of entering firms engaging in innovative investment at $t$. Each of these $M_{e t+1}$ entering firms at $t$ acquires at the start of period $t+1$ a frontier technology to produce an intermediate good that is new to this entering firm with some productivity index $z^{\prime}$.

With probability $\delta_{e}$, this productivity index $z^{\prime}$ drawn by the entrant at $t+1$ is associated with an intermediate good that was already being produced by an incumbent firm at $t$, but with a lower productivity index. Since identical intermediate goods are perfect substitutes in the production of the final consumption good, competition in the product market between the entering firm and the previous incumbent producer of this intermediate good implies that the previous incumbent producer ceases production of the good. In this case, the innovative investment by the entering firm does not result in a net increase in the total measure of products available $M_{t+1}$. Instead, it only results in a positive increment to the average productivity index across existing products. As is common in the literature, we say that this intermediate good that is new to the entering firm was stolen from an incumbent firm.

With the complementary probability $1-\delta_{e}$, this technology allows this entering firm to produce an intermediate good that is new to society as a whole in the sense that it has elasticity of substitution in demand with all other existing intermediate goods determined by $\rho$. In this case, the innovative investment by the entering firm results in a net increase in the total measure of products available $M_{t+1}$. The parameter $\delta_{e}$ thus indexes the extent 
of business stealing by entering firms.

The productivity index $z^{\prime}$ for stolen products in entering firms is drawn in a manner similar to that in Klette and Kortum (2004) and other standard quality ladder models. Specifically, we assume that stolen products in entering firms at $t+1$ have a productivity index $z^{\prime}$ drawn from a distribution such that the expected value of the random variable $z^{\prime}$ raised to the power of $(\rho-1)$ is equal to $\mathbb{E} z^{\prime \rho-1}=\eta_{e s} Z_{t}^{\rho-1} / M_{t}$, with $\eta_{e s}>1 .^{12}$

The productivity index $z^{\prime}$ for products that are new to society in entering firms is drawn in a manner similar to that in Luttmer (2007). Specifically, we assume that new products in entering firms at $t+1$ have a productivity index $z^{\prime}$ drawn from a distribution such that $\mathbb{E} z^{\prime \rho-1}=\eta_{e n} Z_{t}^{\rho-1} / M_{t}$, with $\eta_{e n}>0$.

These assumptions imply that the average value of $z^{\prime \rho-1}$ across all products produced by entering firms at $t+1$ is given by $\mathbb{E} z^{\prime \rho-1}=\eta_{e} Z_{t}^{\rho-1} / M_{t}$, where $\eta_{e} \equiv \delta_{e} \eta_{e s}+\left(1-\delta_{e}\right) \eta_{e n}$.

Now consider the innovative investment required of entering firms. The investment required at time $t$ is affected by aggregate spillovers. We specify these spillovers to ensure that, on a balanced growth path with growth in both the average productivity of products $Z_{t}^{\rho-1} / M_{t}$ and the total measure of products $M_{t}$, aggregate innovative investment by entering firms is constant over time. Specifically, an entrant at time $t$ spends $1 / M_{t}$ units of the research good to launch a new firm at $t+1$ with one product. ${ }^{13}$ If there are a total of $M_{e t+1}$ entering firms at time $t$, then they spend in total $x_{e t}=M_{e t+1} / M_{t}$ units of the research good and acquire $M_{e t+1}$ new products at $t+1$. The resource constraint for the research good is $x_{e t}=Y_{r t}$.

\subsection{Dynamics of aggregate productivity}

We now describe the evolution of the total measure of products available, $M_{t}$, and aggregate productivity, $Z_{t}$, that results from innovative investment by entering firms.

The evolution of the total measure of products available is governed by the exit by incumbent firms from production of existing intermediate goods and the entry into pro-

\footnotetext{
${ }^{12}$ In standard quality ladder models, $\eta_{e s}=\exp \left((\rho-1) \Delta_{s}\right)$, where $\Delta_{s}>0$ denotes the percentage improvement in productivity of stolen products. See Appendix E.3.

${ }^{13}$ The spillover we assume here from the total measure of products $M_{t}$ to the cost of entry follows Acemoglu (2009), Chapter 13.4. Our results are unchanged if each potential entrant chooses an investment level that determines its success probability to acquire a product and become an entering firm. Specifically, suppose that each potential entrant spends $\left(1+y_{e t}\right) / M_{t}$ units of the research good to launch a new firm at $t+1$ with probability of success $f\left(y_{e t}\right)$, where $y_{e t} \geq 0$ is a choice, and $f(\cdot)$ is weakly increasing and concave. (In our baseline model, $f(0)=1$, so $y_{e t}=0$.) With total spending $x_{e t}$ of the research good by potential entrants, the number of entering firms at $t+1$ is $M_{e t+1}=\frac{f\left(y_{e t}\right)}{1+y_{e t}} M_{t} x_{e t}$. With positive entry, the equilibrium level of $y_{e t}$ is constant over time and satisfies $1+y_{e t}=f\left(y_{e t}\right) / f^{\prime}\left(y_{e t}\right)$. Without loss of generality, in our baseline model we assume that $f\left(y_{e t}\right) /\left(1+y_{e t}\right)=1$.
} 
duction of intermediate goods by entering firms. Incumbent firms producing $M_{t}$ products at $t$ cease production of these goods for two reasons. First, a fraction $\delta_{0}$ of those products cease production exogenously. Second, a fraction $\delta_{e} M_{e t+1} / M_{t}=\delta_{e} x_{e t}$ of these products cease production because of the entry of a lower-cost alternative produced by an entering firm (a.k.a. business stealing). Under these assumptions, the dynamics of the total measure of products are given by

$$
M_{t+1}=\left[1-\delta_{0}+\left(1-\delta_{e}\right) x_{e t}\right] M_{t}
$$

The evolution of aggregate productivity $Z_{t}$ from $t$ to $t+1$ is as follows. A measure $M_{e t+1}$ of products produced at $t+1$ are produced in newly entered firms and have average productivity index $\mathbb{E} z^{\prime \rho-1}=\eta_{e} Z_{t}^{\rho-1} / M_{t}$. The complementary measure $M_{t+1}-M_{e t+1}$ of products are produced in incumbent firms that do not experience innovations and hence have average productivity index $\mathbb{E} z^{\prime \rho-1}=Z_{t}^{\rho-1} / M_{t}$ equal to the average productivity index of intermediate goods at date $t$. Thus, aggregate productivity at $t+1$ satisfies

$$
Z_{t+1}^{\rho-1}=\left[M_{t+1}-M_{e t+1}+\eta_{e} M_{e t+1}\right] \frac{Z_{t}^{\rho-1}}{M_{t}} .
$$

This observation, together with equations $M_{e t+1}=x_{e t} M_{t}$ (9), and the resource constraint for the research good, $x_{e t}=Y_{r t}$, imply that the dynamics of aggregate productivity as a function of innovative investment are summarized by

$$
g_{Z t} \equiv \log \left(Z_{t+1}\right)-\log \left(Z_{t}\right)=G\left(Y_{r t}\right)
$$

where

$$
G\left(Y_{r}\right)=\frac{1}{\rho-1} \log \left(1-\delta_{0}+\left(\eta_{e}-\delta_{e}\right) Y_{r}\right)
$$

\subsection{Policies}

In what follows, we consider our model's quantitative implications for the response of aggregate productivity growth at various horizons to a change in innovation subsidies. The innovation subsidies that we consider in our simple model are subsidies $\tau_{e t}$ to entering firms' expenditures on innovation. Specifically, a firm that purchases $x$ units of the research good at time $t$ pays $P_{r t} x$ to a research good producer for that purchase and then receives a rebate of $\tau_{e t} P_{r t} x$ from the government. Changes in innovation subsidies do not directly affect the form of functions $Z$ and $G$ defined in equations (6) and (11), but do result in changes in the equilibrium innovative investment by firms and hence to changes 
in aggregate productivity growth and in the time path for all other macroeconomic variables.

\subsection{Macroeconomic equilibrium conditions}

We provide a full description of the equilibrium in Appendix A. Here, we define some of the notation and present some of the equilibrium conditions we use in our analytic results below.

Households own their labor endowment, the physical capital stock, and incumbent intermediate good producing firms. Households finance investments in physical capital and innovation to create new firms (net of subsidies to innovation) and are subject to lump-sum taxes that finance innovation subsidies.

The final consumption good, whose price is normalized to 1 , is produced by competitive firms. Revenues from the sale of intermediate goods (equal to $Y_{t}$ ) are split into payments to factors of production as follows. A share $(\mu-1) / \mu$ of revenues accrues to variable profits from intermediate goods production, so that (in the absence of innovation by incumbent firms) aggregate dividends received by households at time $t$ are given by $D_{t}=\frac{(\mu-1)}{\mu} Y_{t}$. Of the remaining revenues, a share $\alpha / \mu$ is paid to the owners of physical capital, $R_{k t} K_{t}=\frac{\alpha}{\mu} Y_{t}$, and a share $(1-\alpha) / \mu$ is paid as wages to production labor, $W_{t} L_{p t}=\frac{(1-\alpha)}{\mu} Y_{t}$, where $W_{t}$ and $R_{k t}$ denote the economy-wide wage and rental rate of physical capital, respectively.

Production of the research good is undertaken either by competitive firms or in-house by intermediate good producing firms. These producers do not internalize the intertemporal knowledge spillover from innovation in equation (8). Under these assumptions, the price of the research good, $P_{r t}$, is equal to its marginal cost,

$$
P_{r t}=\frac{Z_{t}^{1-\phi}}{A_{r t}} W_{t}
$$

Given that the research good is priced at marginal cost, wage payments to research labor equal revenues from production of the research good: $W_{t} L_{r t}=P_{r t} Y_{r t}$.

We define the innovation intensity of the economy, $i_{r t}$, as the ratio of innovation expenditure $P_{r t} Y_{r t}$ to output $Y_{t}$, that is, $i_{r t} \equiv P_{r t} Y_{r t} / Y_{t}$. Using the factor shares above and the assumption that labor is freely mobile between production and research, the ratio of production labor to total labor and the ratio of research labor to total labor, $l_{p t} \equiv L_{p t} / L_{t}$ and 
$l_{r t} \equiv L_{r t} / L_{t}$, are related to the innovation intensity of the economy $i_{r t}$ by

$$
l_{r t}=\frac{i_{r t}}{i_{r t}+(1-\alpha) / \mu} \text { and } l_{p t}=1-l_{r t} \text {, }
$$

where the term $(1-\alpha) / \mu$ is the share of labor compensation in output. ${ }^{14}$

We denote total fiscal expenditures in period $t$ on innovation subsidies by $E_{t}$. In the simplified model with only innovation by entrants, $E_{t}=\tau_{e t} i_{r t} Y_{t}$.

\subsection{Balanced growth path}

To develop our analytical results, we consider the impact of changes in innovation policies on the macroeconomic dynamics of an economy that starts on an initial balanced growth path (BGP). We consider BGPs of the following form. Output of the final consumption good and the stock of physical capital both grow at a constant rate $\bar{g}_{Y}$, and aggregate productivity grows at a constant rate $\bar{g}_{Z}=(1-\alpha)\left(\bar{g}_{Y}-\bar{g}_{L}\right)$. The innovation intensity of the economy $i_{r t}$, the allocation of labor to production and research $l_{p t}$ and $l_{r t}$, and output of the research good $Y_{r t}$ all remain constant over time at the levels $\bar{i}_{r}, \bar{l}_{p}, \bar{l}_{r}$, and $\bar{Y}_{r}$, respectively. In specifying the production function for the research good (8) and firms' technology for innovative investment, we have followed Jones (2002) and Bloom et al. (2017) in choosing units such that it is possible to maintain a constant growth rate of aggregate productivity by investing a constant real amount $Y_{r}$ of the research good. In deriving our analytic results, we assume that such a BGP exists.

If $\phi<1$, then our model is a semi-endogenous growth model with the growth rate along the BGP determined by the exogenous growth rate of scientific knowledge $\bar{g}_{A_{r}}$ and population $\bar{g}_{L}$ and other parameter values independent of innovation policies, as in Kortum (1997) and Jones (2002). In this case, it is not possible to have fully endogenous growth because such growth would require growth in innovation expenditure in excess of the growth rate of output. Ongoing balanced growth can occur only to the extent that exogenous scientific progress or population growth reduces the cost of further innovation as aggregate productivity $Z$ grows. Given that real research output is constant on a BGP, then by equation (8), the BGP growth rate of aggregate productiv-

\footnotetext{
${ }^{14}$ In Appendix E.1, we present an extension in which labor is imperfectly substitutable between production and research, as in Jaimovich and Rebelo (2017). This extension only affects equation (13) by reducing the extent to which labor reallocates between production and research in response to policy-induced changes in $i_{r t}$ (therefore reducing the responses of aggregate productivity and output to a given change in $i_{r t}$ ). Assuming congestion in the production of the research good (i.e. in which case research labor in the production of the research good has an exponent less than one), as discussed in Jones (2005), has similar implications.
} 
ity is $\bar{g}_{Z}=\left(\bar{g}_{A r}+\bar{g}_{L}\right) /(1-\phi)$. The growth rate of the total measure of products is $\bar{g}_{M}=\log \left(1-\delta_{0}+\left(1-\delta_{e}\right) \bar{x}_{e}\right)$.

If the knife-edged conditions $\phi=1$ and $\bar{g}_{A r}=\bar{g}_{L}=0$ hold, then our model is an endogenous growth model with the growth rate along the BGP determined by firms' investments in innovative activity, as in Grossman and Helpman (1991b) and Klette and Kortum (2004). ${ }^{15}$ As discussed in Section 5 of Jones (2005), the transition paths of the response of aggregate productivity and output to policy changes are continuous as $\phi$ approaches one, and hence the quantitative implications of our model for the response of the level of aggregate productivity at any finite horizon to changes in innovation policies are continuous in this parameter.

In our applications, we calibrate the model parameters to match a given BGP per capita growth rate of output, $\bar{g}_{Y}-\bar{g}_{L}$. Specifically, given a choice of $\bar{g}_{Y}-\bar{g}_{L}$ and physical capital share in production of the final consumption good of $\alpha$, the growth rate of aggregate productivity in the BGP is $\bar{g}_{Z}=\left(\bar{g}_{Y}-\bar{g}_{L}\right)(1-\alpha)$. For a given choice of $\phi$, we choose the growth rate of scientific knowledge consistent with this productivity growth rate, that is, $\bar{g}_{A r}=(1-\phi) \bar{g}_{Z}-\bar{g}_{L}$.

\section{Analytical results with innovation by entrants only}

In this section, we derive positive and normative analytical results regarding the aggregate impact of policy-driven changes in the innovation intensity of the economy in our simple model with innovation investments only by entering firms. We begin with positive results on the dynamics of aggregate productivity and output that result, up to a first-order approximation, from a policy-induced change in the time path of the innovation intensity of the economy. We then consider the model's implications for the welfare gains to be had from a subsidy to innovative investment on the initial BGP and for the socially optimal innovation intensity of the economy. We conclude with a result regarding the long-run fiscal cost of the innovation subsidies required to induce firms to permanently raise the innovation intensity of the economy. In presenting our results, we focus on the semi-endogenous growth case $(\phi<1)$. We comment briefly on the results that can be derived in the endogenous growth case $(\phi=1)$. Proofs of all results are presented in Appendix B.

In framing the question of how policy-induced changes in the innovation intensity of the economy affect aggregate outcomes at different time horizons, we consider the follow-

\footnotetext{
${ }^{15}$ If $\phi>1$, then our model does not have a BGP, as in this case, a constant innovation intensity of the economy leads to an acceleration of the innovation rate as aggregate productivity $Z$ grows.
} 
ing thought experiment. Consider an economy that is initially on a BGP with growth rate of aggregate productivity $\bar{g}_{Z}$. On this initial BGP, the paths of aggregate productivity and output are given by $\bar{Z}_{t}=\exp \left(t \bar{g}_{Z}\right) \bar{Z}_{0}$ and $\bar{Y}_{t}=\exp \left(t \bar{g}_{Y}\right) \bar{Y}_{0}$, respectively. As a baseline policy experiment, consider a change in innovation subsidies on the initial BGP $\tau_{e t}=\bar{\tau}_{e}$ to new innovation subsidies $\left\{\tau_{e t}^{\prime}\right\}$ beginning in period $t=0$ and continuing on for all $t>0$. Assume that these new innovation policies converge to a constant value $\bar{\tau}_{e}^{\prime}$ and that the equilibrium corresponding to these policies also converges to a new BGP. The innovation intensity of the economy, the allocation of labor in production and research, and output of the research good on this new BGP are denoted by $\bar{i}_{r}^{\prime}, \bar{l}_{p}^{\prime}, \bar{l}_{r}^{\prime}$, and $\bar{Y}_{r}^{\prime}$, respectively.

This policy experiment leads to some observed change in the equilibrium path of the innovation intensity of the economy $\left\{i_{r t}^{\prime}\right\}_{t=0}^{\infty}$ different from the innovation intensity of the economy $\bar{i}_{r}$ on the original BGP. We seek to analytically approximate the resulting change in the equilibrium path of aggregate productivity and output relative to the initial BGP, $\left\{\log Z_{t}^{\prime}-\log \bar{Z}_{t}\right\}_{t=1}^{\infty}$ and $\left\{\log Y_{t}^{\prime}-\log \bar{Y}_{t}\right\}_{t=0^{\prime}}^{\infty}$ given a policy-induced change in the path of the innovation intensity of the economy $\left\{\log i_{r t}^{\prime}-\log \bar{i}_{r}\right\}_{t=0}^{\infty}{ }^{16}$ Note that the initial level of aggregate productivity $Z_{0}=\bar{Z}_{0}$ is a state variable.

\subsection{Productivity in the long run}

The following proposition provides an expression for the long-run change in aggregate productivity that corresponds to a given permanent change in the innovation intensity of the economy.

Proposition 1. Consider a permanent change in innovation policies such that the economy converges to a new BGP with new innovation intensity $\bar{i}_{r}^{\prime}$ and corresponding new allocation of labor to research $\bar{l}_{r}^{\prime}$ given by equation (13) evaluated at $\bar{i}_{r}^{\prime}$. In the semi-endogenous growth case $(\phi<1)$, the level of real innovative investment is unchanged across BGPs (i.e. $\bar{Y}_{r}^{\prime}=\bar{Y}_{r}$ ). Hence, the gap in aggregate productivity between the initial and new BGP converges to

$$
\log \bar{Z}_{t}^{\prime}-\log \bar{Z}_{t}=\frac{1}{1-\phi}\left(\log \bar{l}_{r}^{\prime}-\log \bar{l}_{r}\right) .
$$

Proposition 1 indicates that the impact over the long run of a policy-induced change in the innovation intensity of the economy is determined entirely by two features of the

\footnotetext{
${ }^{16}$ In the Appendix C.4, we show how we can calculate a path of innovation policies that implements a prespecified path of the innovation intensity of the economy as an equilibrium with interior allocations, both in the model with innovation by entrants only and in the model of Section 4 with innovation by entrants and incumbents. Moreover, we show that for the policy experiments that we consider, our quantitative results are very similar if we use a log-linear approximation or the fully nonlinear solution.
} 
model: the parameter $\phi$ indexing the extent of intertemporal knowledge spillovers and (in equation 13) the share of labor compensation in output, $(1-\alpha) / \mu$.

The response in the long run of the level of aggregate productivity to a policy-induced change in the innovation intensity of the economy is very sensitive to the specification of intertemporal knowledge spillovers. For low values of $\phi$, particularly for values less than zero such as those implied by the estimates of Fernald and Jones (2014), the longrun change in log productivity is smaller than the change in the log of the innovation intensity of the economy since, in that case, $1 /(1-\phi)<1$. For values of $\phi$ close to one, the response in the long run of the level of aggregate productivity approaches infinity as the implications of the model converge to those of an endogenous growth model.

\subsection{Productivity transition dynamics}

We now consider features of the model that determine the transition dynamics of aggregate productivity in response to a policy-induced change in the innovation intensity of the economy. We use the notation

$$
\Theta \equiv \frac{d G\left(Y_{r}\right)}{d Y_{r}} \bar{Y}_{r}
$$

where the function $G$ is defined in equation (10) and the derivative $d G\left(Y_{r}\right) / d Y_{r}$ is evaluated at $Y_{r}=\bar{Y}_{r}$ on the initial BGP. Note that our assumptions that $\eta_{e s}>1$ and $\eta_{e n}>0$ imply that $\eta_{e} \equiv \delta \eta_{e s}+(1-\delta) \eta_{e n}>\delta$. Thus, from equation (11), we have $d G\left(Y_{r}\right) / d Y_{r}>0$ and hence $\Theta>0$.

With this notation, we have, to a first-order approximation, the following relationship between real aggregate innovative investment and aggregate productivity growth:

$$
\log Z_{t+1}^{\prime}-\log Z_{t}^{\prime}-\bar{g}_{Z} \approx \Theta\left(\log Y_{r t}^{\prime}-\log \bar{Y}_{r}\right) .
$$

Given this equation, we refer to this parameter $\Theta$ as the impact elasticity of aggregate productivity with respect to a change in real innovative investment.

We can now characterize, up to a first-order approximation, the transition dynamics of aggregate productivity with respect to a policy-induced change in the innovation intensity of the economy with the following proposition.

Proposition 2. Suppose an economy is on an initial baseline BGP and, at time $t=0$, a change in innovation policies induces a new path for the innovation intensity of the economy given by $\left\{i_{r t}^{\prime}\right\}_{t=0}^{\infty}$. The new path for aggregate productivity $\left\{Z_{t}^{\prime}\right\}_{t=1}^{\infty}$ to a first-order approximation is given 
by

$$
\log Z_{t+1}^{\prime}-\log \bar{Z}_{t+1} \approx \sum_{j=0}^{t} \Gamma_{j}\left(\log l_{r t-j}^{\prime}-\log \bar{l}_{r}\right),
$$

where $\Gamma_{0}$ denotes the elasticity of aggregate productivity growth from period $t=0$ to $t=1$ in response to the change in the innovation intensity of the economy at time $t=0$, given by $\Gamma_{0}=\Theta$, and

$$
\Gamma_{j+1}=[1-(1-\phi) \Theta] \Gamma_{j} \text { for } j \geq 0,
$$

where $\Theta$ is the impact elasticity of aggregate productivity defined in equation (15) and $\log l_{r t-j}^{\prime}-$ $\log \bar{l}_{r}$ is given as a function of the transition path for the innovation intensity of the economy as in equation (13).

To help in interpreting the coefficients $\Gamma_{j}$ in equation (17), it is useful to consider two example paths for the policy-induced perturbation to the innovation intensity of the economy: one in which the change in the innovation intensity occurs in the initial period 0 only, and one in which the change in the innovation intensity of the economy is permanent.

In the first case, let $\log i_{r 0}^{\prime}-\log \bar{i}_{r}$ be set such that $\log l_{r 0}^{\prime}-\log \bar{l}_{r}=1$, and let this quantity equal 0 at all subsequent dates $t \geq 1$. In this case, equation (17) gives that $\log Z_{t+1}^{\prime}-\log \bar{Z}_{t+1} \approx \Gamma_{t}$ for $t \geq 0$. Given this one-time perturbation to the innovation intensity of the economy, aggregate productivity rises above its initial BGP path by $\Theta$, and then, if $\phi<1$, gradually returns to that initial BGP path as incomplete intertemporal knowledge spillovers lead the coefficients $\Gamma_{j}$ to decay to zero as in equation (18).

In the second case, let $\log i_{r t}^{\prime}-\log \bar{i}_{r}$ be set such that $\log l_{r 0}^{\prime}-\log \bar{l}_{r}=1$ for all $t \geq 0$. In this case, we have $\log Z_{t+1}^{\prime}-\log \bar{Z}_{t+1} \approx \sum_{j=0}^{t-1} \Gamma_{j}$ for $t \geq 0$. Here, aggregate productivity climbs gradually to its new BGP path at a pace determined by the cumulative sums of the coefficients $\Gamma_{j}$. Note that in this case, by directly summing the coefficients $\Gamma_{j}$, one obtains that this approximation is equal to the exact long-term result in Proposition 1 in the limit.

In the endogenous growth case $(\phi=1)$, the gap in aggregate productivity between the old and new BGP is unbounded. In this case, the new growth rate of aggregate productivity corresponding to a permanent policy-induced change in the innovation intensity of the economy is given to a first-order approximation by

$$
\log Z_{t+1}^{\prime}-\log Z_{t}^{\prime} \approx \bar{g}_{Z}+\Theta\left(\log l_{r}^{\prime}-\log \bar{l}_{r}\right)
$$

where $\log l_{r}^{\prime}-\log \bar{l}_{r}$ is given as a function of the innovation intensity of the economy as in equation (13). 
From Proposition 1, we have that in the semi-endogenous growth case $(\phi<1)$, the long-run elasticity of aggregate productivity with respect to a permanent change in the innovation intensity of the economy given in equation (14) is independent of the impact elasticity $\Theta$. This impact elasticity does, however, affect the model's transition dynamics from the initial BGP to the new BGP as follows.

Corollary 1. Consider two specifications of our model (model 1 and model 2) that are calibrated to the same parameter $\phi<1$ governing intertemporal knowledge spillovers. Assume that the impact elasticity $\Theta$ is higher in model 2 than in model 1, that is, $\Theta^{1}<\Theta^{2}$. Then the elasticities $\left\{\Gamma_{j}\right\}$ defined in Proposition 2 are related in the two models as follows. There exists a cutoff value of $\tilde{J}$ such that $\Gamma_{j}^{1}<\Gamma_{j}^{2}$ for $j<\tilde{J}$ and $\Gamma_{j}^{1}>\Gamma_{j}^{2}$ for $j>\tilde{J}$. Moreover, for any finite $J \geq 1$, $\sum_{j=0}^{J} \Gamma_{j}^{1}<\sum_{j=0}^{J} \Gamma_{j}^{2}$. With endogenous growth $(\phi=1), \Gamma_{J}^{1}=\Gamma_{0}^{1}<\Gamma_{0}^{2}=\Gamma_{J}^{2}$ for all $J \geq 0$.

This corollary has the following implications for two example paths for policy-induced perturbations to the innovation intensity of the economy we considered above. In the case of the policy-induced perturbation to the innovation intensity of the economy in period $t=0$ only, the resulting change in aggregate productivity is larger in the near term in model 2 than in model 1, but then this impact on aggregate productivity dies out faster in model 2 than in model 1. In contrast, the response of aggregate productivity to a permanent policy-induced change in the innovation intensity of the economy is uniformly higher at all finite horizons in model 2 than in model 1. In the long run, as $J \rightarrow \infty$, with semi-endogenous growth, the two models deliver the same response of the level of aggregate productivity.

\subsection{Dynamics of aggregate output}

We now consider the transition path for aggregate output resulting from an innovationpolicy-induced perturbation to the innovation intensity of the economy. The following lemma presents the transition path for aggregate output as a function of the transition paths for aggregate productivity, the allocation of labor, and the equilibrium rental rate on physical capital.

Lemma 1. The path of aggregate output corresponding to a policy-induced change in the innovation intensity of the economy is given by

$$
\log Y_{t}^{\prime}-\log \bar{Y}_{t}=\frac{1}{1-\alpha}\left(\log Z_{t}^{\prime}-\log \bar{Z}_{t}\right)+\left(\log l_{p t}^{\prime}-\log \bar{l}_{p}\right)-\frac{\alpha}{1-\alpha}\left(\log R_{k t}^{\prime}-\log \bar{R}_{k}\right),
$$

where $R_{k t}$ is the rental rate on physical capital and the term $\log l_{p t}^{\prime}-\log \bar{l}_{p}$ is given as a function of the innovation intensity of the economy as in equation (13). 
A policy-induced increase in the innovation intensity of the economy has two main effects on the path of aggregate output. The first is a direct effect to reduce aggregate output because of the policy-induced reallocation of labor from current production of the final consumption good to research. To a first-order approximation, this negative effect is given by $\left(\log l_{p t}^{\prime}-\log \bar{l}_{p}\right) \approx-\bar{l}_{r}\left(\log i_{r t}^{\prime}-\log \bar{i}_{r}\right) .{ }^{17}$ The second main effect is through the cumulated impact of this policy-induced change in the innovation intensity of the economy on aggregate productivity as captured by the term $\frac{1}{1-\alpha}\left(\log Z_{t}^{\prime}-\log \bar{Z}_{t}\right)$. This effect is equal to zero on impact at $t=0$ and cumulates over time, converging to the limit as specified in Proposition 1 with dynamics as specified in Proposition 2. The final term in equation (20) reflects changes in the ratio of physical capital to output along the transition from the initial BGP to the final BGP. This term is equal to zero on both the initial and the new BGP. With these results, we have that the level of output on the new BGP relative to the initial BGP is given by

$$
\log \bar{Y}_{t}^{\prime}-\log \bar{Y}_{t}=\left(\frac{1}{(1-\alpha)(1-\phi)}-\frac{\bar{l}_{r}}{\bar{l}_{p}}\right)\left(\log \bar{l}_{r}^{\prime}-\log \bar{l}_{r}\right) .
$$

\subsection{Welfare}

We now summarize the welfare gains or losses associated with a new allocation that deviates from an initial BGP by the consumption equivalent change in welfare, defined as the scalar $\xi$ multiplying the baseline BGP path for consumption required to implement the same change in welfare as is achieved under the new allocation. Under the assumption that the initial baseline BGP allocation of physical capital is not distorted, ${ }^{18}$ the following lemma provides an expression for the consumption equivalent change in welfare corresponding to a innovation-policy-induced perturbation of the initial BGP allocation.

Lemma 2. If the Euler equation for physical capital is undistorted on the initial BGP so that the rental rate on physical capital is equal to the marginal product of physical capital, then, up to a first-order approximation, the consumption equivalent change in welfare corresponding to the macroeconomic dynamics from an innovation-policy-induced perturbation of the initial BGP

\footnotetext{
${ }^{17}$ Note that on impact at $t=0$, aggregate productivity and the stock of physical capital are fixed, so $\left(\log R_{k 0}^{\prime}-\log \bar{R}_{k}\right)=\left(\log Y_{0}^{\prime}-\log \bar{Y}_{0}\right)$ and $\log Y_{0}^{\prime}-\log \bar{Y}_{0}=(1-\alpha)\left(\log l_{p 0}^{\prime}-\log \bar{l}_{p}\right)=$ $-(1-\alpha) \bar{l}_{r}\left(\log i_{r 0}^{\prime}-\log \bar{i}_{r}\right)$.

${ }^{18}$ In Appendix B, we introduce a production subsidy that can undo the inefficiencies in physical capital accumulation arising from markups and the corporate profits tax, but otherwise does not affect our analytic results.
} 
allocation is given by

$$
\log \xi \approx(1-\tilde{\beta}) \sum_{t=0}^{\infty} \tilde{\beta}^{t} \frac{\bar{Y}}{\bar{C}}\left[\left(\log Z_{t}^{\prime}-\log \bar{Z}_{t}\right)+(1-\alpha)\left(\log l_{p t}^{\prime}-\log \bar{l}_{p}\right)\right]
$$

where $\tilde{\beta}=\beta \exp \left(\gamma \bar{g}_{L}+(1-\gamma) \bar{g}_{Y}\right)$ is the ratio of the gross growth rate of output to the gross interest rate on the initial $B G P$.

We see in expression (22) that an increase in the innovation intensity of the economy has two effects on welfare. It will initially decrease the resources available for consumption and physical investment through the reallocation of labor from current production to research, and then increase those resources as aggregate productivity rises in response to firms' past increased investments in innovation, raising welfare. In this way, our model's implications for the welfare change corresponding to a change in the innovation intensity of the economy are tightly linked to its implications for the macroeconomic dynamics induced by that change in policies.

Consider now the elasticity of the consumption equivalent change in welfare $\xi$ with respect to a policy-induced one-time change in the innovation intensity of the economy. That is, assume that $\log i_{r 0}^{\prime}-\log \bar{i}_{r}=1$, and let this quantity equal 0 at all subsequent dates $t \geq 1$. As discussed above, in this case, equations (13) and (17) imply that $\log Z_{t+1}^{\prime}-$ $\log \bar{Z}_{t+1} \approx \bar{l}_{p} \Gamma_{t}$ for $t \geq 0$ and $\log l_{p t}^{\prime}-\log \bar{l}_{p} \approx-\bar{l}_{r}$ for $t=0$. From equation (18), we then have that the elasticity of the consumption equivalent change in welfare is given by

$$
\log \xi \approx(1-\tilde{\beta})\left[\frac{\tilde{\beta} \Theta}{1-\tilde{\beta}[1-(1-\phi) \Theta]}-(1-\alpha) \frac{\bar{l}_{r}}{\bar{l}_{p}}\right] \frac{\bar{Y}}{\bar{C}} \bar{l}_{p} .
$$

The elasticity of the consumption equivalent change in welfare that results from a permanent increase in the innovation intensity of the economy is equal to that in equation (23) divided by $1-\tilde{\beta}$.

We define the socially optimal allocation as the solution to the following problem: choose current production plans of all intermediate goods firms, together with the investments in innovation by those firms and all macroeconomic aggregates, to maximize the utility of the representative agent subject to constraints (1) through (11). If the economy starts on the socially optimal allocation, then up to a first order, the change in welfare corresponding to any change in the allocation of labor between production and research should be zero. Hence, on the BGP of the socially optimal allocation, the allocation of labor between research and production, $\bar{l}_{r}^{*} / \bar{l}_{p}^{*}$, should be such that this perturbation has no first-order impact on welfare (that is, $\log \xi=0$ ). That is, the term in the square brackets in equation 
(23) should be equal to zero. This reasoning leads to the following proposition. ${ }^{19}$

Proposition 3. On the BGP of the socially optimal allocation, the allocation of labor between research and production is given by

$$
\frac{\bar{l}_{r}^{*}}{\overline{l_{p}^{*}}}=\left(\frac{1}{1-\alpha}\right)\left(\frac{\tilde{\beta} \Theta}{1-\tilde{\beta}[1-(1-\phi) \Theta]}\right) .
$$

\subsection{Fiscal implications}

We now consider the fiscal cost of innovation policies required to induce firms to permanently raise the innovation intensity of the economy from $\bar{i}_{r}$ to $\vec{i}_{r}$. We characterize the fiscal cost in terms of the change in fiscal expenditures on innovation subsidies relative to aggregate output from the initial BGP to the new BGP to which the economy converges in the next proposition. Note that we have assumed that the policymaker has access to lump-sum taxes to finance expenditures on innovation subsidies.

Proposition 4. Consider our model on a BGP with semi-endogenous growth and positive firm entry. Suppose that innovation subsidies change permanently from $\bar{\tau}_{e}$ to $\bar{\tau}_{e}{ }^{\prime}$. Then, across the initial and new BGPs, the innovation intensity of the economy changes from $\bar{i}_{r}$ to $\bar{i}_{r}^{\prime}$, and fiscal expenditures relative to aggregate output change from $\bar{E} / \bar{Y}$ to $\bar{E}^{\prime} / \bar{Y}^{\prime}$, with these changes given by

$$
\log \bar{i}_{r}^{\prime}-\log \bar{i}_{r}=\log \left(1-\bar{\tau}_{e}\right)-\log \left(1-\bar{\tau}_{e}^{\prime}\right)
$$

and

$$
\frac{\bar{E}^{\prime}}{\bar{Y}^{\prime}}-\frac{\bar{E}}{\bar{Y}}=\bar{i}_{r}^{\prime}-\bar{i}_{r}
$$

This result implies that in the long run, changes in innovation subsidies result in a change in the innovation intensity of the economy determined only by the change in the innovation subsidy rate independent of the other parameters of the model. Equivalently, the change in the innovation intensity of the economy in the long run is equal to the change in fiscal expenditures on these subsidies relative to aggregate output. At short and medium horizons, however, this policy will result in a change in the path of the innovation intensity of the economy from $\bar{i}_{r}$ on the initial BGP to $\left\{i_{r t}^{\prime}\right\}_{t=0}^{\infty}$. The innovation intensity may vary over time in response to a permanent change in innovation policies because the consumption interest rate and the rate of change in the price of the research good are not constant on the transition path from one BGP to another.

\footnotetext{
${ }^{19}$ Jones and Williams (1998) consider a related perturbation argument to characterize the optimal level of R\&D investment.
} 


\subsection{Quantitative implications for the impact elasticity $\Theta$}

In our simple model with innovative investment only by entering firms, the impact elasticity $\Theta$ is given from equation (11) by

$$
\Theta=\frac{1}{\rho-1} \frac{\exp \left(\bar{g}_{Z}\right)^{\rho-1}-\exp (G(0))^{\rho-1}}{\exp \left(\bar{g}_{Z}\right)^{\rho-1}},
$$

where $\rho$ is the elasticity of substitution between intermediate goods in the production of the final consumption good $Y_{t}, \bar{g}_{Z}$ denotes the growth rate of aggregate productivity on the initial BGP to which the model is calibrated, and $G(0)$ denotes the rate of productivity growth that would occur in the absence of any innovative investment by firms.

It is straightforward to show that if $\rho>1$ and $\bar{g}_{Z}>0$, then $\Theta$ is decreasing in $\rho$ and has an upper bound of

$$
\Theta \leq \bar{g}_{Z}-G(0) .
$$

This upper bound is achieved when $\rho \rightarrow 1$.

The bound on the impact elasticity $\Theta$ in equation (26) is not simply a feature of our specific model. Instead, it follows simply from the concavity of the function $G$ defined in equation (11). Specifically, for any concave function $G\left(Y_{r}\right)$, we have $\Theta \equiv G^{\prime}\left(Y_{r}\right) Y_{r} \leq$ $G\left(Y_{r}\right)-G(0)$. Once our model is calibrated to a given initial BGP, we have $\bar{g}_{Z}=G\left(\bar{Y}_{r}\right)$. Equation (26) immediately follows. Intuitively, since $G$ is a concave function, the marginal product of innovative investment on productivity growth is bounded above by its average product.

In our simple model with innovative investment only by entering firms, the term $\bar{g}_{Z}-$ $G(0)$ can be interpreted as the contribution of innovative investment by entering firms to aggregate productivity growth on the initial BGP.

One implication of expression (26) is that, when evaluating the quantitative implications of specific models for the dynamics of aggregate productivity following a given policy-induced change in the innovation intensity of the economy, we are able to derive an upper bound on the model-implied impact elasticity $\Theta$ based on the difference between the initial growth rate of aggregate productivity $\bar{g}_{Z}$ to which the model is calibrated and the counterfactual productivity growth rate $G(0)$ that is typically set implicitly by assumption in the specification of the model. For example, many Neo-Schumpeterian models directly assume that if there is no innovative investment, then the level of aggregate productivity remains constant, that is, $G(0)=0$. With this assumption, the bound on the impact elasticity is then simply the BGP growth rate of productivity $\bar{g}_{Z}$. This bound is quite restrictive quantitatively if the baseline growth rate of productivity $\bar{g}_{Z}$ to which 
the model is calibrated on the initial BGP is low. In contrast, in models in which the model-implied value $G(0)$ is strictly negative, such as expanding varieties models with exogenous exit of products (i.e., in our model, $\delta_{e}<1$ and $\delta_{0}>0$ ), the impact elasticity $\Theta$ is not so tightly restricted quantitatively by this bound. Note that, conditional on the aggregate statistic $\bar{g}_{Z}-G(0)$, the upper bound on $\Theta$ does not depend on the specific stochastic process for product-level productivity as a function of firms' investments in innovation. Of course, the specifics of the stochastic process of product-level productivity do shape the model's implications on firm dynamics.

\section{Introducing innovation by incumbent firms}

We now introduce innovation by incumbent firms into our model. In the next section, we derive conditions under which our analytical results from Section 3 hold in this extended model. We specify two technologies available for incumbent firms for innovative investment. One of these allows incumbent firms to acquire products that are new to the firm. The other allows incumbent firms to improve their own existing products. We discuss the models that are nested by our framework after we introduce the technologies that incumbent firms use to invest in innovation.

\subsection{Investments in new products by incumbent firms}

A firm that owns the frontier technology for producing a particular intermediate good also possesses the capacity to acquire the frontier technology on additional goods through innovative investment. Specifically, if an incumbent firm at $t$ has the frontier technology to produce an intermediate good with index $z$, it also has the opportunity to invest $x_{m t}(z)$ units of the research good to acquire an additional product (new to the firm) at $t+1$ with probability $h\left(x_{m t}(z) / s_{t}(z)\right)$, where $s_{t}(z)$ is defined in $(7)$. Here, $h(\cdot)$ is a strictly increasing and concave function with $h(0)=0$ and $h(x)<1$ for all $x$. This technology is specified so that a firm must invest $x_{m t}(z)$ in proportion to the size $s_{t}(z)$ of its current product with index $z$ at time $t$ to attain any given probability of acquiring a new product at $t+1$.

Consider now the productivity index $z^{\prime}$ for a newly acquired product that an incumbent firm obtains at $t+1$ arising from innovative investment associated with a product with index $z$ at $t$. As is the case with entry, acquisition of new products by incumbent firms may arise from business stealing from other incumbent firms or from the creation of products that are new to society. 
With probability $\delta_{m}$, the product acquired by the incumbent firm at $t+1$ is stolen from another incumbent firm and has productivity index $z^{\prime}$ at $t+1$ drawn at random from a distribution such that $\mathbb{E} z^{\prime \rho-1}=\eta_{m s} z^{\rho-1}$, with $\eta_{m s}>1$. We assume that the product it displaces had productivity $z$ at $t$.

With complementary probability $1-\delta_{m}$, the newly acquired product is new to society. We assume that the productivity index $z^{\prime}$ in this case is drawn from a distribution such that $\mathbb{E} z^{\prime \rho-1}=\eta_{m n} z^{\rho-1}$, with $\eta_{m n}>0$. We define $\eta_{m}=\delta_{m} \eta_{m s}+\left(1-\delta_{m}\right) \eta_{m n}{ }^{20}$

We define the aggregate quantity of this type of innovative investment by incumbent firms as

$$
x_{m t} \equiv \sum_{z} x_{m t}(z) M_{t}(z)
$$

\subsection{Investment in continuing products by incumbent firms}

Incumbent firms have research capacity associated with each product that they produce at $t$ that allows them to invest to improve the index $z$ of that product if they retain it at $t+1$. We assume that if an incumbent firm with a product with productivity $z$ at $t$ spends $x_{c t}(z)$ of the research good on improving that product, it draws a new productivity index $z^{\prime}$, conditional on not losing that product to exogenous exit or business stealing, from a distribution such that

$$
\mathbb{E} z^{\prime \rho-1}=\zeta\left(\frac{x_{c t}(z)}{s_{t}(z)}\right) z^{\rho-1} .
$$

We assume that $\zeta(\cdot)$ is a strictly increasing and concave function, with $\zeta(x)>0$ for all $x \geq 0$. Note that the investment $x_{c t}(z)$ required to achieve a given expected growth of $z^{\rho-1}$ scales with the size $s_{t}(z)$ of the product being invested in at $t$.

We assume that $\eta_{e s}>\zeta(x)$ and $\eta_{m s}>\zeta(x)$ for all $x$. These inequalities correspond to the requirement that a product that is stolen from incumbent firms is, in expectation, produced with a higher $z^{\prime}$ at $t+1$ in its new firm than it would have had as a continuing product in the firm that previously produced it. Equivalently, stolen products have larger average size than continuing products in incumbent firms. We also assume that the probability that incumbent firms lose a product lies between 0 and 1 , $0<\left(1-\delta_{0}-\delta_{m} h\left(x_{m}\right)-\delta_{e} x_{e}\right)<1$. These assumptions are justified if the time period in the model is short enough. ${ }^{21}$

\footnotetext{
${ }^{20}$ As we show below, with this specification of the technology for incumbent firms to acquire new products, their investment in this type of innovation scales up one to one with the size of the firm. Akcigit and Kerr (2010) present a model in which this type of innovation does not scale up with firm size. In Appendix E.4, we examine the extent to which our analytic results extend in a variation of our model in which firms' investments to acquire new products do not scale up one to one with firm size.

${ }^{21}$ This is because $\zeta(x)$ denotes the expected improvement per unit of time in $z^{\rho-1}$ for an incumbent firm
} 
We define the aggregate quantity of this type of innovative investment by incumbent firms as

$$
x_{c t} \equiv \sum_{z} x_{c t}(z) M_{t}(z)
$$

With these investment technologies for incumbent firms, the resource constraint for the research good is given by

$$
x_{c t}+x_{m t}+x_{e t}=Y_{r t}
$$

We define a BGP in this extended model in the same manner as we did in Section 2.6, except here we add the condition that each category of aggregate real innovative investment also be constant over time $\left(x_{c t}=\bar{x}_{c}, x_{m t}=\bar{x}_{m}\right.$, and $\left.x_{e t}=\bar{x}_{e}\right)$.

\subsection{Innovative investment and productivity growth}

We consider innovation policies that can be applied to each of the three categories of innovative investment $\left(x_{c t}, x_{m t}\right.$, and $\left.x_{e t}\right)$. Throughout we assume that subsidy rates are category-specific but not specific to individual firms or products. We refer to these category-specific subsidies as $\tau_{c t}, \tau_{m t}$, and $\tau_{e t}$. We say these innovation subsidies are $u n i-$ form if $\tau_{c t}=\tau_{m t}=\tau_{e t}$. Uniform innovation subsidies are equivalent to a subsidy to the production of the research good.

With the category-specific policies and innovative investment technologies for incumbent firms that we have specified above, in equilibrium, the innovation expenditures associated with each product produced by an incumbent firm are directly proportional to the size of these products. Moreover, when firms' innovative investments are directly proportional to the size of the products that they produce, the resulting dynamics for the size of existing products are consistent with a strong form of Gibrat's law — the growth and death rates of products are independent of the size of a product. Given these two features of the equilibrium of the model, we characterize the growth rate of aggregate productivity as a simple function of current aggregate real innovative investment in each of the categories of investment by incumbents and entrants as follows.

Lemma 3. In an equilibrium with innovation policies applied to each category of innovative investment as described above, the dynamics of aggregate productivity as a function of innovative

and hence shrinks to 1 as the length of the time period shrinks to zero. Likewise, $\delta_{0}, \delta_{e}, \delta_{m}, h\left(x_{m}\right)$, and $x_{e}$ are all rates per unit of time that shrink to zero as the length of the time period shrinks to zero. In contrast, $\eta_{e s}$ and $\eta_{m s}$ correspond to the realized improvement in $z^{\rho-1}$ for products that are stolen. These parameters are assumed to be independent of the time period. 
investment by firms are summarized by $g_{z t} \equiv \log \left(Z_{t+1}\right)-\log \left(Z_{t}\right)=G\left(x_{c t}, x_{m t}, x_{e t}\right)$, where $G$ is given by

$$
G\left(x_{c}, x_{m}, x_{e}\right)=\frac{1}{\rho-1} \log \left(\left(1-\delta_{0}-\delta_{m} h\left(x_{m}\right)-\delta_{e} x_{e}\right) \zeta\left(x_{c}\right)+\eta_{m} h\left(x_{m}\right)+\eta_{e} x_{e}\right) .
$$

The growth rate of aggregate productivity in the absence of innovative investment by firms in this extended model is denoted by $G^{0} \equiv G(0,0,0) .^{22}$

As shown in Lemma 3, the growth rate of aggregate productivity from period $t$ to period $t+1$ is a simple function of the aggregate quantities of the three categories of innovative investment undertaken by firms: $x_{c t}, x_{m t}, x_{e t}$. In particular, our assumptions imply that we do not have to keep track of the details of the distribution $M_{t}$ of indices $z$ across intermediate goods or of other attributes of incumbent firms to calculate the equilibrium relationship between incumbent firms' innovative investments and the growth rate of aggregate productivity.

\subsection{Nested models}

Our model nests five commonly used models in the literature: three types of expanding varieties models and two types of Neo-Schumpeterian models.

If $\delta_{e}=\delta_{m}=0$, then there is no business stealing and hence all new products acquired by incumbent and entering firms are new products for society, expanding the measure of products $M_{t}$. This is the assumption typically made in an expanding varieties model. Luttmer (2007) is an example of an expanding varieties model in which there is only innovative investment in entry. (Note that we do not consider the endogenous exit of products due to fixed operating costs featured in that paper.) Atkeson and Burstein (2010) is an example of an expanding varieties model in which there is innovative investment in entry and by incumbent firms in continuing products. Luttmer (2011) is an example of an expanding varieties model in which there is innovative investment in entry and in the acquisition of new products by incumbent firms.

Neo-Schumpeterian models based on the quality ladder framework typically assume $\delta_{e}=\delta_{m}=1$ and $\delta_{0}=0$. The simplest versions of these models do not accommodate growth in the measure of varieties $M_{t}$. Grossman and Helpman (1991a) and Aghion and

\footnotetext{
${ }^{22}$ In our model, $G(0,0,0)=\frac{1}{\rho-1} \log \left(\left(1-\delta_{0}\right) \zeta(0)\right)$, where $\left(1-\delta_{0}\right) \zeta(0)$ corresponds to the expected growth rate of $z^{\rho-1}$ of incumbent products if no firms invest in innovation. $G(0,0,0)$ can be positive or negative. We speculate that a value of $G(0,0,0)<0$ may be derived from the fact that productive knowledge in firms is embodied in individuals who are familiar with both the knowledge gained through innovation and the procedures for training new workers in that knowledge, and the workforce within firms is constantly turning over and workers themselves have a life cycle. See, for example, Bloom et al. (2018).
} 
Howitt (1992) are examples of Neo-Schumpeterian models in which there is only innovative investment in entry. Klette and Kortum (2004) is an example of a Neo-Schumpeterian model in which there is innovative investment in entry and by incumbent firms in acquiring new products (new to the firm, not to society). Acemoglu and Cao (2015) is an example of a Neo-Schumpeterian model in which there is innovative investment in entry and by incumbent firms in improving their own products.

In Appendix D, we discuss several recent models in the literature that are not nested in our model. In these unnested models, it is not possible to derive a simple relationship between aggregate productivity growth and real innovative investments of the form of equation (28) in Lemma 3. In particular, the transition dynamics of aggregate productivity in those models also depend on the evolution of a distribution of a state variable across firms. As a result, the transition dynamics in these models are much less tractable than in our model.

\section{Extending analytical results}

In this section, we first generalize our definition of the impact elasticity of aggregate productivity growth with respect to real innovative investment. We then establish conditions under which we can apply our analytical results from Section 3 in this model. We then show that these results can be applied if the allocation of real innovative investment on the initial BGP is conditionally efficient as defined below. Finally, we present extensions of our results from Section 3 that follow when the allocation of innovative investment on the initial BGP is not conditionally efficient.

\subsection{Impact elasticities}

We generalize our definition of the impact elasticity $\Theta$ as follows. For $i=c, m, e$, we let

$$
\Theta_{i}=\frac{\partial}{\partial x_{i}} G\left(\bar{x}_{c}, \bar{x}_{m}, \bar{x}_{e}\right) \bar{Y}_{r}
$$

denote the impact elasticity of a change in aggregate innovation expenditure devoted entirely to changing investment category $x_{i}$, with this elasticity evaluated at the initial BGP allocation of investment. Since the sum of investments across categories must equal total investment, we can write the impact elasticity of any particular policy-induced perturba- 
tion of innovative investment as

$$
\Theta=\Theta_{c} \frac{d x_{c}}{d Y_{r}}+\Theta_{m} \frac{d x_{m}}{d Y_{r}}+\Theta_{e} \frac{d x_{e}}{d Y_{r}}
$$

where the terms $d x_{i} / d Y_{r}$ indicate how, at the margin, any particular change in aggregate innovative investment is allocated across categories subject to the constraint imposed by the resource constraint (27) that

$$
\frac{d x_{c}}{d Y_{r}}+\frac{d x_{m}}{d Y_{r}}+\frac{d x_{e}}{d Y_{r}}=1
$$

The parameter assumptions we have made above ensure that $\Theta_{c}, \Theta_{m}, \Theta_{e}>0$ on the initial BGP.

\subsection{Conditional efficiency on the initial BGP}

In this subsection, we show that the positive and normative results from Section 3 extend to this model with innovative investment by incumbent firms when the equilibrium allocation of innovative investment on the initial BGP is conditionally efficient. Specifically, we say that the vector of investments $x_{c t}, x_{m t}, x_{e t}$ is conditionally efficient if it is interior, so that $x_{c t}, x_{m t}, x_{e t}>0$, and it solves the problem of minimizing

$$
\bar{Y}_{r}^{*}=\min _{x_{c}, x_{m}, x_{e}} x_{c}+x_{m}+x_{e}
$$

subject to the constraint that $G\left(x_{c}, x_{m}, x_{e}\right)=\bar{g}_{Z}$.

Note that if the initial BGP allocation is conditionally efficient, then equation (30) implies that $\Theta=\Theta_{c}=\Theta_{m}=\Theta_{e}>0$. Hence, the model-implied impact elasticity $\Theta$ of aggregate productivity growth with respect to a policy-induced change in aggregate innovative investment in equation (30) is independent of the details of how a change in policy results in a reallocation of innovative investment across categories, as captured in the terms $d x_{c} / d Y_{r}, d x_{m} / d Y_{r}$, and $d x_{e} / d Y_{r}$ in equation (30).

We next present a result on conditions under which the equilibrium allocation of innovative investment on the initial BGP is conditionally efficient.

Lemma 4. Assume that under uniform policies, there exists an equilibrium allocation of innovative investment on an initial BGP that is interior. Then this equilibrium allocation of innovative investment is conditionally efficient if either $(i)$ there is no business stealing $\left(\delta_{m}=\delta_{e}=0\right)$ or (ii) there is no marginal return to investment by incumbents in improving their own products (i.e., $\zeta(x)=\bar{\zeta}$ for all $x$ and $x_{c t}=\bar{x}_{c}$ is simply an exogenous parameter), and if the extent of 
business stealing and the expected size of new products acquired by entrants and incumbent firms are equal (i.e., $\delta_{m}=\delta_{e}$ and $\eta_{m}=\eta_{e}$ ). Alternatively, for any parameter values, given a conditionally efficient allocation of innovative investment, we can choose initial policies such that this allocation is also the equilibrium allocation of innovative investment on the BGP corresponding to those policies.

We then have the following extensions of our analytical results if the allocation on the initial BGP is conditionally efficient.

Proposition 5. If the allocation of innovative investment on an initial BGP is conditionally efficient, then the dynamics of aggregate productivity and output with respect to a policy-induced change in the innovation intensity of the economy are given as in Proposition 2 and Lemma 1. The formula in Proposition 1 for the change in aggregate productivity across BGPs, as a function of the policy-induced reallocation of labor to research across BGPs, holds to a first-order approximation and is an upper bound on the actual change in aggregate productivity across BGPs. The upper bound on the impact elasticity $\Theta$ given in equation (26) applies with $G(0,0,0)$ replacing $G(0)$ in that equation. The welfare implications of policy-induced changes in the innovation intensity of the economy are given as in Lemma 2, and the corresponding allocation of labor on the socially optimal BGP is given as in (24). If the innovation policies on the initial and new BGPs are uniform, then the fiscal cost of the policies required to induce a given change in the innovation intensity of the economy is given as in Proposition 4.

We next provide results regarding the dynamics of aggregate productivity following a change in innovation policies in the more general case in which the allocation of innovative investment on the initial BGP is not conditionally efficient.

\subsection{Productivity dynamics without conditional efficiency}

As discussed above, in the event that the initial allocation of innovative investment on the initial BGP is not conditionally efficient, then the positive implications of our model for the impact elasticity $\Theta$ depend on the specifics of the reallocation of aggregate innovative investment across categories of investment as specified in the terms $d x_{c} / d Y_{r}, d x_{m} / d Y_{r}$, and $d x_{e} / d Y_{r}$ in equation (30) in response to any given change in innovation policies. In addition, the model's implied impact elasticity may vary over time if the perturbation to innovation policies varies over time.

To make progress in deriving analytical results without assuming conditional efficiency in the initial BGP, we restrict attention to new innovation policies $\tau_{c t}^{\prime}, \tau_{m t}^{\prime}, \tau_{e t}^{\prime}$ such 
that the relative subsidies of innovative investment by incumbent and entering firms are constant over time after the new policy is in place, in the sense that

$$
\frac{1-\tau_{c t}^{\prime}}{1-\tau_{e t}^{\prime}}=\frac{1-\bar{\tau}_{c}^{\prime}}{1-\bar{\tau}_{e}^{\prime}} \text { and } \quad \frac{1-\tau_{m t}^{\prime}}{1-\tau_{e t}^{\prime}}=\frac{1-\bar{\tau}_{m}^{\prime}}{1-\bar{\tau}_{e}^{\prime}}
$$

for all $t \geq 0$. While we do allow the level of subsidies as indexed by $\tau_{e t}^{\prime}$ to vary over time, we do require that it converge to a constant $\bar{\tau}_{e}^{\prime}$ corresponding to a new BGP. With these assumptions, we then have the following proposition, which extends Propositions 1 and 2.

Proposition 6. Consider the equilibrium transition of an economy from an initial BGP to a new $B G P$ given new innovation policies that satisfy condition (32). If the allocation of innovative investment on the new BGP and on the transition to that BGP is interior, then the dynamics of aggregate productivity are given, to a first-order approximation, by

$$
\log Z_{t+1}^{\prime}-\log \bar{Z}_{t+1} \approx \sum_{j=0}^{t} \Gamma_{j}^{\prime}\left[\log l_{r t-j}^{\prime}-\log \bar{l}_{r}-\left(\log \bar{Y}_{r}^{\prime}-\log \bar{Y}_{r}\right)\right],
$$

where $\Gamma_{0}^{\prime}=\Theta^{\prime}$ and $\Gamma_{j+1}^{\prime}=\left[1-(1-\phi) \Theta^{\prime}\right] \Gamma_{j}^{\prime}$. The impact elasticity $\Theta^{\prime}$ is given by equation (30) independent of the date $t$, with the terms $\Theta_{i}^{\prime}$ defined as in equation (29) evaluated at the new $B G P$ allocation of innovative investment $\bar{x}_{c}^{\prime}, \bar{x}_{m}^{\prime}, \bar{x}_{e}^{\prime}$, and with $d x_{m} / d Y_{r}=0$,

$$
\frac{d x_{e}}{d Y_{r}}=\left[1+\frac{\delta_{e} \zeta^{\prime}\left(\bar{x}_{c}^{\prime}\right)}{\left(1-\delta_{0}-\delta_{m} h\left(\bar{x}_{m}^{\prime}\right)-\delta_{e} \bar{x}_{e}^{\prime}\right) \zeta^{\prime \prime}\left(\bar{x}_{c}^{\prime}\right)}\right]^{-1},
$$

and $d x_{c} / d Y_{r}=1-d x_{e} / d Y_{r}$. The allocation of labor to research is related to the innovation intensity of the economy as in equation (13). Given this first-order approximation to the path of aggregate productivity, equation (20) for the dynamics of GDP and equation (22) characterizing the consumption equivalent measure of welfare apply.

The dynamics of productivity described in Proposition 6 differ from those described in Proposition 2 in two respects. First, the impact elasticity $\Theta^{\prime}$ used in Proposition 6 is evaluated at the allocation of real innovative investment on the new BGP rather than on the initial BGP (as is the case with $\Theta$ above). Second, the term $\log \bar{Y}_{r}^{\prime}-\log \bar{Y}_{r}$ reflecting the change in the level of aggregate real innovative investment between the initial BGP and the new BGP affects the dynamics of productivity in the same way as a reallocation of labor from production to research. In this sense, an increase in the efficiency of innovative investment (in lowering the real quantity of investment required to attain BGP produc- 
tivity growth rate $\bar{g}_{Z}$ ) has an impact on the dynamics of TFP equivalent to an increase in the allocation of labor to research.

One could use the results in Proposition 6 to assess the aggregate implications of arbitrary changes in innovation policies that satisfy condition (32) if one specifies all of the parameters of our model including the technologies for innovative investment $h(\cdot)$ and $\zeta(\cdot)$. To do so, one would specify a particular change in policies, compute the allocation of innovative investment on the new BGP, and then compute the model-implied values of the impact elasticity $\Theta^{\prime}$ and the efficiency gain (or loss) embodied in the term $\log \bar{Y}_{r}^{\prime}-\log \bar{Y}_{r}$. In this case, the two statistics $\Theta$ (on the original BGP) and $\phi$ are no longer sufficient to approximate the dynamics of productivity.

We conclude our analytical results regarding the dynamics of productivity following a policy-induced change in the innovation intensity of the economy when the allocation of innovative investment on the initial BGP is not conditionally efficient by characterizing a restricted class of perturbations to innovation policies such that the productivity dynamics in Proposition 6 coincide with those in Proposition 2. For this restricted class of policy changes, the two statistics $\Theta$ on the original BGP and $\phi$ are sufficient to conduct our analysis.

\subsection{Proportional policy changes}

Let $\bar{\tau}_{c}, \bar{\tau}_{m}$, and $\bar{\tau}_{e}$ denote the innovation subsidies on the initial BGP. Let the new innovation subsidies starting in period $t=0$ satisfy (32) and the condition that they converge to constants $\bar{\tau}_{c}^{\prime}, \bar{\tau}_{m}^{\prime}$, and $\bar{\tau}_{e}^{\prime}$ such that

$$
\frac{1-\bar{\tau}_{c}^{\prime}}{1-\bar{\tau}_{c}}=\frac{1-\bar{\tau}_{m}^{\prime}}{1-\bar{\tau}_{m}}=\frac{1-\bar{\tau}_{e}^{\prime}}{1-\bar{\tau}_{e}}
$$

With this restriction that the policies on the new BGP are proportional to those on the initial BGP as in (34), the allocation of real innovative investment on the new BGP is equal to that on the old BGP. As a result, $\bar{Y}_{r}^{\prime}=\bar{Y}_{r}$ and the impact elasticity $\Theta^{\prime}$ as defined in Proposition 6 is equal to that computed at the allocation of innovative investment on the initial BGP (and hence denoted by $\Theta$ ). We prove these results and their further implications in the following proposition.

Proposition 7. Consider a change in policies from $\bar{\tau}_{c}, \bar{\tau}_{m}, \bar{\tau}_{e}$ to $\bar{\tau}_{c t}^{\prime}, \bar{\tau}_{m t}^{\prime}, \bar{\tau}_{e t}^{\prime}$ that satisfies equations (32) and (34). Assume that the allocation of innovative investment on the initial BGP is interior. Then, the allocation of real innovative investment is the same on the initial and new BGPs. As a result, the change in aggregate productivity across the initial and new BGPs is given as in Propo- 
sition 1, and the dynamics of aggregate productivity from the initial to the new BGP are given to a first-order approximation as in Proposition 2 where the impact elasticity $\Theta$ is computed as in Proposition 6 with derivatives evaluated at the initial BGP allocation of real innovative investment. The dynamics of GDP and the calculation of the welfare impact of the policy change are as in Lemmas 1 and 2. Under the further restriction that the initial (and final) policies are uniform, then the fiscal cost of these policies is related to the policy-induced change in the innovation intensity of the economy as in Proposition 4.

Note that Proposition 7 makes no reference to Proposition 3 characterizing the allocation of labor between production and research on the socially optimal BGP. This is because on the socially optimal BGP, the allocation of investment is conditionally efficient, and hence the impact elasticity $\Theta$ in equation (24) is different from the impact elasticity discussed in Proposition 7 (unless the initial equilibrium allocation of investment is conditionally efficient).

As a corollary to this proposition, we next show that, under certain additional restrictions, we can bound the impact elasticity $\Theta$ corresponding to a proportional policy change by the impact elasticity with respect to entry $\Theta_{e}$.

Corollary 2. Assume that on the initial BGP, the allocation of innovative investment is interior, $\Theta_{c} \geq \Theta_{e}$, and $d x_{c} / d Y_{r}=1-d x_{e} / d Y_{r} \leq 0$, with $d x_{e} / d Y_{r}$ as defined in equation (33) evaluated on the initial BGP. Then the impact elasticity $\Theta$ corresponding to a proportional change in policies satisfying equations (32) and (34) is bounded above by $\Theta_{e}$.

We now sketch the proof of the corollary. In Appendix B, we discuss the restrictions on the underlying parameters that must be satisfied on the initial BGP for the conditions of this corollary to hold.

As stated in Proposition 7, under the assumption that the policy change is a proportional policy change, we have that we can evaluate the impact elasticity $\Theta$ using the allocation of innovative investment on the initial BGP. As shown in the proof of that proposition, with such a policy change we have $d x_{m} / d Y_{r}=0$. From equation (30), these two results imply that

$$
\Theta=\Theta_{e}+\frac{d x_{c}}{d Y_{r}}\left(\Theta_{c}-\Theta_{e}\right) .
$$

When the initial allocation of innovative investment is conditionally efficient, as discussed in Proposition 5, we have that $\Theta_{c}=\Theta_{e}$, and hence $\Theta=\Theta_{e}$. Alternatively, if the economy features no business stealing (i.e., $\delta_{e}=0$ ), then we have $d x_{c} / d Y_{r}=0$, so, again, $\Theta=$ $\Theta_{e}$. With business stealing (i.e., $\delta_{e}>0$ ), an increase in entry $x_{e}$ raises the equilibrium probability of losing a product for incumbents and thus discourages investment $x_{c}$, so 
$d x_{c} / d x_{e}<0$. Moreover, if $\delta_{e}$ is positive but not too large, then $d x_{c} / d Y_{r}<0$. Hence, by equation (35), when $\Theta_{c} \geq \Theta_{e}$, then we have $\Theta \leq \Theta_{e} .{ }^{23}$

Under what conditions should we expect to have $\Theta_{c} \geq \Theta_{e}$ on the initial BGP? If $\tau_{c}=$ $\tau_{e}$ on the initial BGP, then we have $\Theta_{c} \geq \Theta_{e}$ with this inequality being strict if there is business stealing. Intuitively, since entrants do not internalize their negative impact on investment by incumbents in equilibrium, with uniform policies, there is too much investment in entry relative to investment by incumbents from a social perspective. We conduct our measurement below under the assumptions of Corollary 2, so that $\Theta \leq \Theta_{e}$.

We now turn to the question of what data we might use to measure the key parameters of our model.

\section{Measurement}

In this section, we use our analytical results to measure the aggregate implications of a change in innovation policies for the dynamics of aggregate productivity and output. We focus here on an economy that starts with uniform subsidies for innovative investment, and we consider the implications of a proportional change in policies to a new, higher level of uniform innovation subsidies. We consider one specification of the model in which there is no business stealing, which implies that the allocation of innovative investment on the initial BGP is conditionally efficient. In this case, the impact elasticity is $\Theta=\Theta_{e}$. We consider an alternative specification of the model in which the allocation of innovative investment on the initial BGP is not conditionally efficient because of business stealing. In this case, under the assumptions of Corollary $2, \Theta \leq \Theta_{e}$. In both cases, then, we measure $\Theta_{e}$ and use this measure of the impact elasticity to characterize the aggregate implications of a uniform change in innovation policies.

Given the functional form for $G$ in equation (28), we can calculate the term $\Theta_{e}$ directly as

$$
\Theta_{e}=\frac{1}{\rho-1} \frac{\left(\eta_{e}-\delta_{e} \zeta\left(\bar{x}_{c}\right)\right) \bar{x}_{e}}{\exp \left(\bar{g}_{Z}\right)^{\rho-1}} \frac{\bar{Y}_{r}}{\bar{x}_{e}} .
$$

From (28) we have that $\left(\eta_{e}-\delta_{e} \zeta\left(\bar{x}_{c}\right)\right) \bar{x}_{e}=\exp \left(G\left(\bar{x}_{c}, \bar{x}_{m}, \bar{x}_{e}\right)\right)^{\rho-1}-\exp \left(G\left(\bar{x}_{c}, \bar{x}_{m}, 0\right)\right)^{\rho-1}$. Hence,

$$
\Theta_{e}=\frac{1}{\rho-1}\left[\frac{\exp \left(\bar{g}_{Z}\right)^{\rho-1}-\exp \left(G\left(\bar{x}_{\mathcal{c}}, \bar{x}_{m}, 0\right)\right)^{\rho-1}}{\exp \left(\bar{g}_{Z}\right)^{\rho-1}}\right] \frac{\bar{Y}_{r}}{\bar{x}_{e}} .
$$

\footnotetext{
${ }^{23}$ In Appendix B, we show that if our conditions are violated, then it is possible that an increase in innovative investment might reduce aggregate productivity growth on impact. This possibility that the impact elasticity $\Theta$ might be negative in a model of this kind is discussed in Acemoglu and Cao (2015).
} 
We provide formulas for $\Theta_{c}$ and $\Theta_{m}$ in Appendix C.1.

We can derive a bound on $\Theta_{e}$ similar to the one we obtained in equation (26) for the model with innovative investment by entrants only. Specifically, given the definition that $\Theta_{e} \equiv \frac{\partial}{\partial x_{e}} G\left(\bar{x}_{c}, \bar{x}_{m}, \bar{x}_{e}\right) \bar{Y}_{r}$, concavity of the function $G\left(\bar{x}_{c}, \bar{x}_{m}, x_{e}\right)$ in its third argument $x_{e}$ implies that $\frac{\partial}{\partial x_{e}} G\left(\bar{x}_{c}, \bar{x}_{m}, \bar{x}_{e}\right) \leq \frac{\left(\bar{g}_{Z}-G\left(\bar{x}_{c}, \bar{x}_{m}, 0\right)\right)}{\bar{x}_{e}}$. This argument gives the bound

$$
\Theta_{e} \leq\left(\bar{g}_{Z}-G\left(\bar{x}_{c}, \bar{x}_{m}, 0\right)\right) \frac{\bar{Y}_{r}}{\bar{x}_{e}}
$$

where this bound is tight as $\rho \rightarrow 1$. The term $\bar{g}_{Z}-G\left(\bar{x}_{c}, \bar{x}_{m}, 0\right)$ can be interpreted as the contribution of innovation by entering firms to productivity growth on the initial BGP, and $\bar{x}_{e} / \bar{Y}_{r}$ is the fraction of innovative investment undertaken by entering firms. Once one knows the term $\bar{g}_{Z}-G\left(\bar{x}_{c}, \bar{x}_{m}, 0\right)$, it is straightforward to calculate the term in square brackets in equation (36).

We measure $\Theta_{e}$ using equation (36). We set the elasticity of substitution between goods $\rho=4$, which lies within the range of estimates in Broda and Weinstein (2006). To measure the contribution of innovation by entering firms to productivity growth on the initial BGP, we consider two alternative specifications of our model: one with no business stealing and one with business stealing.

Under the assumption that there is no business stealing (that is, $\delta_{m}=\delta_{e}=0$ ), the contribution of innovation by entering firms to productivity growth (the term in square brackets in equation (36)) is equal to the aggregate size of products produced in entering firms on the initial BGP, which we denote by $\bar{s}_{e}$. This measure of size corresponds to the sum of product size $s_{t+1}(z)$ as defined in equation (7) across all products produced at $t+1$ by firms that newly entered at that date. Hence, if there is no business stealing,

$$
\Theta=\Theta_{e}=\frac{1}{\rho-1} \bar{s}_{e} \frac{\bar{Y}_{r}}{\bar{x}_{e}} .
$$

We measure $\bar{s}_{e}$ using firm dynamics data from the Longitudinal Business Database on the share of total employment in new firms (created within the past year).

We consider an alternative specification of our model that includes business stealing, that is, $\delta_{m}, \delta_{e}>0$. In this case, the initial equilibrium is not conditionally efficient. For these specifications of our model, we set $\Theta$ equal to its upper bound, $\Theta_{e}$ (under the assumptions of Corollary 2). To measure $\Theta_{e}$ in this case, we can no longer set the term in square brackets in (36) equal to $\bar{s}_{e}$. Instead, this term is less than the size of entering firms by the degree to which entry displaces incumbent firms. Instead, we draw on external estimates of the contribution of entrants to productivity growth on the initial BGP to mea- 
sure this term. Specifically, we choose $G\left(\bar{x}_{c}, \bar{x}_{m}, 0\right)$ so that $\left(\bar{g}_{Z}-G\left(\bar{x}_{c}, \bar{x}_{m}, 0\right)\right) / \bar{g}_{Z}=0.257$, which corresponds to estimates of the portion of annual trend productivity growth due to entry in Akcigit and Kerr (2010). ${ }^{24}$ With this measure of the contribution of innovation by entrants to growth, the term in square brackets in equation (36) is equal to 0.011 , which is substantially less than $\bar{s}_{e}$.

For both specifications of our model, we use the model to infer the fraction of innovative investment undertaken by entering firms, as denoted by $\bar{x}_{e} / \bar{Y}_{r}$, since these expenditures are not recorded in the accounts for the nonfinancial corporate sector if entering firms undertake these investments before incorporating. To make this inference, we use the equilibrium condition that entering firms have zero expected profits. On a BGP, this condition can be written as

$$
\frac{\bar{P}_{r t} \bar{x}_{e}}{\bar{Y}_{t}}=\frac{\exp \left(\bar{g}_{Y}\right)}{1+\bar{R}} \frac{\bar{v}}{\left(1-\tau_{e}\right)} \bar{s}_{e}
$$

where $\bar{v}$ denotes the ratio of the value of all incumbent products relative to output $Y_{t}$ on a BGP and $\bar{R}$ denotes the real interest rate on a BGP. We measure $\bar{v}$ as the discounted present value of dividends paid to the owners of all incumbent products as follows.

In our model, the dividends $D_{t}$ that households receive as owners of all incumbent firms at time $t$ are equal to the monopoly profits that incumbent firms earn on their production less post-subsidy expenditures on innovative investment by these incumbent firms. The term $V_{t}$ denotes the discounted present value of these dividends from period $t$ on. Let $d_{t}=D_{t} / Y_{t}$ and $v_{t}=V_{t} / Y_{t}$ denote the ratios of these dividends and value to output at time $t$, and let $\bar{d}$ and $\bar{v}$ denote these ratios of dividends and value to output on a BGP. As described in Appendix C, we use National Income and Product Accounts (NIPA) data for the nonfinancial corporate sector to measure these dividends. When doing so, we allow for a corporate profits tax.

The associated ratio of the value of these dividends to output $\bar{v}$ on the initial BGP is then given by

$$
\bar{v}=\bar{d}\left[1-\frac{\exp (\bar{g} Y)}{1+\bar{R}}\left(1-\bar{s}_{e}\right)\right]^{-1} .
$$

Thus, equations (39) and (40) allow us to infer the investments of entrants in innovation on a BGP given our estimates of dividends earned by owners of incumbent products.

We also use NIPA data for the nonfinancial corporate sector to measure the expenditure on innovative investment by incumbent firms $P_{r t}\left(x_{c t}+x_{m t}\right)$ relative to output. The

\footnotetext{
${ }^{24}$ Garcia-Macia et al. (2016) estimate a contribution of entrants in growth of $12.8 \%$ in the period 2003-2013 and $19.1 \%$ in the period $1976-1986$.
} 
innovative intensity of the economy $\bar{i}_{r}$ is given by the sum of innovative investments by incumbent firms and our imputed measure of innovative investment by entering firms. These formulas allow us to measure the fraction of innovative investment undertaken by entering firms, $\bar{x}_{e} / \bar{Y}_{r}$.

Throughout our calculations, we consider a period to be one year. As described in Appendix $C$, we draw on external estimates of the interest rate $\bar{R}$ and $\bar{\tau}_{e}=\bar{\tau}_{c}=\bar{\tau}_{m}$ on the initial BGP. We use NIPA data for the nonfinancial corporate sector to measure the growth rate of output $\bar{g}_{Y}$, the share of physical capital in the production function $\alpha$, the markup $\mu$, dividends relative to output $\bar{d}$ on the initial BGP, and the innovative investment of incumbent firms $\bar{P}_{r t}\left(\bar{x}_{c}+\bar{x}_{m}\right)$ relative to aggregate output. Our procedure gives us an estimate of the portion of innovative investment undertaken by entrants of $\bar{x}_{e} / \bar{Y}_{r}=0.34$. We use this estimate in the specifications of our model both without and with business stealing.

In the specification of our model without business stealing, with $\rho=4, \bar{s}_{e}=0.027$, and $\bar{x}_{e} / \bar{Y}_{r}=0.34$, our estimate of the impact elasticity in this case is $\Theta=0.026$. This impact elasticity is substantially higher than the bound in equation (26) of $\bar{g}_{Z}=0.014$ that would apply if $G(0,0,0)=0$. Specifically, $G(0,0,0) \leq-0.012$. The implied value of $G\left(\bar{x}_{c}, \bar{x}_{m}, 0\right)$ is 0.004 .

In our specification of the model with business stealing, when we combine estimates of the contribution of entrants' investment to aggregate productivity growth described above with our inferred measure of the share of innovative investment undertaken by entrants, our measure of the impact elasticity in this case is $\Theta_{e}=0.010$. The implied value of $G\left(\bar{x}_{c}, \bar{x}_{m}, 0\right)$ is 0.01 .

In our analysis of the aggregate implications of changes in innovation policies, we use external estimates of the degree of intertemporal knowledge spillovers $\phi$. Specifically, we consider two alternative values. We consider a high degree of intertemporal knowledge spillovers, $\phi=0.96$, which is close to the value assumed in the literature with fully endogenous growth. ${ }^{25}$ As an alternative, we consider a low degree of intertemporal knowledge spillovers, $\phi=-1.6$, taken from estimates of this parameter in Fernald and Jones (2014).

To summarize, in the next section we discuss the following four specifications of our model: one with no business stealing $(\Theta=0.026)$ and low intertemporal knowledge spillovers $(\phi=-1.6)$, one with no business stealing and high intertemporal knowledge

\footnotetext{
${ }^{25}$ We choose the specific number $\phi=0.96$ so that the model is as close as possible to an endogenous growth model while still allowing for computation of the exact transition path of the economy in a reasonable amount of time.
} 
spillovers $(\phi=0.96)$, and two more with business stealing $(\Theta=0.01)$ and low and high intertemporal knowledge spillovers, respectively. The full set of parameters that we use in our calculations is given in Table 2 in Appendix C.

\section{Results}

In each of the four calibrations of our model, we consider the dynamics of aggregate productivity and output that follow from a proportional policy change starting at $t=0$ that induces a permanent, constant increase in the allocation of labor to research (that is, $\log l_{r t}^{\prime}-\log \bar{l}_{r}$ is positive and constant for $t \geq 0$ ). This reallocation of labor corresponds to a permanent increase in the innovation intensity of the economy given by equation (13). In the long run, the fiscal cost and the rates of the innovation subsidies required to implement this increase in the innovation intensity of the economy are given as in Proposition 4. We compute the path of innovation subsidies required to implement this reallocation of labor in the transition numerically.

In the first three rows of Table 1, we report the elasticity of aggregate productivity relative to trend $\left(\log Z_{t}^{\prime}-\log \bar{Z}_{t}\right)$ with respect to this permanent change in the allocation of labor at horizons of $t=1$ year, $t=20$ years, and $t=\infty$. From Proposition 2 , the elasticity of aggregate productivity at one year is given by the impact elasticity $\Theta$, and the elasticity of aggregate productivity at 20 years is given by $\sum_{j=0}^{19} \Gamma_{j}$. From Proposition 1 , the long-run elasticity of aggregate productivity is given by $1 /(1-\phi)$.

In rows 4-6 of Table 1, we report the elasticity of aggregate output relative to trend $\left(\log Y_{t}^{\prime}-\log \bar{Y}_{t}\right)$ with respect to this permanent change in the allocation of labor on impact (at $t=0$ ) and at horizons of $t=20$ years and $t=\infty$. From Lemma 1, the elasticity of output on impact is given by $-(1-\alpha) \bar{l}_{r} / \bar{l}_{p}$. The elasticity of output at $t=20$ is given by $\sum_{k=0}^{19} \Gamma_{j} /(1-\alpha)-\bar{l}_{r} / \bar{l}_{p}$ plus an adjustment for changes in the rental rate along the transition that we compute numerically. The elasticity of output in the long run is given in equation (21)

In row 7 of Table 1, we report the elasticity of the consumption equivalent change in welfare calculated in equation (23) (we assume that there is a production subsidy that undoes the markup distortion on physical capital investment), and in row 8 we report, for the cases with conditional efficiency, the share of labor devoted to research on the socially optimal BGP, as given in Proposition 3.

Interpreting elasticities To help interpret these elasticities in Table 1, we consider a change in innovation policies that results in a permanent change in the allocation of labor 
of $\log l_{r t}^{\prime}-\log \bar{l}_{r}=0.1$. The implied responses of aggregate productivity, output, and welfare are equal to the elasticities given in rows 1-7 of Table 1 multiplied by 0.1. This change in the allocation of labor corresponds, in our calibration, to a permanent change in the innovation intensity of the economy from $\bar{i}_{r}=0.089$ to $\bar{i}_{r}^{\prime}=0.10$. The corresponding annual fiscal cost of these policies in the long run is then equal to $1.1 \%$ of output.

Consider first the implied long-run elasticities of aggregate productivity and output in response to this policy change. In the two specifications of the model with low intertemporal knowledge spillovers (low $\phi$ ), the long-run responses of aggregate productivity and output are relatively modest, equal to $3.8 \%$ for each. In contrast, in the two specifications of the model with high intertemporal knowledge spillovers, the long-run responses of aggregate productivity and output (in logs) are 65 and 91 times larger, respectively. It is clear that the model's implications for long-run productivity and output are very sensitive to the calibration of intertemporal knowledge spillovers, $\phi$. In contrast, these implications are independent of the impact elasticity $\Theta$.

As discussed in Corollary 1 , the impact elasticity $\Theta$ interacts with the intertemporal knowledge spillovers $\phi$ to shape the dynamics of aggregate productivity and output from the initial BGP to the new BGP. In row 4 of Table 1 , we see that the initial $(t=0)$ response of output to this policy-induced reallocation of labor is to fall by $1.1 \%$ in all four specifications of our model. The response of aggregate productivity in year 1 (in row 1 ) is $0.26 \%$ ( 26 basis points) with no business stealing and $0.1 \%$ with business stealing. This relatively small response of aggregate productivity implies that aggregate output is below trend for the first 6 years of the transition in the case with no business stealing and for the first 15 years of the transition in the case with business stealing.

By year $t=20$, aggregate output is above trend in all cases (row 5), but the response is not very large. With no business stealing, output is $2.0 \%(4.2 \%)$ above trend with low (high) intertemporal knowledge spillovers. With business stealing, by year $t=20$, output is only $0.3-0.7 \%$ above trend, depending on the extent of intertemporal knowledge spillovers.

We draw two conclusions from these results. First, we see that the medium-term elasticity of output is not very sensitive to the assumed intertemporal knowledge spillovers in comparison to what is found for the long-run elasticities. Second, these small modelimplied responses of aggregate output after 20 years suggest that it might be difficult to see the impact on aggregates of a change in innovation policies of this magnitude over a horizon of two decades in the presence of normal business cycle shocks. That is, in a world in which the standard deviation of annual output per worker around trend is 2 to 3, policy-induced movements in output of the magnitudes considered here are rela- 
tively small. In this respect, our findings rationalize empirical studies finding a weak link between R\&D and productivity growth using time series data (see, e.g., CBO 2005).

The modest responses of aggregate productivity and output over a 20-year horizon implied by the elasticities in rows 2 and 5 of Table 1 stand in contrast to our model's normative implications for innovation policies. In row 7 of Table 1, we see that the consumption equivalent variation corresponding to this policy change ranges from $1.7 \%$ to $20 \%$ of aggregate consumption, all from a policy change with annual fiscal costs in the long run of only $1.1 \%$ of GDP. Likewise, in row 8 of Table 1, we see that our model's implications for the share of labor allocated to research on the socially optimal BGP (in the cases without business stealing, so that the initial allocation of innovative investment is conditionally efficient) are considerably larger than our initial calibrated level ( $\bar{l}_{r}^{*}$ ranges from 0.30 to 0.69 as opposed to our baseline level of $\bar{l}_{r}=0.12$ ). Note that we have assumed that innovation subsidies are financed by lump-sum taxes. Hence, we have abstracted from the welfare losses associated with the distortions that would arise if lump-sum taxes were unavailable.

These welfare implications are driven by the implications of our model for the long run and our calibration of the gap between the growth rate of output and the interest rate (which implies $\tilde{\beta}=0.986$ ). Since interest rates are not much higher than the growth rate, households place a high weight on the implications of innovation policies for consumption in the long run. In contrast, if one considers the implications of innovation policies for welfare using preferences (2) over aggregate consumption but only over the first 20 years of the transition (that is, $t=0, \ldots, 20$ ), the change in welfare over the medium term is actually negative in the two specifications of the model with business stealing.

Discussion Here we discuss the implications of our analytical results for the sensitivity of our measurement of the impact elasticity $\Theta$ to our assumptions and uncertainties in measurement.

One common assumption made in the literature is that aggregate productivity would remain constant in the absence of innovative investment by firms (i.e., $G(0,0,0)=0$ ). As shown in Proposition 5, this assumption, combined with the assumption that the allocation of innovative investment on the initial BGP is conditionally efficient, implies the bound $\Theta \leq \bar{g}_{Z}$, which is quite restrictive when the model is applied to advanced economies with relatively low baseline levels of TFP growth.

Once one relaxes the assumption that the allocation of innovative investment on the initial BGP is conditionally efficient, then, as demonstrated in Proposition 6, it is possible for changes in innovation policies to have a large impact on aggregate productivity 


\begin{tabular}{|c|c|c|c|c|}
\hline \multirow[b]{2}{*}{ Intertemporal spillovers } & \multicolumn{2}{|c|}{ No business stealing } & \multicolumn{2}{|c|}{ With business stealing } \\
\hline & Low $\phi$ & High $\phi$ & Low $\phi$ & High $\phi$ \\
\hline Aggregate productivity & & & & \\
\hline 1: Year $1, \Theta$ & 0.026 & 0.026 & 0.010 & 0.010 \\
\hline 2: Year 20 & 0.29 & 0.52 & 0.16 & 0.20 \\
\hline 3: Long run & 0.38 & 25.00 & 0.38 & 25.00 \\
\hline Aggregate output & & & & \\
\hline 4: Year 0 & -0.11 & -0.11 & -0.11 & -0.11 \\
\hline 5: Year 20 & 0.20 & 0.42 & 0.03 & 0.07 \\
\hline 6: Long run & 0.36 & 33.18 & 0.36 & 33.18 \\
\hline 7: Welfare (equivalent variation) & 0.26 & 2.01 & 0.17 & 0.73 \\
\hline 8: Optimal share of labor in research & 0.30 & 0.69 & n.a. & n.a. \\
\hline
\end{tabular}

Table 1: Elasticity of aggregate productivity, output, and welfare with respect to research labor at various time horizons, and optimal innovation intensity

Note: business stealing $\left(\delta_{e}=0\right.$ or 0.2$)$, spillovers ( $\phi=-1.6$ or 0.96 )

growth by reallocating investment to the category with the highest social return. Using the results in Proposition 7 and Corollary 2, we have aimed to make progress on measurement when we relax the assumption that the allocation of innovative investment on the initial BGP is conditionally efficient by replacing that assumption with two alternative assumptions: (1) that the change in innovation policies is proportional, and (2) that the impact of investment by incumbent firms in improving their own products on aggregate productivity growth $\Theta_{c}$ is at least as large as that of innovative investment by entrants $\Theta_{e}$. In combination with the result that innovative investment by incumbent firms in improving their own products either stays the same or falls when aggregate innovative investment rises, we can apply an alternative bound to $\Theta$ given by $\Theta_{e}$ in equation (36). To implement this bound, we have considered one specification of our model with the extreme assumption of no business stealing. As we have discussed in equation (38), this specification of our model gives the highest possible value of $\Theta$ under these assumptions. Of course, larger values of $\Theta$ would be possible if one considers policy changes that are not proportional or if one assumes that $\Theta_{c}<\Theta_{e}$ on the initial BGP.

Our measurement of $\Theta_{e}$ using equation (36) is sensitive to the measurement of the share of innovative investment carried out by entrants $\bar{x}_{e} / \bar{Y}_{r}$. In this paper, we have estimated this share of innovative investment by entrants under the assumption that their 
investment is not measured in NIPA data for the nonfinancial corporate sector and instead must be inferred using equations (40) and (39). This measurement is, in turn, particularly sensitive to imputations of the rental rate on physical capital $R_{k}$, as this imputed rental rate is used to compute the share of compensation of physical capital in output $\alpha / \mu$, the corresponding share of variable profits in output $(\mu-1) / \mu$, and thus the implied ratio of dividends $\bar{d}$ and firm intangible value $\bar{v}$ to output in the initial BGP. If one imputes a higher rental rate $R_{k}$ than we have done, then one would find correspondingly lower values of $\bar{d}, \bar{v}$, and $\bar{x}_{e} / \bar{Y}_{r}$. In this case, one would estimate a higher impact elasticity $\Theta_{e}$ than we have done. In future research, it may be useful to pursue alternative approaches to measuring the share of innovative investment undertaken by entering firms $\bar{x}_{e} / \bar{Y}_{r}$ so as to develop more robust estimates of the impact elasticity $\Theta_{e}$.

\section{Conclusion}

In this paper, we have derived a simple first-order approximation to the transition dynamics of aggregate productivity and output in response to a policy-induced change in the innovation intensity of the economy implied by a model that nests some of the canonical models of growth through firms' investments in innovation. We see our results as a useful guide to researchers looking to use these models to address quantitative questions regarding the impact of policy-induced changes in firms' investments in innovation on macroeconomic dynamics and welfare.

As an alternative to our model-based approach to measuring the aggregate implications of innovation policies, one might try to directly examine the results of policy changes (see, e.g., Bloom et al. 2013). Of course, this may be difficult to do in aggregate data if it would take a very large policy-induced change in the innovation intensity of the economy to bring about a clearly detectable change in aggregate productivity growth.

In our measurement exercises, we have not focused on the productivity and welfare gains that might be achieved by reallocating a given level of investment in innovation across different categories of innovative investment. As noted in the discussion to Proposition 6, in the context of our model, one can conduct an analysis of policy changes that favor one category of innovative investment over another if one has information to fix the parameters of the innovative investment technologies $h(\cdot)$ and $\zeta(\cdot)$. More complex models in the literature consider a wider array of reasons why the marginal contribution of heterogeneous firms' innovative investments to aggregate productivity growth might vary across firms. One challenge for research in this area is to find reliable metrics for evaluating which firms should be doing relatively more innovation spending and by 
how much these firms should increase their investments in innovation. 


\section{References}

Acemoglu, Daron, Introduction to Modern Economic Growth, Princeton University Press, 2009.

- and Dan Cao, "Innovation by Entrants and Incumbents," Journal of Economic Theory, May 2015, 157 (C), 255-294.

_, Ufuk Akcigit, Harun Alp, Nicholas Bloom, and William R. Kerr, "Innovation, Reallocation and Growth," Working Paper 18993, National Bureau of Economic Research, April 2013.

Aghion, Philippe and Peter Howitt, "A Model of Growth Through Creative Destruction," Econometrica, March 1992, 60 (2), 323-351.

_, Ufuk Akcigit, and Peter Howitt, "What Do We Learn From Schumpeterian Growth Theory?," in Philippe Aghion and Steven Durlauf, eds., Handbook of Economic Growth, Vol. 2, pp. 515-563, Elsevier, 2014.

Akcigit, Ufuk and William R. Kerr, "Growth Through Heterogeneous Innovations," Working Paper 16443, National Bureau of Economic Research, November 2010.

_, Douglas Hanley, and Nicolas Serrano-Velarde, "Back to Basics: Basic Research Spillovers, Innovation Policy and Growth," Working Paper 19473, National Bureau of Economic Research, September 2013.

Atkeson, Andrew and Ariel Tomas Burstein, "Innovation, Firm Dynamics, and International Trade," Journal of Political Economy, June 2010, 118 (3), 433-484.

Bloom, Nicholas, Aprajit Mahajan, David McKenzie, and John Roberts, "Do Management Interventions Last? Evidence from India," Working Paper 24249, National Bureau of Economic Research, January 2018.

_ , Charles I. Jones, John Van Reenen, and Michael Webb, “Are Ideas Getting Harder to Find?," Working Paper 23782, National Bureau of Economic Research, September 2017.

_ , Mark Schankerman, and John Van Reenen, "Identifying Technology Spillovers and Product Market Rivalry," Econometrica, July 2013, 81 (4), 1347-1393.

Bloom, Nick, Rachel Griffith, and John Van Reenen, “Do R\&D Tax Credits Work? Evidence from a Panel of Countries 1979-1997," Journal of Public Economics, July 2002, 85 (1), 1-31.

Broda, Christian and David E. Weinstein, "Globalization and the Gains From Variety," Quarterly Journal of Economics, May 2006, 121 (2), 541-585.

CBO, "Research and Development and Productivity Growth: A Background Paper," Working Paper, Congressional Budget Office, 2005. 
Corrado, Carol A. and Charles R. Hulten, "Innovation Accounting," in Dale W. Jorgenson J. Steven Landefeld and Paul Schreyer, eds., Measuring Economic Sustainability and Progress, pp. 595-626, University of Chicago Press, September 2014.

Corrado, Carol, Charles Hulten, and Daniel Sichel, "Intangible Capital and U.S. Economic Growth," Review of Income and Wealth, September 2009, 55 (3), 661-685.

_ , Peter Goodridge, and Jonathan Haskel, "Constructing a Price Deflator for R\&D: Calculating the Price of Knowledge Investments as a Residual," Technical Report 11-03, The Conference Board, Economics Program, October 2011.

Fernald, John G. and Charles I. Jones, "The Future of US Economic Growth," American Economic Review, May 2014, 104 (5), 44-49.

Ferraro, Domenico, Soroush Ghazi, and Pietro Peretto, "Implications of Tax Policy for Innovation and Aggregate Productivity Growth," April 2017.

Garcia-Macia, Daniel, Pete Klenow, and Chang-Tai Hsieh, "How Destructive is Innovation?," Working Paper 22953, National Bureau of Economic Research, December 2016.

Griliches, Zvi, "Issues in Assessing the Contribution of Research and Development to Productivity Growth," Bell Journal of Economics, Spring 1979, 10 (1), 92-116.

_ , "The Search for R\&D Spillovers," Scandinavian Journal of Economics, Supplement 1992, $94,29-47$.

Grossman, Gene M. and Elhanan Helpman, Innovation and Growth in the Global Economy, MIT Press, 1991.

_ and _ , "Quality Ladders in the Theory of Growth," Review of Economic Studies, January $1991,58(1), 43-61$.

Hall, Robert E., "Corporate Earnings Track the Competitive Benchmark," Working Paper 10150, National Bureau of Economic Research, November 2003.

Jaimovich, Nir and Sergio Rebelo, "Nonlinear Effects of Taxation on Growth," Journal of Political Economy, February 2017, 125 (1), 265-291.

Jones, Charles I., "Sources of U.S. Economic Growth in a World of Ideas," American Economic Review, March 2002, 92 (1), 220-239.

_ , "Growth and Ideas," in Philippe Aghion and Steven N. Durlauf, eds., Handbook of Economic Growth, Vol. 1, pp. 1063-1111, Elsevier, 2005.

- and John C. Williams, "Measuring the Social Return to R\&D," Quarterly Journal of Economics, November 1998, 113 (4), 1119-1135.

Kendrick, John W., "Total Capital and Economic Growth," Atlantic Economic Journal, 1994, 22 (1), 1-18. 
Klette, Tor Jakob and Samuel Kortum, "Innovating Firms and Aggregate Innovation," Journal of Political Economy, October 2004, 112 (5), 986-1018.

Kortum, Samuel S., "Research, Patenting, and Technological Change," Econometrica, November 1997, 65 (6), 1389-1420.

Lentz, Rasmus and Dale T. Mortensen, "An Empirical Model of Growth Through Product Innovation," Econometrica, November 2008, 76 (6), 1317-1373.

_ and _ , "Optimal Growth Through Product Innovation," Review of Economic Dynamics, January 2016, 19, 4-19.

Luttmer, Erzo G. J., "Selection, Growth, and the Size Distribution of Firms," Quarterly Journal of Economics, August 2007, 122 (3), 1103-1144.

_ , "On the Mechanics of Firm Growth," Review of Economic Studies, 2011, 78 (3), 10421068.

McGrattan, Ellen R. and Edward C. Prescott, "Taxes, Regulations, and the Value of U.S. and U.K. Corporations," Review of Economic Studies, July 2005, 72 (3), 767-796.

Peters, Michael, "Heterogeneous Mark-Ups, Growth and Endogenous Misallocation," 2016.

Poterba, James M., “The Rate of Return to Corporate Capital and Factor Shares: New Estimates Using Revised National Income Accounts and Capital Stock Data," CarnegieRochester Conference Series on Public Policy, June 1998, 48, 211-246.

Rivera-Batiz, Luis A. and Paul M. Romer, "Economic Integration and Endogenous Growth," Quarterly Journal of Economics, May 1991, 106 (2), 531-555.

Romer, Paul M., "Endogenous Technological Change," Journal of Political Economy, October 1990, 98 (5), S71-S102.

Tyson, Laura and Greg Linden, "The Corporate R\&D Tax Credit and U.S. Innovation and Competitiveness; Gauging the Economic and Fiscal Effectiveness of the Credit," Working Paper, Center for American Progress, January 6, 2012. 


\section{Contents (Appendix)}

$\begin{array}{ll}\text { A Definition of Equilibrium } & 1\end{array}$

$\begin{array}{ll}\text { B Proofs } & 7\end{array}$

$\begin{array}{ll}\text { C Quantitative analysis } & 20\end{array}$

C.1 Impact elasticities . . . . . . . . . . . . . . . . . . . . 20

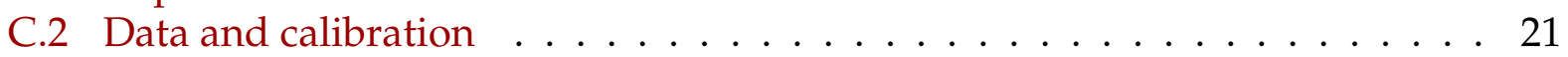

C.3 Calibration of additional parameters to solve nonlinear transition dynamics 26

C.4 Solving the model . . . . . . . . . . . . . . . . . . . . 29

C.5 Additional numerical results . . . . . . . . . . . . . . 35

D Discussion of models not nested in our framework 43

E Variations of baseline model 45

E.1 Occupation choice . . . . . . . . . . . . . . . . . 45

E.2 Goods and labor used as inputs in research . . . . . . . . . . . . . . . . . 46

E.3 Klette and Kortum (2004) specification . . . . . . . . . . . . . . . . . . 48

E.4 Alternative specification of incumbent technology to acquire new products 50

\section{A Definition of Equilibrium}

Here we fill in the details of our definition of equilibrium in the full model with innovation by entrants and incumbent firms.

Time is discrete and labeled $t=0,1,2, \ldots$. Let the grid of possible values of the productivity index $z$ be given by $z_{n}=n \Delta$, for the integers $n$.

An allocation in this model is a sequence of aggregate variables $\left\{K_{t}, L_{t}, L_{p t}, L_{r t}, C_{t}, Y_{t}, Y_{r t}, Z_{t}, M_{t}\right\}$, product-level variables $\left\{y_{t}(z), k_{t}(z), l_{t}(z), x_{c t}(z), x_{m t}(z), x_{e t}\right\}$, and a sequence of measures $\left\{M_{t}\left(z_{n}\right)\right\}$, where $M_{t}\left(z_{n}\right)$ denotes the measure of intermediate goods in period $t$ with frontier technology for producing that good indexed by $z_{n}$.

An allocation is feasible if it satisfies equations (1), (3), (4), $L_{p t}=\sum_{z} l_{t}(z) M_{t}(z), K_{t}=$ $\sum_{z} k_{t}(z) M_{t}(z), L_{p t}+L_{r t}=L_{t},(8)$ with $Z_{t}$ given by (6), $M_{t}=\sum_{z} M_{t}(z)$, and (27) with $x_{m t} \equiv$ $\sum_{z} x_{m t}(z) M_{t}(z)$ and $x_{c t} \equiv \sum_{z} x_{c t}(z) M_{t}(z)$. Note that equation (5) is an equilibrium result, not a feasibility condition. To finish the definition of feasibility, we now give a more detailed description of the technologies for innovative investment so as to fully describe the transition law for the measure $M_{t}(z)$ given in equation (49) below.

Each period, each intermediate good faces probability $\delta_{0}$ of exiting for exogenous reasons.

In period $t+1$, entering firms that invested in total $x_{e t}$ in period $t$ begin production 
of a measure $M_{e t+1}=x_{e t} M_{t}$ of intermediate goods. A fraction $\left(1-\delta_{e}\right)$ of these goods are new to society. A fraction $\mathcal{F}_{e}\left(z_{n} ; \frac{z_{t}^{\rho-1}}{M_{t}}\right)$ of these goods that are new to society have productivity index $z_{n}$. This distribution of productivities for new products satisfies

$$
\sum_{n} z_{n}{ }^{\rho-1} \mathcal{F}_{e}\left(z_{n} ; \frac{Z_{t}^{\rho-1}}{M_{t}}\right)=\eta_{e n} \frac{Z_{t}^{\rho-1}}{M_{t}}
$$

A fraction $\delta_{e}$ of these goods are stolen from incumbent firms. Specifically, a good existing at $t$ with productivity index $z_{n}$ is drawn with probability $M_{t}\left(z_{n}\right) / M_{t}$, and an increment of $j>0$ steps on the grid of productivity indices is drawn from a distribution $\mathcal{J}_{e}(j)$ independent of $n$. The stolen good then has productivity index $z_{n+j}$ at $t+1$. This distribution of increments to the productivities for stolen products in entering firms satisfies

$$
\sum_{j} \exp ((\rho-1) j \Delta) \mathcal{J}_{e}(j)=\eta_{e s}
$$

These assumptions imply that the distribution of productivities acquired through business stealing by entering firms satisfies

$$
\sum_{z_{n}}\left[\sum_{j} \exp ((\rho-1) j \Delta) \mathcal{J}_{e}(j)\right] z_{n}{ }^{\rho-1} \frac{M_{t}\left(z_{n}\right)}{M_{t}}=\eta_{e s} \frac{Z_{t}^{\rho-1}}{M_{t}} .
$$

Define the notation

$$
\tilde{M}_{e t+1}\left(z_{n}\right)=\left(1-\delta_{e}\right) x_{e t} M_{t} \mathcal{F}_{e}\left(z_{n} ; \frac{Z_{t}^{\rho-1}}{M_{t}}\right)+\delta_{e} x_{e t} \sum_{j} \mathcal{J}_{e}(j) M_{t}\left(z_{n-j}\right) .
$$

These assumptions together imply that in the simple model with innovative investment by entering firms only, the evolution of the measure $M_{t}(z)$ is given by

$$
M_{t+1}\left(z_{n}\right)=\left(1-\delta_{c t}\right) M_{t}\left(z_{n}\right)+\tilde{M}_{e t+1}\left(z_{n}\right)
$$

where $\left(1-\delta_{c t}\right)=\left(1-\delta_{0}-\delta_{e} x_{e t}\right)$.

We now consider the contribution to the dynamics of the measure $M_{t}(z)$ from innovative investment by incumbent firms. Each product produced by an incumbent firm has associated with it a technology for improving the productivity index $z$ associated with that product and a technology for acquiring an additional product. There is no technological connection between products, so we treat the innovative investments associated with each product separately. As specified in the text in Section 4 , for each existing product at $t$ 
with productivity index $z_{n}$, there is a technology $h\left(x_{m t}(z) / s_{t}(z)\right)$ (with $s_{t}(z)=\left(z / Z_{t}\right)^{\rho-1}$ as defined in equation 7$)$ that links the innovative investment $x_{m t}\left(z_{n}\right)$ associated with that good with the probability that the firm making this investment acquires a new product at $t+1$. Conditional on the incumbent firm acquiring a new product, with probability $\left(1-\delta_{m}\right)$ this product is new to society and has productivity index $z_{n+j}$ drawn from distribution $\mathcal{F}_{m}(j)$, with $j$ drawn independent of $n$. This distribution has the property that

$$
\sum_{j} \exp ((\rho-1) j \Delta) \mathcal{F}_{m}(j)=\eta_{m n}
$$

With complementary probability $\delta_{m}$, the newly acquired product is stolen from an incumbent firm. In this case, a good that also has productivity index $z_{n}$ at $t$ is stolen, and the firm that steals it draws an increment of $j>0$ steps to the productivity index of that good (giving it productivity index $z_{n+j}$ at $t+1$ ) from a distribution $\mathcal{J}_{m}(j)$, with $j$ drawn independent of $n$. This distribution of increments to the productivities for stolen products in incumbent firms satisfies

$$
\sum_{j} \exp ((\rho-1) j \Delta) \mathcal{J}_{m}(j)=\eta_{m s}
$$

Define the notation

$$
\tilde{M}_{m t+1}\left(z_{n}\right)=\sum_{j}\left[\left(1-\delta_{m}\right) \mathcal{F}_{m}(j)+\delta_{m} \mathcal{J}_{m}(j)\right] h\left(x_{m t}\left(z_{n-j}\right) / s_{t}\left(z_{n-j}\right)\right) M_{t}\left(z_{n-j}\right) .
$$

Likewise, for each existing product at $t$ with productivity index $z_{n}$, there is a technology that links the innovative investment $x_{c t}\left(z_{n}\right)$ associated with that good with the increment to the productivity index of that good at $t+1$ conditional on it not exiting exogenously or being stolen by another firm. Specifically assume that, conditional on investment $x_{c t}\left(z_{n}\right)$, if the good does not exit exogenously and is not stolen by another firm, then it has new productivity index $z_{n+j}$, with increment $j$ (where $j$ does not need to be positive) drawn from distribution $\mathcal{F}_{c}\left(j ; x_{c t}\left(z_{n}\right) / s_{t}\left(z_{n}\right)\right)$ that satisfies

$$
\sum_{j} \exp ((\rho-1) j \Delta) \mathcal{F}_{c}\left(j ; x_{c t}\left(z_{n}\right) / s_{t}\left(z_{n}\right)\right)=\zeta\left(x_{c t}\left(z_{n}\right) / s_{t}\left(z_{n}\right)\right) \text {. }
$$

Define the notation

$$
\tilde{M}_{c t+1}\left(z_{n}\right)=\sum_{j} \mathcal{F}_{c}\left(j ; x_{c t}\left(z_{n-j}\right) / s_{t}\left(z_{n-j}\right)\right) \times
$$




$$
\left(1-\delta_{e} x_{e t}-\delta_{m} h\left(x_{m t}\left(z_{n-j}\right) / s_{t}\left(z_{n-j}\right)\right)\right) M_{t}\left(z_{n-j}\right) .
$$

Given an allocation, the implied transition law defining feasible sequences of measures $M_{t}(z)$ is then given by

$$
M_{t+1}\left(z_{n}\right)=\tilde{M}_{e t+1}\left(z_{n}\right)+\tilde{M}_{m t+1}\left(z_{n}\right)+\tilde{M}_{c t+1}\left(z_{n}\right) .
$$

We define the following prices at time $t$ in terms of the consumption good. Let $W_{t}$ and $P_{r t}$ denote the prices at $t$ of labor and the research good, respectively. Let $R_{k t}$ denote the rental rate of physical capital at $t$. Let $p_{t}(z)$ denote the price at $t$ of an intermediate good with productivity index $z$. Let $M C\left(R_{k}, W\right)$ denote the unit cost function corresponding to the production function $k^{\alpha} l^{1-\alpha}$ (with productivity index $z$ normalized to zero). We define the markup at $t$ on an intermediate good with productivity index $z$ by $\mu_{t}(z)=$ $z p_{t}(z) / M C\left(R_{k t}, W_{t}\right)$.

We define equilibrium to include a secondary market in the rights to the frontier technology to produce and innovate on an intermediate good. Let $V_{t}(z)$ denote the price of those rights at $t$ for an intermediate good with index $z$ at $t$. These rights are cum dividends in the sense that they include the rights to produce immediately in the current period.

Let $1 /\left(1+R_{t}\right)$ denote the price of the consumption good at $t+1$ relative to the consumption good at $t$. Let the price of the consumption good at $t=0$ be the numeraire. To simplify the notation for intertemporal prices, define $Q_{0}=1$ and $Q_{t+1}=Q_{t} /\left(1+R_{t}\right)$ for all $t \geq 0$.

Households are endowed with labor $L_{t}$ in each period $t$, which they can either supply to intermediate goods producing firms to produce current output, $L_{p t}$, or supply to producers of the research good, $L_{r t}$. In period $t=0$, households are also endowed with ownership of the physical capital stock $K_{0}$ and of all of the incumbent intermediate goods producing firms. Collectively, these intermediate goods producing firms operate all of the available frontier technologies for producing intermediate goods and hence have value in the aggregate of $\sum_{z} V_{0}(z) M_{0}(z)$. Households choose consumption $C_{t}$, next period's physical capital stock $K_{t+1}$, and investment in entry $x_{e t}$ to maximize utility (2) subject to the date zero budget constraint

$$
\begin{gathered}
\sum_{t=0}^{\infty} Q_{t}\left[C_{t}+\left(1-\tau_{e t}\right) P_{r t} x_{e t}+K_{t+1}-\left(1-d_{k}\right) K_{t}-E_{t}\right]= \\
R_{k 0} K_{0}+W_{0} L_{0}+\sum_{z} V_{0}(z) M_{0}(z)+
\end{gathered}
$$




$$
\sum_{t=1}^{\infty} Q_{t}\left[\sum_{n} V_{t}\left(z_{n}\right) \tilde{M}_{e t}\left(z_{n}\right)+R_{k t} K_{t}+W_{t} L_{t}\right],
$$

where $\tilde{M}_{e t+1}\left(z_{n}\right)$ is given as a function of the household's investment in entry $x_{e t}$ as in equation (43).

Final consumption goods producing firms purchase inputs $y_{t}(z)$ at prices $p_{t}(z)$ and sell output $Y_{t}$ determined by equation (4) at price 1 . They choose input purchases to maximize profits $\left(1+\tau_{y t}\right) Y_{t}-\sum_{z} p_{t}(z) y_{t}(z)$, where $\tau_{y t}$ is a subsidy over the production of the final good, which we introduce to undo the distortion on physical capital accumulation arising from markups (and, in the full quantitative model, also the distortion arising from the corporate profits tax).

Research good producing firms hire labor $L_{r t}$ at wage $W_{t}$ and sell output $Y_{r t}$ determined by equation (8) at price $P_{r t}$ to maximize profits $P_{r t} Y_{r t}-W_{t} L_{r t}$, taking the productivity term $Z_{t}^{\phi-1}$ as given.

Intermediate goods producing firms with productitivity index $z$ rent physical capital $k_{t}(z)$ at rental rate $R_{k t}$ and hire production labor $l_{t}(z)$ at wage $W_{t}$ to produce output $y_{t}(z)$ determined by equation (3). These firms are monopolistic competitors that compete in a Bertrand fashion with a latent competitor. Specifically, on each product $z$, firms face a latent competitor who is allowed, under rules of intellectual property, to use technology to produce the same intermediate good with productivity $z-\log \bar{\mu}(z)$. With Bertrand competition, the optimal markup is $\mu(z)=\min \left\{\frac{\rho}{\rho-1}, \bar{\mu}(z)\right\}$. Variable profits from production earned on intermediate goods are

$$
\pi_{t}(z)=\frac{\mu(z)-1}{\mu(z)} p_{t}(z) y_{t}(z)
$$

We impose $\mu(z)=\mu$. Variable profits are therefore given by $\pi_{t}(z)=\frac{\mu-1}{\mu}\left(1+\tau_{y t}\right) Y_{t} s_{t}(z)$, with size $s_{t}(z)$ defined in equation (7).

In the simple version of our model with innovative investment only by entering firms, we have that the price of a frontier technology $z$ must satisfy

$$
V_{t}(z)=\pi_{t}(z)+\left(\frac{1-\delta_{c t}}{1+R_{t}}\right) V_{t+1}(z)
$$

where the term $1-\delta_{c t}$ is determined by the innovative investment of entrants according to $1-\delta_{c t}=1-\delta_{0}-\delta_{e} x_{e t}$. From equations (51) and (52), we have that $V_{t}(z)=V_{t} s_{t}(z)$, 
where the factor of proportionality $V_{t}$ satisfies the following recursion:

$$
V_{t}=\left(1+\tau_{y}\right) \frac{\mu-1}{\mu} Y_{t}+\frac{\left(1-\delta_{c t}\right)}{1+R_{t}} V_{t+1}
$$

The first order condition for the household's optimal choice of $x_{e t} \geq 0$, together with equations (41), (42), (43), and $\eta_{e} \equiv \delta_{e} \eta_{e s}+\left(1-\delta_{e}\right) \eta_{e n}$, imply that

$$
\left(1-\tau_{e t}\right) \frac{P_{r t}}{M_{t}} \geq \frac{1}{1+R_{t}} V_{t+1} \frac{\eta_{e}}{M_{t}} \frac{Z_{t}^{\rho-1}}{Z_{t+1}^{\rho-1}},
$$

with this expression holding as an equality if $x_{e t}>0$. This condition (54) corresponds to the condition that the household earn non-positive profits from investment in entry.

In the version of our model with innovative investment by incumbent firms, these firms choose innovative investment $x_{m t}(z)$ and $x_{c t}(z)$ to maximize the value of their products. This value maximization problem is given by

$$
\begin{gathered}
V_{t}\left(z_{n}\right)=\max _{x_{m}, x_{c} \geq 0} \pi_{t}(z)-P_{r t}\left(\left(1-\tau_{m t}\right) x_{m}+\left(1-\tau_{c t}\right) x_{c}\right)+ \\
\frac{1}{1+R_{t}} \sum_{j} V_{t+1}\left(z_{n+j}\right)\left[\left(1-\delta_{m}\right) \mathcal{F}_{m}(j)+\delta_{m} \mathcal{J}_{m}(j)\right] h\left(x_{m} / s_{t}\left(z_{n}\right)\right)+ \\
\frac{1}{1+R_{t}} \sum_{j} V_{t+1}\left(z_{n+j}\right) \mathcal{F}_{c}\left(j ; x_{c} / s_{t}\left(z_{n}\right)\right)\left(1-\delta_{c t}\left(z_{n}\right)\right) .
\end{gathered}
$$

The term $\left(1-\delta_{c t}\left(z_{n}\right)\right)$ is determined by the innovative investments of other firms according to

$$
1-\delta_{c t}\left(z_{n}\right)=1-\delta_{e} x_{e}-\delta_{m} h\left(x_{m t}\left(z_{n}\right) / s_{t}\left(z_{n}\right)\right) .
$$

In the proof of Lemma 3, we show that $x_{m t}(z)=x_{m t} s_{t}(z)$ and $x_{c t}(z)=x_{c t} s_{t}(z)$, so that, as in the simple model, $V_{t}(z)=V_{t} s_{t}(z)$, where $V_{t}$ now satisfies the recursion in equation (61). As a result, the first order condition for the household's optimal choice of $x_{e t} \geq 0$ continues to be equation (54).

An equilibrium is a feasible allocation together with prices such that households choose consumption, investment in physical capital and investment in entering firms to maximize utility subject to their budget constraint (50), final consumption and research good producing firms maximize profits, intermediate goods producing firms maximize variable profits from production as monopolistic competitors, and these intermediate goods producing firms choose innovative investment to maximize the value of their products as in (55). 
The socially optimal allocation is the feasible allocation that maximizes household utility.

In Appendix C.4, we show how we can calculate a path of innovation policies that implements a given pre-specified path of the innovation intensity of the economy as an equilibrium with interior allocations.

\section{B Proofs}

When deriving our proofs, we allow for a production subsidy $\tau_{y}$ (introduced in Appendix A). We note that with $\tau_{y} \neq 0$, the innovation intensity of the economy is defined as the ratio of innovative investments to firms' output inclusive of the production subsidy, $i_{r t} \equiv$ $\frac{P_{r t} Y_{r t}}{\left(1+\tau_{y}\right) Y_{t}}$.

Proposition 1 Equation (8) implies that

$$
\log \bar{Z}_{t}^{\prime}-\log \bar{Z}_{t}=\frac{1}{1-\phi}\left[\left(\log \bar{l}_{r}^{\prime}-\log \bar{l}_{r}\right)-\left(\log \bar{Y}_{r}^{\prime}-\log \bar{Y}_{r}\right)\right],
$$

where $\bar{Y}_{r}^{\prime}$ is the use of the research good on the new BGP. Note from equations (27) and (10) that in our simple model with only entry, $Y_{r}$ is constant on any BGP so that $\bar{Y}_{r}^{\prime}=\bar{Y}_{r}$. This proves the result.

Proposition 2 Log-linearizing equation (10) (or equivalently, from equation 16), we obtain

$$
g_{Z t}-\bar{g}_{Z}=\frac{\partial G}{\partial Y_{r}} \bar{Y}_{r}\left(\log Y_{r t}^{\prime}-\log \bar{Y}_{r}\right)=\Theta\left(\log l_{r t}^{\prime}-\log \bar{l}_{r t}+(\phi-1)\left(\log Z_{t}^{\prime}-\log \bar{Z}_{t}\right)\right),
$$

where the second equality uses equation (8). Combining these expressions with the law of motion for aggregate productivity,

$$
\left(\log Z_{t+1}^{\prime}-\log \bar{Z}_{t+1}\right)=\left(\log Z_{t}^{\prime}-\log \bar{Z}_{t}\right)+g_{Z t}-\bar{g}_{Z},
$$

we obtain the following AR1 process for deviations of aggregate productivity from BGP,

$$
\left(\log Z_{t+1}^{\prime}-\log \bar{Z}_{t+1}\right)=(1+(\phi-1) \Theta)\left(\log Z_{t}^{\prime}-\log \bar{Z}_{t}\right)+\Theta\left(\log l_{r t}^{\prime}-\log \bar{l}_{r}\right),
$$

which implies equation (17). This proves the result. 
Corollary 1 The implied coefficient $\Gamma_{0}=\Theta$ is clearly increasing in $\Theta$. If the two models share the same value of intertemporal knowledge spillovers as indexed by $\phi<1$, then the term $[1-(1-\phi) \Theta]$ governing the rate of decay of the coefficients $\Gamma_{k}$ in equation (18) is decreasing in $\Theta$. This proves the first part of the result. The cumulative sums of coefficients $\Gamma_{k}$ in the second part of the result are given by

$$
\sum_{j=0}^{J} \Gamma_{j}=\frac{1}{1-\phi}\left[1-[1-(1-\phi) \Theta]^{J}\right],
$$

which, holding $\phi$ fixed, is increasing in $\Theta$ for any finite $J$. This proves the result.

Lemma 1 This result is obtained by equation (5) and the equilibrium condition that the rental rate on physical capital be related to the capital-output ratio by

$$
R_{k t}=\left(1+\tau_{y}\right) \frac{\alpha}{\mu} \frac{Y_{t}}{K_{t}}
$$

Lemma 2 Let the economy be on an initial BGP with the allocation marked by bars. For any alternative feasible allocation, we have that the equivalent variation is defined by

$$
\xi^{1-\gamma} \sum_{t=0}^{\infty}\left(\beta \exp \left(\gamma \bar{g}_{L}\right)\right)^{t} \bar{C}_{t}^{1-\gamma}=\sum_{t=0}^{\infty}\left(\beta \exp \left(\gamma \bar{g}_{L}\right)\right)^{t} C_{t}^{\prime 1-\gamma}
$$

Since on a BGP, $\bar{C}_{t}=\exp \left(t \bar{g}_{Y}\right) \bar{C}_{0}$, we have

$$
\xi^{1-\gamma}=(1-\tilde{\beta}) \sum_{t=0}^{\infty} \tilde{\beta}^{t}\left(\frac{C_{t}^{\prime}}{\bar{C}_{t}}\right)^{1-\gamma},
$$

where $\tilde{\beta}=\beta \exp \left(\gamma \bar{g}_{L}+(1-\gamma) \bar{g}_{Y}\right)$. Up to a first-order approximation, around the initial BGP,

$$
\log \tilde{\zeta}=(1-\tilde{\beta}) \sum_{t=0}^{\infty} \tilde{\beta}^{t}\left(\log C_{t}^{\prime}-\log \bar{C}_{t}\right) .
$$

From the resource constraint of the final consumption good, equation (1), we have, up to a first-order approximation,

$$
\begin{gathered}
\log C_{t}^{\prime}-\log \bar{C}_{t}=\frac{\bar{Y}_{t}}{\bar{C}_{t}}\left[\left(\log Z_{t}^{\prime}-\log \bar{Z}_{t}\right)+(1-\alpha)\left(\log l_{p t}^{\prime}-\log \bar{l}_{p}\right)\right]+ \\
\frac{\bar{K}_{t}}{\bar{C}_{t}}\left[\left(\alpha \frac{\bar{Y}_{t}}{\bar{K}_{t}}+1-d_{k}\right)\left(\log K_{t}^{\prime}-\log \bar{K}_{t}\right)-\exp (\bar{g} Y)\left(\log K_{t+1}^{\prime}-\log \bar{K}_{t+1}\right)\right]
\end{gathered}
$$


so

$$
\begin{gathered}
\sum_{t=0}^{\infty} \tilde{\beta}^{t}\left(\log C_{t}^{\prime}-\log \bar{C}_{t}\right)=\sum_{t=0}^{\infty} \tilde{\beta}^{t} \frac{\bar{Y}_{t}}{\bar{C}_{t}}\left[\left(\log Z_{t}^{\prime}-\log \bar{Z}_{t}\right)+(1-\alpha)\left(\log l_{p t}^{\prime}-\log \bar{l}_{p t}\right)\right]+ \\
\sum_{t=0}^{\infty} \tilde{\beta}^{t} \frac{\bar{K}_{t}}{\bar{C}_{t}}\left[\left(\alpha \frac{\bar{Y}_{t}}{\bar{K}_{t}}+1-d_{k}\right)\left(\log K_{t}^{\prime}-\log \bar{K}_{t}\right)-\exp \left(\bar{g}_{Y}\right)\left(\log K_{t+1}^{\prime}-\log \bar{K}_{t+1}\right)\right]
\end{gathered}
$$

At $t=0, \log K_{0}^{\prime}=\log \bar{K}_{0}$ and, on any BGP in which the Euler equation for physical capital is undistorted (which can be achieved by setting $\tau_{y t}=\bar{\tau}_{y}=\mu-1$ ), we have

$$
\exp \left(\bar{g}_{Y}\right)=\tilde{\beta}\left(\alpha \frac{\bar{Y}_{t}}{\bar{K}_{t}}+1-d_{k}\right)
$$

Hence

$$
\sum_{t=0}^{\infty} \tilde{\beta}^{t}\left(\log C_{t}^{\prime}-\log \bar{C}_{t}\right)=\sum_{t=0}^{\infty} \tilde{\beta}^{t} \frac{\bar{Y}_{t}}{\bar{C}_{t}}\left[\left(\log Z_{t}^{\prime}-\log \bar{Z}_{t}\right)+(1-\alpha)\left(\log l_{p t}^{\prime}-\log \bar{l}_{p}\right)\right] .
$$

Given this result in combination with (58), we obtain equation (22).

Proposition 3 The allocation of labor between research and production on the socially optimal allocation is set so that the welfare gains in equation (23) from perturbations to the innovation intensity of the economy are equal to zero. This delivers the result in equation (24).

Proposition 4 To prove this result, we use the zero profits at entry condition to show that the total post-subsidy expenditure on innovative investment relative to output $\left(1-\tau_{e}\right) \bar{s}_{r}$ is constant across BGPs. On a BGP, the value $v_{t}=V_{t} /\left(\left(1+\tau_{y}\right) Y_{t}\right)$ is constant over time at $\bar{v}$ and equation (53) implies

$$
\bar{v}=\left(\frac{\mu-1}{\mu}\right)\left[1-\frac{\exp \left(\bar{g}_{Y}\right)}{1+\bar{R}} \frac{1-\bar{\delta}_{c}}{\exp \left((\rho-1) \bar{g}_{Z}\right)}\right]^{-1}
$$

where $1-\bar{\delta}_{c}=1-\delta_{0}-\delta_{e} \bar{x}_{e}$ is the exit rate of existing products on the BGP. Dividing both sides of (54) by $Y_{t}$ implies that on a BGP with positive entry, we obtain

$$
\left(1-\bar{\tau}_{e}\right) \frac{\bar{i}_{r}}{\bar{Y}_{r}}=\frac{\exp \left(\bar{g}_{Y}\right)}{1+\bar{R}} \frac{\eta_{e}}{\exp \left((\rho-1) \bar{g}_{Z}\right)}\left(\frac{\mu-1}{\mu}\right)\left[1-\frac{\exp \left(\bar{g}_{Y}\right)}{1+\bar{R}} \frac{1-\bar{\delta}_{c}}{\exp \left((\rho-1) \bar{g}_{Z}\right)}\right]^{-1} .
$$


With semi-endogenous growth $(\phi<1), \bar{g}_{Y}, \bar{g}_{Z}$, and $\bar{R}$ are constant across BGPs. By the resource constraint $\bar{Y}_{r}=\bar{x}_{e}$ and equation (11), $\bar{Y}_{r}$ is also constant across BGPs. Thus, equation (59) implies that

$$
\bar{i}_{r t}\left(1-\bar{\tau}_{e}\right)=\bar{i}_{r t}^{\prime}\left(1-\bar{\tau}_{e}^{\prime}\right)
$$

and hence

$$
\frac{\bar{E}_{t}^{\prime}}{\bar{Y}_{t}^{\prime}}-\frac{\bar{E}_{t}}{\bar{Y}_{t}}=\tau_{e}^{\prime} \bar{i}_{r t}^{\prime}-\tau_{e} \bar{i}_{r t}=\bar{i}_{r t}^{\prime}-\bar{i}_{r t}
$$

This proves the result.

Lemma 3 Refer to the definition of equilibrium in Appendix A. Conjecture that in equilibrium incumbent firms scale their investment in innovation to acquire new products and improve their existing products in proportion to the size of these existing products, that is, $x_{m t}(z)=x_{m t} s_{t}(z)$ and $x_{c t}(z)=x_{c t} s_{t}(z)$. We first show that equation (28) holds under this conjecture and then verify that the conjecture holds in equilibrium.

Under the conjecture that investment by incumbent firms in acquiring new products scales with product size, given the investment technology for incumbent firms to acquire new products specified in equations (44), (45), and (46), the probability that an incumbent firm producing a product with index $z$ at $t$ acquires a new product for the firm at $t+1$ is $h\left(x_{m t}\right)$, independent of the index $z$ of that product. Hence, incumbent firms acquire in the aggregate measure $h\left(x_{m t}\right) M_{t}$ new products - a measure $\delta_{m} h\left(x_{m t}\right) M_{t}$ are stolen from other incumbent firms and a complementary measure $\left(1-\delta_{m}\right) h\left(x_{m t}\right) M_{t}$ are new to society. From equations (44) and (45), for existing products with productivity $z$, these newly acquired products have average value of $z^{\prime \rho-1}$ equal to $\eta_{m n} z^{\rho-1}$ and $\eta_{m s} z^{\rho-1}$, respectively. Averaging across all existing products at $t$ then gives that the average value of $\exp \left((\rho-1) z^{\prime}\right)$ across all newly acquired products in incumbent firms at $t+1$ is given by

$$
\eta_{m} \sum_{z} z^{\rho-1} \frac{M_{t}(z)}{M_{t}}=\eta_{m} \frac{Z_{t}^{\rho-1}}{M_{t}} .
$$

Given the investment technology for incumbent firms to improve existing products specified in equations (47) and (48), if investment in improving existing products scales with product size, then the transition probabilities for the index $z$ at $t$ to $z^{\prime}$ at $t+1$ for products produced by the same incumbent firm at $t$ and $t+1$ are as follows. Of the $M_{t}$ existing products in incumbent firms at $t$, a measure $\delta_{0} M_{t}$ are lost to exogenous exit, a measure $\delta_{m} h\left(x_{m t}\right) M_{t}$ are lost to business stealing by other incumbent firms, and a measure $\delta_{e} M_{e t}=\delta_{e} x_{e t} M_{t}$ are lost to business stealing by entering firms. The products that exit at $t$ for either exogenous or endogenous reasons have productivity indices $z$ at $t$ 
drawn uniformly from the current distribution of these productivity indices $M_{t}(z) / M_{t}$. The measure $\left(1-\delta_{0}-\delta_{m} h\left(x_{m t}\right)-\delta_{e} x_{e t}\right) M_{t}$ of existing products that continue with the same incumbent firm from $t$ to $t+1$ each experience expected growth in $z^{\rho-1}$ from $t$ to $t+1$ of $\zeta\left(x_{c t}\right)$. That is, averaging across products that do not exit gives that the average value of $z^{\prime \rho-1}$ at $t+1$ for all products that are produced by the same firm at $t$ and $t+1$ is given by

$$
\zeta\left(x_{c t}\right) \frac{Z_{t}^{\rho-1}}{M_{t}}
$$

and the fraction of products at $t$ that are in this category at $t+1$ is

$$
1-\delta_{c t}=1-\delta_{0}-\delta_{m} h\left(x_{m t}\right)-\delta_{e} x_{e t}
$$

Putting these results together gives that the value of $Z_{t+1}^{\rho-1}$ is a sum of three components:

$$
Z_{t+1}^{\rho-1}=\left(1-\delta_{c t}\right) M_{t} \zeta\left(x_{c t}\right) \frac{Z_{t}^{\rho-1}}{M_{t}}+h\left(x_{m t}\right) M_{t} \eta_{m} \frac{Z_{t}^{\rho-1}}{M_{t}}+x_{e t} M_{t} \eta_{e} \frac{Z_{t}^{\rho-1}}{M_{t}}
$$

where the first term is the measure of continuing products in incumbent firms times the average value of $z^{\prime \rho-1}$ for such products, the second term is the product of the measure of new products in incumbent firms times the average value of $z^{\prime \rho-1}$ for such products, and the third term is the corresponding measure of new products in entering firms times the average value of $z^{\prime \rho-1}$ for such products. Taking logs of this expression gives equation (28). It also follows that the dynamics of the total measure of products are given by

$$
M_{t+1}=\left[1-\delta_{c t}+h\left(x_{m t}\right)+x_{e t}\right] M_{t}
$$

To complete the proof, we must show that in equilibrium, firms actually choose to scale their innovative investments in proportion to the size of the products with which those investments are associated. We do so as follows.

Since markups are constant across products and time, we again have that variable profits scale with product size (equation (51)). Under the conjecture that incumbent firms' innovative investments scale with size, then the equilibrium value function $V_{t}(z)$ in equation (55) also scales with size with $V_{t}(z)=V_{t} s_{t}(z)$, where $V_{t}$ satisfies

$$
V_{t}=\max _{x_{m}, x_{c} \geq 0}\left(1+\tau_{y}\right) \frac{\mu-1}{\mu} Y_{t}-P_{r t}\left(\left(1-\tau_{m t}\right) x_{m}+\left(1-\tau_{c t}\right) x_{c}\right)+
$$




$$
\frac{1}{1+R_{t}} V_{t+1}\left[\eta_{m} h\left(x_{m}\right)+\left(1-\delta_{c t}\right) \zeta\left(x_{c}\right)\right] \frac{Z_{t}^{\rho-1}}{Z_{t+1}^{\rho-1}} .
$$

With this form for $V_{t}(z)=V_{t} s_{t}(z)$, we have that the first-order conditions of the incumbent firm's profit maximization problem (55) with respect to $x_{m}$ and $x_{z}$, given in equations (62) and (63) below, imply that the optimal choices of $x_{c t}$ and $x_{m t}$ both scale with the size of the product. Note that the zero profits at entry condition is still given by equation (54). This proves the result.

We use the following formulas in the analysis of the model with innovation by incumbents.

\section{Equilibrium First-Order Conditions for Innovative Investment by Incumbent Firms}

Observe that the first-order conditions of (61) with respect to $x_{c}$ and $x_{m}$ imply that

$$
\left(1-\tau_{c t}\right) P_{r t} \geq \frac{1-\delta_{c t}}{1+R_{t}} V_{t+1} \zeta^{\prime}\left(x_{c t}\right) \frac{Z_{t}^{\rho-1}}{Z_{t+1}^{\rho-1}}
$$

and

$$
\left(1-\tau_{m t}\right) P_{r t} \geq \frac{\eta_{m}}{1+R_{t}} V_{t+1} h^{\prime}\left(x_{m t}\right) \frac{Z_{t}^{\rho-1}}{Z_{t+1}^{\rho-1}} .
$$

These first-order conditions are equalities if $x_{c t}, x_{m t}>0$. These first-order conditions, together with the zero profits at entry condition (54), imply that if the allocation of investment in period $t$ is interior, then

$$
\frac{\left(1-\tau_{c t}\right)}{\left(1-\tau_{e t}\right)} \eta_{e}=\left(1-\delta_{c t}\right) \zeta^{\prime}\left(x_{c t}\right)
$$

and

$$
\frac{\left(1-\tau_{m t}\right)}{\left(1-\tau_{c t}\right)}\left(1-\delta_{c t}\right) \zeta^{\prime}\left(x_{c t}\right)=\eta_{m} h^{\prime}\left(x_{m t}\right) .
$$

Formulas for $\Theta_{i}$ Let $\bar{x}_{c}, \bar{x}_{m}$, and $\bar{x}_{e}$ denote the allocation of innovative investment on a BGP and $\bar{Y}_{r}$ aggregate real innovative investment. At this allocation of innovative investment, the values of $\Theta_{i}$ are given by

$$
\begin{gathered}
\Theta_{c}=\frac{1}{\rho-1} \frac{\left(1-\bar{\delta}_{c}\right) \zeta^{\prime}\left(\bar{x}_{c}\right)}{\exp \left((\rho-1) \bar{g}_{Z}\right)} \bar{Y}_{r,} \\
\Theta_{m}=\frac{1}{\rho-1} \frac{\left(\eta_{m}-\delta_{m} \zeta\left(\bar{x}_{c}\right)\right) h^{\prime}\left(\bar{x}_{m}\right)}{\exp \left((\rho-1) \bar{g}_{Z}\right)} \bar{Y}_{r},
\end{gathered}
$$




$$
\Theta_{e}=\frac{1}{\rho-1} \frac{\left(\eta_{e}-\delta_{e} \zeta\left(\bar{x}_{c}\right)\right)}{\exp \left((\rho-1) \bar{g}_{Z}\right)} \bar{Y}_{r}
$$

Our parameter assumptions imply that $\left(1-\bar{\delta}_{c}\right)>0, \eta_{m}>\delta_{m} \zeta\left(\bar{x}_{c}\right)$, and $\eta_{e}>\delta_{e} \zeta\left(\bar{x}_{c}\right)$, and hence $\Theta_{i}>0$. This is because, for $i=e, m$, the assumptions $\eta_{i s}>\delta_{i} \zeta(x), \eta_{\text {in }}>0$, and $0 \leq \delta_{i} \leq 1$ imply that $\eta_{i}>\delta_{i} \zeta\left(\bar{x}_{c}\right)$.

By definitions (66) and (68), on the initial BGP, $\Theta_{c} \geq \Theta_{e}$ if and only if

$$
\left(1-\bar{\delta}_{c}\right) \zeta^{\prime}\left(\bar{x}_{c}\right) \geq \eta_{e}-\delta_{e} \zeta\left(\bar{x}_{c}\right)
$$

In an interior BGP, this inequality is equivalent (by equation (64)) to

$$
\frac{1-\bar{\tau}_{c}}{1-\bar{\tau}_{e}} \geq 1-\frac{\delta_{e} \zeta\left(\bar{x}_{c}\right)}{\eta_{e}} .
$$

Lemma 4 Let $\bar{x}_{c}, \bar{x}_{m}$, and $\bar{x}_{e}$ be an interior equilibrium allocation of investment on an initial BGP corresponding to policies $\tau_{c}, \tau_{m}$, and $\tau_{e}$. We now examine the conditions under which this equilibrium allocation of innovative investment is a solution to this cost minimization problem (31).

Because the allocation of innovative investment on the initial BGP is interior, it satisfies equations (64) and (65) at the specified policies. Moreover, on a BGP, we must have that the growth rate of aggregate productivity is given by

$$
\bar{g}_{Z}=G\left(\bar{x}_{c}, \bar{x}_{m}, \bar{x}_{e}\right) .
$$

Compare these first-order conditions to those characterizing a conditionally efficient allocation of innovative investment. An interior allocation of innovative investment $x_{c}^{*}, x_{m}^{*}, x_{e}^{*}$ is a solution to the cost minimization problem (31) if equation (71) is satisfied and

$$
\frac{\partial}{\partial x_{m}} G\left(x_{c}^{*}, x_{m}^{*}, x_{e}^{*}\right)=\frac{\partial}{\partial x_{e}} G\left(x_{c}^{*}, x_{m}^{*}, x_{e}^{*}\right) \Longleftrightarrow\left(\eta_{m}-\delta_{m} \zeta\left(x_{c}^{*}\right)\right) h^{\prime}\left(x_{m}^{*}\right)=\eta_{e}-\delta_{m} \zeta\left(x_{c}^{*}\right)
$$

and

$$
\frac{\partial}{\partial x_{c}} G\left(x_{c}^{*}, x_{m}^{*}, x_{e}^{*}\right)=\frac{\partial}{\partial x_{e}} G\left(x_{c}^{*}, x_{m}^{*}, x_{e}^{*}\right) \Longleftrightarrow\left(1-\delta_{0}-\delta_{m} h\left(x_{m}^{*}\right)-\delta_{e} x_{e}^{*}\right) \zeta^{\prime}\left(x_{c}^{*}\right)=\eta_{e}-\delta_{e} \zeta\left(x_{c}^{*}\right) .
$$


These first-order conditions coincide with the equilibrium conditions (64) and (65) if

$$
\frac{\left(1-\tau_{c}\right)}{\left(1-\tau_{e}\right)}=\frac{\eta_{e}-\delta_{e} \zeta\left(x_{c}^{*}\right)}{\eta_{e}}
$$

and

$$
\frac{\left(1-\tau_{m}\right)}{\left(1-\tau_{e}\right)}=\frac{\eta_{m}}{\eta_{e}}\left(\frac{\eta_{e}-\delta_{e} \zeta\left(x_{c}^{*}\right)}{\eta_{m}-\delta_{m} \zeta\left(x_{c}^{*}\right)}\right)
$$

Hence, if (i) $\delta_{e}=\delta_{m}=0$ and/or (ii) $\delta_{e}=\delta_{m}>0$, and $\zeta\left(x_{c}^{*}\right)=\bar{\zeta}$ and $\eta_{m}=\eta_{e}$, the equilibrium BGP is conditionally efficient if policies are uniform, that is, $\frac{\left(1-\tau_{c}\right)}{\left(1-\tau_{e}\right)}=\frac{\left(1-\tau_{m}\right)}{\left(1-\tau_{e}\right)}=$ 1.

Now consider the problem of finding policies to implement a conditionally efficient allocation of innovative investment $x_{c}^{*}, x_{m}^{*}, x_{e}^{*}$ as an equilibrium outcome with $Y_{r}^{*}$ equal to the aggregate of these three categories of innovative investment. To do so, set the ratios of subsidies $\left(1-\tau_{c}\right) /\left(1-\tau_{e}\right)$ and $\left(1-\tau_{m}\right) /\left(1-\tau_{e}\right)$ as in equations (74) and (75). Then choose the level of the subsidy rate, $\tau_{e}<1$, arbitrarily. To construct the equilibrium with this level of subsidies, solve for the constant in the value function $\bar{v}$ and the BGP ratio of the relative price of the research good to output $\bar{P}_{r} / \bar{Y}$ that satisfy the BGP version of equation (61) given by

$$
\begin{gathered}
\bar{v}=\left[\frac{\mu-1}{\mu}-\frac{\left(1-\tau_{e}\right) \bar{P}_{r}}{\left(1+\tau_{y}\right) \bar{Y}}\left(\left(\frac{1-\tau_{c}}{1-\tau_{e}}\right) x_{c}^{*}+\left(\frac{1-\tau_{m}}{1-\tau_{e}}\right) x_{m}^{*}\right)\right] \times \\
{\left[1-\left[\left(1-\delta_{0}-\delta_{m} h\left(x_{m}^{*}\right)-\delta_{e} x_{e}^{*}\right) \zeta\left(x_{c}^{*}\right)+\eta_{m} h\left(x_{m}^{*}\right)\right] \frac{\exp \left(\bar{g}_{Y}-(\rho-1) \bar{g}_{Z}\right)}{1+\bar{R}}\right]^{-1}}
\end{gathered}
$$

and the BGP version of the zero profits at entry condition (54)

$$
\frac{\left(1-\tau_{e}\right) \bar{P}_{r}}{\left(1+\tau_{y}\right) \bar{Y}}=\eta_{e} \frac{\exp \left(\bar{g}_{Y}-(\rho-1) \bar{g}_{Z}\right)}{1+\bar{R}} \bar{v}
$$

It is straightforward to show that a unique positive solution of these two equations for $\bar{v}$ and $\bar{P}_{r} / \bar{Y}$ exists since the solution of $\bar{v}$ in equation (76) is strictly decreasing in $\bar{P}_{r} / \bar{Y}$. The equilibrium level of aggregate productivity $\bar{Z}_{t}$ is then found as follows. From equation (8), we have

$$
x_{c}^{*}+x_{m}^{*}+x_{e}^{*}=Y_{r}^{*}=A_{r t} L_{t} \bar{Z}_{t}^{\phi-1} \bar{l}_{r}
$$

and from the equilibrium condition (12) combined with labor market clearing and the fact that the production labor share of output (inclusive of the production subsidy) is given 
by $\frac{1-\alpha}{\mu}$, we then solve for $\bar{l}_{r}$ using

$$
\frac{\bar{P}_{r}}{\left(1+\tau_{y}\right) \bar{Y}}=\frac{1-\alpha}{\mu} \frac{1}{Y_{r}^{*}} \frac{\bar{l}_{r}}{1-\bar{l}_{r}} .
$$

Given $L_{t}$ and $A_{r t}$, we solve for $\bar{Z}_{t}$ using $Y_{r}^{*}=A_{r t} L_{t} \bar{Z}_{t}^{\phi-1} \bar{l}_{r}$. This proves the result. ${ }^{26}$

Proposition 5 To prove this proposition, we use the following results.

First observe that equation (13) holds in our extended model. Second, log-linearizing equation (28), we obtain

$$
g_{Z t}-\bar{g}_{Z} \approx \Theta_{c} \frac{\bar{x}_{c}}{\bar{Y}_{r}}\left(\log x_{c t}^{\prime}-\log \bar{x}_{c}\right)+\Theta_{m} \frac{\bar{x}_{m}}{\bar{Y}_{r}}\left(\log x_{m t}^{\prime}-\log \bar{x}_{m}\right)+\Theta_{e} \frac{\bar{x}_{e}}{\bar{Y}_{r}}\left(\log x_{e t}^{\prime}-\log \bar{x}_{e}\right)
$$

where these derivatives are evaluated at the initial BGP allocation. From the resource constraint for the research good, we have

$$
\frac{\bar{x}_{c}}{\bar{Y}_{r}}\left(\log x_{c t}^{\prime}-\log \bar{x}_{c}\right)+\frac{\bar{x}_{m}}{\bar{Y}_{r}}\left(\log x_{m t}^{\prime}-\log \bar{x}_{m}\right)+\frac{\bar{x}_{e}}{\bar{Y}_{r}}\left(\log x_{e t}^{\prime}-\log \bar{x}_{e}\right)=\left(\log Y_{r t}^{\prime}-\log \bar{Y}_{r}\right) .
$$

The first-order conditions of the minimization problem that defines $\bar{Y}_{r}^{*}$ imply that, in a conditionally efficient allocation, $\Theta_{c}=\Theta_{m}=\Theta_{e}$. Thus,

$$
g_{Z t}-\bar{g}_{Z} \approx \Theta\left(\log Y_{r t}^{\prime}-\log \bar{Y}_{r}\right)
$$

where $\Theta=\Theta_{c}=\Theta_{m}=\Theta_{e}$. The proof of Proposition 2 then follows as before. Lemmas 1 and 2 also follow using the same proofs as before.

The result that Proposition 1 holds to a first-order approximation is shown as follows. Using equations (8) and (80), the growth rate of productivity between periods $t$ and $t+1$ is given by

$$
g_{Z t}-\bar{g}_{Z} \approx \Theta\left(\log l_{r t}^{\prime}-\log \bar{l}_{r}+(\phi-1)\left(\log Z_{t}^{\prime}-\log \bar{Z}_{t}\right)\right) .
$$

Recall that if $\phi<1$, the growth rate of aggregate productivity is constant on all BGPs. Thus, following any change in innovation policies, when the economy converges to a new BGP, it has the same growth rate of productivity as it had on the initial BGP. Substituting $g_{Z t}-\bar{g}_{Z}=0$ in equation (81) gives equation (14) as a first-order approximation.

\footnotetext{
${ }^{26}$ We can use a very similar strategy to implement as the BGP of an equilibrium any interior allocation of innovative investment (conditionally efficient or not) together with any interior allocation of labor between production and research $\bar{l}_{r}$. Specifically, we set the ratios of subsidies $\left(1-\tau_{c}\right) /\left(1-\tau_{e}\right)$ and $\left(1-\tau_{m}\right) /\left(1-\tau_{e}\right)$ from equations (64) and (65) (given $\bar{x}_{c}, \bar{x}_{m}$, and $\bar{x}_{e}$ ). We solve for $\bar{P}_{r} / \bar{Y}$ from equation (79) with $\bar{Y}_{r}=$ $\bar{x}_{c}+\bar{x}_{m}+\bar{x}_{e}$. We solve for $\bar{v}$ and $\tau_{e}$ from equations (76) and (77). We solve for $\bar{Z}_{t}$ from equation (78).
} 
To see that (14) is an upper bound on the change in productivity from the initial BGP to the new BGP for any policy change resulting in a change in the allocation of labor of size $\log \bar{l}_{r}^{\prime}-\log \bar{l}_{r}$ across BGPs, recall that the change in productivity across BGPs is given by equation (56). Since the initial BGP is conditionally efficient, we have that $\bar{Y}_{r}$ minimizes the amount of the research good needed to attain the BGP growth rate $\bar{g}_{Z}$ and hence the term $\bar{Y}_{r}^{\prime}-\bar{Y}_{r} \geq 0$.

We prove the bound on the impact elasticity in equation (26) as follows. Consider first a policy-induced change in the innovation intensity of the economy in which all three types of innovative investment are increased proportionately, so that

$$
\log x_{c t}^{\prime}-\log \bar{x}_{c}=\log x_{m t}^{\prime}-\log \bar{x}_{m}=\log x_{e t}^{\prime}-\log \bar{x}_{e}=\log Y_{r t}^{\prime}-\log \bar{Y}_{r}
$$

In this case, we can prove that the impact elasticity $\Theta$ associated with this particular perturbation of innovative investment has an upper bound given by equation (26). The proof of this point follows from the concavity of the function $F(a)$ defined as

$$
F(a) \equiv G\left(a \bar{x}_{c}, a \bar{x}_{m}, a \bar{x}_{e}\right) .
$$

We prove the concavity of $F(\cdot)$ below. Note that

$$
F^{\prime}(1)=\frac{\partial G}{\partial x_{c}} \bar{Y}_{r} \frac{\bar{x}_{c}}{\bar{Y}_{r}}+\frac{\partial G}{\partial x_{m}} \bar{Y}_{r} \frac{\bar{x}_{m}}{\bar{Y}_{r}}+\frac{\partial G}{\partial x_{e}} \bar{Y}_{r} \frac{\bar{x}_{e}}{\bar{Y}_{r}}
$$

so that

$$
F^{\prime}(1)=\Theta_{c} \frac{\bar{x}_{c}}{\bar{Y}_{r}}+\Theta_{m} \frac{\bar{x}_{m}}{\bar{Y}_{r}}+\Theta_{e} \frac{\bar{x}_{e}}{\bar{Y}_{r}} .
$$

Hence, $F^{\prime}(1)$ is the value of $\Theta$ corresponding to a change in policies such that the change in each component of innovative investment is directly proportional to the change in the aggregate $Y_{r}$, that is the terms $d x_{i} / d Y_{r}=\bar{x}_{i} / \bar{Y}_{r}$ in equation (30). If $F(a)$ is concave, we have $F^{\prime}(1) \leq F(1)-F(0)$. From the definition of $F(a)$, we have that $F(1)-F(0)=$ $\bar{g}_{Z}-G^{0}$. This proves that our bound on $\Theta$ given by (26) holds for policy changes that result in proportional changes in the components of real innovative investment whenever $F(a)$ is concave.

When the initial BGP is conditionally efficient, we have that the value of $\Theta$ is independent of how the policy-induced change in $Y_{r}$ is allocated across components of aggregate investment, so we have that $F^{\prime}(1)=\Theta$ for any policy change.

We prove that the function $F$ is concave as follows. The assumptions made above that $\eta_{e s}>\zeta\left(\bar{x}_{c}\right)$ and $\eta_{m s}>\zeta\left(\bar{x}_{c}\right)$, together with the assumptions that $\eta_{e n}, \eta_{m n}>0$, imply that 
$\eta_{m}-\delta \zeta\left(\bar{x}_{c}\right)>0$ and $\eta_{e}-\delta \zeta\left(\bar{x}_{c}\right)>0$. These inequalities, together with the assumptions that the functions $\zeta(\cdot)$ and $h(\cdot)$ and $\log (\cdot)$ are all strictly concave, imply that the function $F(a)$ is concave.

This proves the result.

Proposition 6 Under the assumption that the new BGP allocation of real innovative investment is interior, first-order conditions (64) and (65) hold as equalities at that allocation $\bar{x}_{c}^{\prime}, \bar{x}_{m}^{\prime}, \bar{x}_{e}^{\prime}$, and aggregate real innovative investment $\bar{Y}_{t}^{\prime}$ is given by equation (27) at that allocation. If the allocation of innovative investment remains interior on the transition from the initial BGP to the new BGP, then, since the new policies satisfy condition (32), these same equations (with ratios $\frac{1-\tau_{c t}^{\prime}}{1-\tau_{e t}^{\prime}}$ and $\frac{1-\tau_{m t}^{\prime}}{1-\tau_{e t}^{\prime}}$ constant over time) are satisfied by the allocation of innovative investment $x_{c t}^{\prime}, x_{m t}^{\prime}, x_{e t}^{\prime}$ and $Y_{r t}^{\prime}$ in each period $t \geq 0$ of the transition.

We obtain the expressions for $d x_{c} / d Y_{r}, d x_{m} / d Y_{r}$, and $d x_{e} / d Y_{r}$ given in the statement of the proposition by differentiating these three equations, evaluating these derivatives at the new BGP allocation of innovative investment. Specifically, the result that $d x_{m} / d Y_{r}=0$ is obtained by combining equations (64) and (65) to obtain

$$
\frac{\left(1-\bar{\tau}_{c}^{\prime}\right)}{\left(1-\bar{\tau}_{e}^{\prime}\right)} \eta_{e}=\eta_{m} h^{\prime}\left(x_{m t}^{\prime}\right)
$$

Since $h$ is strictly concave, the result that in a transition in which all investment is interior, $x_{m t}^{\prime}=\bar{x}_{m}^{\prime}$ is immediate. This observation also implies that if $\delta_{e}=0$, then, from equation (64), $d x_{c} / d Y_{r}=0$ as well, since $x_{m t}=\bar{x}_{m}^{\prime}$ in every period $t$ of the transition to the new BGP. Hence, if there is no business stealing, we have $d x_{e} / d Y_{r}=1$ and $\Theta=\Theta_{e}$.

More generally, without imposing $\delta_{e}=0$, we have

$$
\Theta^{\prime}=\Theta_{e}^{\prime} \frac{d x_{e}}{d Y_{r}}+\Theta_{c}^{\prime} \frac{d x_{c}}{d Y_{r}}
$$

where $d x_{e} / d Y_{r}$ is given as in the statement of the proposition and $d x_{c} / d Y_{r}=1-d x_{e} / d Y_{r}$.

To derive the dynamics of aggregate productivity given in the statement of the proposition, we use the equations

$$
\begin{gathered}
\log Z_{t+1}^{\prime}-\log Z_{t}^{\prime}-\bar{g}_{Z}=\Theta^{\prime}\left(\log Y_{r t}^{\prime}-\log \bar{Y}_{r}^{\prime}\right), \\
\log \bar{Z}_{t+1}^{\prime}-\log \bar{Z}_{t}^{\prime}=\log \bar{Z}_{t+1}-\log \bar{Z}_{t}=\bar{g}_{Z}
\end{gathered}
$$

and equations (8) and (56). 
In this proposition, we take a first-order approximation to equations (64), (65), and (27), which define equilibrium innovative investment around the allocation of innovative investment on the new BGP. We do so since, under the assumption that policies satisfy equation (32), the equilibrium allocation is a solution to these equations with no variation in policies over time. In contrast, if we had taken a first-order approximation to equations (64), (65), and (27) around the allocation of innovative investment on the initial BGP, we would have to include the change in policies from the initial to the new BGP in the approximation since the allocation of innovative investment on the initial BGP does not satisfy these equations at the new policies.

Proposition 7 Under the assumption that the allocation of real innovative investment on the initial BGP is interior, first-order conditions (64) and (65) hold as equalities at this allocation and the growth rate of aggregate productivity is given by (28) with $g_{Z}=\bar{g}_{Z}$. The corresponding level of $\bar{Y}_{r}$ is given by equation (27). If the policies on the new BGP satisfy (34), then these equations are unchanged on the new BGP, and hence the allocation of real innovative investment is the same on the old and the new BGP.

The proof that Proposition 1 holds then follows the original proof given that we have shown that aggregate innovative investment $\bar{Y}_{r}$ is unchanged by policies across the initial and final BGP.

The proof that the dynamics of aggregate productivity are given as in Proposition 2 is a direct application of Proposition 6 with $\log \bar{Y}_{r}^{\prime}=\log \bar{Y}_{r}$ and $\Theta=\Theta^{\prime}$. The proofs of Lemmas 1 and 2 follow as before.

If the initial and final policies are uniform, then we have that firms' after-subsidy expenditure on innovative investment relative to output is given by $\left(1-\bar{\tau}_{e}\right) \bar{i}_{r}$ on the initial BGP and $\left(1-\bar{\tau}_{e}^{\prime}\right) \bar{i}_{r}^{\prime}$ on the new BGP, and fiscal expenditures on these policies relative to output are given by $\bar{\tau}_{e} \bar{i}_{r}$ on the initial BGP and $\bar{\tau}_{e}^{\prime} \bar{i}_{r}^{\prime}$ on the new BGP. We now follow the line of argument in Proposition 4 to show that $\left(1-\bar{\tau}_{e}\right) \bar{i}_{r}$ remains constant across BGPs, which implies the conclusions of that proposition.

From equation (61), we have that on a BGP, $\bar{v}=V_{t} /\left[\left(1+\tau_{y}\right) Y_{t}\right]$ is given by

$$
\bar{v}=\left[1-\frac{\exp \left(\bar{g}_{Y}\right)}{1+\bar{R}}\left(\eta_{m} h\left(\bar{x}_{m}\right)+\left(1-\bar{\delta}_{c}\right) \zeta\left(\bar{x}_{c}\right)\right)\right]^{-1}\left[\frac{\mu-1}{\mu}-\frac{\left(1-\bar{\tau}_{e}\right) \bar{P}_{r t}}{\left(1+\tau_{y}\right) \bar{Y}_{t}}\left(\bar{x}_{m}+\bar{x}_{c}\right)\right] .
$$

The free entry condition implies that

$$
\frac{\left(1-\bar{\tau}_{e}\right)}{\left(1+\tau_{y}\right)} \frac{\bar{P}_{r t}}{\bar{Y}_{t}}=\frac{\exp \left(\bar{g}_{Y}\right)}{1+\bar{R}} \eta_{e} \overline{\mathcal{v}}
$$


Since the variables $\bar{g}_{Y}, \bar{R}, \tau_{y}$ and the allocation of investment by incumbent firms $\bar{x}_{c}, \bar{x}_{m}$ are constant across the initial and new BGP, we have that the term

$$
\left(1-\bar{\tau}_{e}\right) \frac{\bar{P}_{r t}}{\bar{Y}_{t}}=\left(1-\bar{\tau}_{e}^{\prime}\right) \frac{\bar{P}_{r t}^{\prime}}{\bar{Y}_{t}^{\prime}}
$$

is also constant across the initial and new BGP. The fiscal result then follows from the observation that $\bar{Y}_{r}=\bar{Y}_{r}^{\prime}$.

Discussion of Corollary 2 From the proof of Proposition 6, we have that $d x_{m} / d Y_{r}=0$ and $d x_{c} / d Y_{r}$ and $d x_{e} / d Y_{r}$ are given as in the statement of that proposition, with these expressions evaluated at the initial BGP allocation of investment (equal to the new BGP allocation of investment). Hence, the impact elasticity $\Theta$ is given by equation (35). To derive the bound $\Theta \leq \Theta_{e}$ in the corollary, we need two additional parameter restrictions to be satisfied on the initial BGP: $\Theta_{c} \geq \Theta_{e}$, and $d x_{c} / d Y_{r} \leq 0$ with $d x_{c} / d Y_{r}=1-d x_{e} / d Y_{r}$ and $d x_{e} / d Y_{r}$ defined from equation (33). We now discuss the restrictions on the underlying parameters that must be satisfied on the initial BGP for the conditions of this corollary to hold.

Recall condition (70) that, in an interior equilibrium,

$$
\Theta_{c} \geq \Theta_{e} \Longleftrightarrow \frac{1-\bar{\tau}_{c}}{1-\bar{\tau}_{e}} \geq 1-\frac{\delta_{e} \zeta\left(\bar{x}_{c}\right)}{\eta_{e}}
$$

Here the term $\delta_{e} \zeta\left(\bar{x}_{c}\right) / \eta_{e}$ denotes the ratio of the counterfactual employment in products produced by incumbents that are stolen by entrants to the actual employment in products produced by entrants. By equation (83) we have $\Theta_{c} \geq \Theta_{e}$ whenever $\bar{\tau}_{c} \leq \bar{\tau}_{e}$, that is when innovation policy favors innovative investment by entrants relative to innovative investment by incumbents. We can also relate this condition to Lemma 4 . If the initial allocation is conditionally efficient, then $\Theta_{c}=\Theta_{e}$ and policies $\bar{\tau}_{c}, \bar{\tau}_{e}$ on the initial BGP are such that this expression is an equality. If there is no business stealing (i.e., $\delta_{e}=0$ ), then $\Theta_{c} \geq \Theta_{e}$ if and only if $\bar{\tau}_{e} \geq \bar{\tau}_{c}$. If there is business stealing, so that $\delta_{e}>0$, then it is still the case that $\Theta_{c} \geq \Theta_{e}$ whenever $\bar{\tau}_{e} \geq \bar{\tau}_{c}$, but it is also possible to have this condition satisfied with $\bar{\tau}_{c}>\bar{\tau}_{e}$ as long as the difference in subsidies is not too large.

Now consider the parameter restrictions required to ensure that $d x_{c} / d Y_{r} \leq 0$. This holds if and only if $d x_{e} / d Y_{r}$ as defined in equation (33) is greater than one. Observe from equation (33) that since $\zeta^{\prime \prime}(x)<0$, we have that $d x_{e} / d Y_{r} \geq 1$ if and only if the 
denominator of that equation evaluated at the initial BGP allocation satisfies

$$
1+\frac{\delta_{e} \zeta^{\prime}\left(\bar{x}_{c}\right)}{\left(1-\delta_{0}-\delta_{m} h\left(\bar{x}_{m}\right)-\delta_{e} \bar{x}_{e}\right) \zeta^{\prime \prime}\left(\bar{x}_{c}\right)} \geq 0
$$

In an interior equilibrium, from equation (64), this condition is equivalent to the following upper bound on the extent of business stealing, as measured by the term $\delta_{e} \zeta\left(\bar{x}_{c}\right) / \eta_{e}$ relative to the curvature of the function $\zeta\left(x_{c}\right)$ :

$$
\frac{\delta_{e} \zeta\left(\bar{x}_{c}\right)}{\eta_{e}} \leq-\left(\frac{1-\tau_{c}}{1-\tau_{e}}\right) \frac{\zeta\left(\bar{x}_{c}\right) \zeta^{\prime \prime}\left(\bar{x}_{c}\right)}{\left(\zeta^{\prime}\left(\bar{x}_{c}\right)\right)^{2}} .
$$

If this bound is not satisfied, then investment by incumbents is so elastic to changes in the probability of losing a product that the equilibrium solution for entry falls (locally) when $Y_{r}$ rises $\left(d x_{e} / d Y_{r}<0\right)$.

Finally, note that $d x_{e} / d Y_{r}$ is unbounded above as the denominator in equation (33) approaches zero from above. This implies that $d x_{c} / d Y_{r}$ is unbounded below under the same conditions. In this case, we can have $\Theta<0$ if $\Theta_{c}>\Theta_{e}$. In this case, Corollary 2 still applies $\left(\Theta \leq \Theta_{e}\right)$, but the dynamics of the economy have aggregate productivity and output falling in response to a policy induced increase in the innovation intensity of the economy. This possibility is discussed in Acemoglu and Cao (2015).

\section{Quantitative analysis}

Section C.1 provides additional expressions to measure impact elasticities. Section C.2 provides additional details of the calibration procedure for our analytic elasticities. Section C.3 describes how we calibrate additional parameters that are required to solve the model nonlinearly. Section C.4 provides the equations that are used to solve the model (BGP and transition dynamics). Section C.5 provides additional details for the results of Section 7.

\section{C.1 Impact elasticities}

By equation (68),

$$
\Theta_{e}=\frac{1}{\rho-1} \frac{\left(\eta_{e}-\delta_{e} \zeta\left(\bar{x}_{c}\right)\right) \bar{x}_{e}}{\exp \left(\bar{g}_{Z}\right)^{\rho-1}} \frac{\bar{Y}_{r}}{\bar{x}_{e}} .
$$


Given the definition of $G$ in (28), we have that

$$
\exp \left(G\left(\bar{x}_{c}, \bar{x}_{m}, \bar{x}_{e}\right)\right)^{\rho-1}-\exp \left(G\left(\bar{x}_{c}, \bar{x}_{m}, 0\right)\right)^{\rho-1}=\left(\eta_{e}-\delta_{e} \zeta\left(\bar{x}_{c}\right)\right) \bar{x}_{e},
$$

which combined with equation (85) implies equation (36). We can also express $\Theta_{e}$ as

$$
\Theta_{e}=\frac{1}{\rho-1}\left[1-\delta_{e} \frac{\operatorname{avsize} e_{c}}{\operatorname{avsize}_{e}}\right] \bar{s}_{e} \frac{\bar{Y}_{r}}{\bar{x}_{e}}
$$

where we used

$$
\bar{s}_{e}=\frac{\eta_{e} \bar{x}_{e}}{\exp \left(\bar{g}_{Z}\right)^{\rho-1}}
$$

and

$$
\frac{\operatorname{avsize}_{c}}{\operatorname{avsize}_{e}}=\frac{\zeta\left(\bar{x}_{c}\right)}{\eta_{e}}
$$

where avsize $e_{c}$ denotes the average size of continuing products and avsize denotes the average size of new products acquired by entering firms. Therefore, given a target for the term in square brackets in equation (36), and given data on $\frac{a v \bar{s} i z e_{c}}{a v \bar{s} i e_{e}}$ and $\bar{s}_{e}$, we can back out the implied level of $\delta_{e}$.

By equations (66) and (64),

$$
\Theta_{c}=\left[\frac{1-\bar{\tau}_{c}}{1-\bar{\tau}_{e}}\right]\left[\frac{1}{1-\delta_{e} \frac{a v \bar{s} \bar{z} z e_{c}}{a v \bar{s} i z e_{e}}}\right] \Theta_{e}=\left[\frac{1-\bar{\tau}_{c}}{\rho-1}\right]\left[\frac{1+\bar{R}}{\exp \left(\bar{g}_{Y}\right)}\right] \frac{\bar{i}_{r}}{\bar{v}^{\prime}}
$$

where the second equality uses equations (39) and (86). Therefore, the value of $\Theta_{c}$ is independent of the extent of business stealing $\delta_{e}, \delta_{m}$ (or, similarly, is independent of the contribution of entrants to productivity growth).

Finally, by equations (67), (64), and (65),

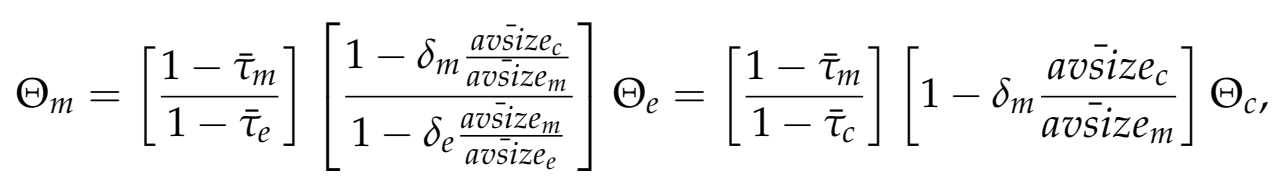

where the second equation uses equation (87).

\section{C.2 Data and calibration}

We set the time period in the model to one year and calibrate the BGP of the model using average data for the period 1990-2014 (whenever possible).

We first describe how we assign values to the parameters determining the elasticities 
required to evaluate the aggregate implications of a change in innovation policies. We then describe how we parameterize the model to evaluate its full nonlinear dynamics.

List of model parameters to calculate analytic elasticities The parameters and BGP statistics that we need to assign to calculate our elasticities analytically are: the degree of intertemporal knowledge spillovers $\phi$, the impact elasticity $\Theta$, the share of physical capital in $\operatorname{costs} \alpha$, the share of production labor in firms' output (inclusive of production subsidies) $\frac{(1-\alpha)}{\mu}$, the share of innovative investment in firms' output (inclusive of production subsidies) $\bar{i}_{r}$, the discount factor (which equals the ratio of the output growth rate to the interest rate, $\left.\tilde{\beta}=\frac{\exp \left(\bar{g}_{Y}\right)}{1+\bar{R}}\right)$, the parameter governing the intertemporal elasticity of substitution $\gamma$, consumption-to-output ratio $\frac{\bar{C}}{\bar{Y}}$, and the depreciation rate of physical capital $d_{k}$ (which is required to calculate the dynamics of the rental rate $R_{k}$ ). We set $\Theta$ equal to its upper bound, $\Theta_{e}$. To measure $\Theta_{e}$, we use expression (36), which requires assigning values to the elasticity of substitution $\rho$, the baseline productivity growth rate $\bar{g}_{Z}$ (which, given $\alpha$ and $\bar{g}_{Y}$, requires a value for the growth rate of the labor force $\bar{g}_{L}$ ), the counterfactual growth rate when investment by entrants is set to zero $G\left(\bar{x}_{c}, \bar{x}_{m}, 0\right)$, and the ratio of innovative investments by entrants to total investments $\frac{\bar{x}_{e}}{\bar{Y}_{r}}$. To measure $\frac{\bar{x}_{e}}{\bar{Y}_{r}}$ we use equation 39 (together with 40), which require measures of dividends relative to output $\bar{d}$, employment shares of entering firms $\bar{s}_{e}$, and innovation subsidy rates for investment by entrants $\tau_{e}$. We also require initial BGP values for the innovation subsidies for incumbent firms, $\tau_{c}$ and $\tau_{m}$, and the production subsidy (which we set to undo the distortions on capital accumulation arising from markups and the corporate profits tax). In measuring the rental rate of capital and firm dividends, we introduce a corporate profits tax, which we denote by $\tau_{\text {corp. }}$. This tax is applied to the variable profits of intermediate good firms and the return to physical capital. In what follows, we describe how we assign values to these parameters and targets, which are reported in Table 2.

As described in the text, we consider two values of $\phi: \phi=-1.6$ and $\phi=0.96$. We set the elasticity of substitution $\rho$ to 4 in the CES aggregator in equation (4). Note that this assumption fixes the term $1 /(\rho-1)$ that enters into our impact elasticity formulas. Holding the equilibrium markup $\mu$ fixed, changes in this parameter $\rho$ have no impact on any other implication of our model for the elasticities of aggregate productivity and welfare with respect to changes in aggregate innovative investment other than through this term. Hence, it is clear that our measured elasticities will be larger if we choose a value of $1<\rho<4$ and smaller if we choose a value of $\rho>4$. Note that our upper bound for the impact elasticity in equation (37) is independent of $\rho$.

We fix a BGP consumption interest rate of $\bar{R}=4 \%$. This rate of return is close to 
that estimated by Poterba (1998) (5.1\%), Hall (2003) (4.46\%), and McGrattan and Prescott (2005) (4.1\% for 1990-2001). We have set it at the low end of these estimates to reflect the decline in real interest rates that has occurred over the past several decades. We set the growth rate of the labor force $\bar{g}_{L}=0.007$ corresponding to the annual growth rate of employment in the nonfinancial corporate sector over the period 1990-2014. We set the intertemporal elasticity parameter $\gamma \rightarrow 1$ (i.e., $\log$ utility). ${ }^{27}$

Output and innovative investment by incumbent firms To measure innovative investment and factor payments, we use data from the integrated macroeconomic accounts and fixed assets tables for the US nonfinancial corporate sector derived from the US national income and product accounts (NIPA).

Since 2013, NIPA includes measures of investments and stocks in intellectual property products going back to 1929. These intellectual property products include research and development, software, and artistic and literary originals. Research and development by the nonfinancial corporate sector accounts for roughly half of these investments.

In our model, total expenditures on innovative investments correspond to output of the research good $P_{r t} Y_{r t}$, which equals the compensation of research labor $W_{t} L_{r t}$. We presume that what is measured in the data is the innovative investment expenditures of incumbent firms $P_{r t}\left(x_{c t}+x_{m t}\right)$, and infer innovative investment expenditures of entering firms $P_{r t} x_{e t}$ (since we assume that entrants are not in the nonfinancial corporate sector when they make these expenditures).

We measure aggregate firms' output inclusive of the production subsidy in our model, $\left(1+\tau_{y}\right) Y_{t}$, as gross value added of the nonfinancial corporate sector less indirect business taxes less measured innovative investment expenditures by incumbent firms. With these adjustments, we obtain $\frac{\bar{P}_{r t}\left(\bar{x}_{c}+\bar{x}_{m}\right)}{\left(1+\tau_{y}\right) \bar{Y}_{t}}=0.061$ (the average of this measure for the period 1990-2014). The corresponding BGP growth rate of output of the final consumption good is $\bar{g}_{Y}=0.025$ and the discount factor $\tilde{\beta}=\exp \left(\bar{g}_{Y}\right) /(1+\bar{R})=0.986$.

Payments to physical capital and profits In the data, gross value added of the nonfinancial corporate sector is decomposed into indirect business taxes, compensation of employees, and gross operating surplus. We measure compensation of production labor

\footnotetext{
${ }^{27}$ The agents' intertemporal elasticity of substitution is used only in computing the transition dynamics of physical capital, for given changes in research labor as we do in our policy counterfactuals. Hence, our results regarding the transition dynamics of aggregate productivity do not depend on this parameter. Moreover, our results on welfare, to a first approximation, do not depend on this parameter. Only the transition dynamics of aggregate output conditional on the transition dynamics of aggregate productivity are affected by the intertemporal elasticity of substitution.
} 
$W_{t} L_{p t}$ in our model as compensation of employees in the nonfinancial corporate sector less measured innovative investment expenditures by incumbent firms.

In our model, a portion of gross operating surplus is paid as rental payments to physical capital, a portion is paid as corporate profits taxes (taxes on income and wealth in the NIPA), and a portion is paid to owners of firms as after-tax variable profits less expenditures on innovative investment. To measure rental payments to physical capital, $R_{k} K_{t}$, we impute the rental rate to physical capital using the standard user cost formula implied by our model, $\bar{R}_{k}=\frac{\bar{R}}{1-\tau_{\text {corp }}}+d_{k}$, with a depreciation rate of physical capital $d_{k}=0.055$ and a corporate profits tax $\tau_{\text {corp }}=0.161$ calculated as described below, which imply $\bar{R}_{k}=0.1027$. We measure $K_{t}$ by the replacement value of physical capital ("Nonfinancial assets, nonfinancial corporate business") minus the replacement value of intangible capital ("Nonresidential intellectual property products, nonfinancial corporate business, current cost basis"), which results in $\bar{K}_{t}=2.125 \times\left(1+\tau_{y}\right) \bar{Y}_{t}$. We measure the depreciation rate $d_{k}$ as the ratio of "Consumption of fixed capital, structures, equipment, and intellectual property products, nonfinancial corporate business" minus consumption of intangible capital, to the replacement value of physical capital. In order to measure consumption of intangible capital, we multiply its replacement value by its depreciation rate. We measure the corporate profits tax $\tau_{\text {corp }}$ as the ratio of payments of taxes on income and wealth in the data, $0.037 \times\left(1+\tau_{y}\right) \bar{Y}_{t}$, to the tax base of this tax in our model (i.e., variable profits plus physical capital income net of depreciation, $\left.\left(1+\tau_{y}\right) \bar{Y}_{t}-\bar{W}_{t} \bar{L}_{p t}-d_{k} \bar{K}_{t}=0.228 \times\left(1+\tau_{y}\right) \bar{Y}_{t}\right)$. In choosing this tax base, we have assumed that firms cannot expense their investments in innovation from profits for tax purposes. We make this assumption so that it is possible for the equilibrium to be conditionally efficient in the presence of uniform innovation subsidies and a positive corporate profits tax.

Following this procedure, we obtain an average share (over the period 1990-2014) of production labor in firms' output (inclusive of production subsidies) of $\frac{\bar{W}_{t} \bar{L}_{p t}}{\left(1+\bar{\tau}_{y}\right) \bar{Y}_{t}}=$ $\frac{(1-\alpha)}{\mu}=0.654$, a share of capital $\frac{\bar{R}_{k t} \bar{K}_{t}}{\left(1+\bar{\tau}_{y}\right) \bar{Y}_{t}}=\frac{\alpha}{\mu}=0.218$, and a share of variable profits in output $\left(1-\frac{\bar{R}_{k t} \bar{K}_{t}+\bar{W}_{t} \bar{L}_{p t}}{\left(1+\bar{\tau}_{y}\right) \bar{Y}_{t}}\right)=\left(\frac{\mu-1}{\mu}\right)=0.127$, so $\alpha=0.25$ and $\mu=1.146$. We assume that in the initial BGP innovative subsidies are uniform, with $\bar{\tau}_{e}=\bar{\tau}_{c}=\bar{\tau}_{m}=0.03$, obtained from Tyson and Linden (2012) (Table 7 in that paper reports estimates of corporate R\&D tax credit claims relative to R\&D business spending in the United States). This gives us

$$
\bar{d}=\frac{\bar{D}_{t}}{\left(1+\tau_{y}\right) \bar{Y}_{t}}=\left(\frac{\mu-1}{\mu}\right)\left(1-\bar{\tau}_{c o r p}\right)-\left(1-\bar{\tau}_{e}\right) \frac{\bar{P}_{r t}\left(\bar{x}_{c}+\bar{x}_{m}\right)}{\left(1+\bar{\tau}_{y}\right) \bar{Y}_{t}}=0.047
$$


In order to remove the distortions induced by the markup and the corporate profits tax in the allocation of physical capital when calculating welfare, we set the production subsidy $\bar{\tau}_{y}=\frac{\mu}{\bar{R}+d_{k}}\left(\frac{\bar{R}}{\left(1-\tau_{c o r p}\right)}+d_{k}\right)-1=0.24 .{ }^{28}$ Our choice of $\bar{\tau}_{y}$ only affects our welfare calculations. Given measures of $\alpha, \bar{g}_{L}$, and $\bar{g}_{Y}$, we construct estimates of the BGP growth rate of total factor productivity $\bar{g}_{Z}=0.0136$. We calculate the ratio of consumption to output as

$$
\frac{\bar{C}}{\bar{Y}}=1-\frac{\bar{I}}{\bar{K}} \frac{\bar{K}}{\bar{Y}}=1-\left(\exp \left(\bar{g}_{Y}\right)-\left(1-d_{k}\right)\right) \frac{\alpha\left(1+\tau_{y}\right)}{\mu \bar{R}_{k}}=0.789
$$

Product-level dynamics To measure the employment shares of entering firms $\bar{s}_{e}$, we use annual data from the Longitudinal Business Database (LBD) in the United States on the dynamics of establishments and firms that own them. We make the identifying assumption that an establishment in the LBD data corresponds to an intermediate good in the model. Products in entering firms in the model correspond to establishments in the data that are new (they are active in year $t$ but not in year $t-1$ ) and are owned by new firms. The average value of $\bar{s}_{e}$ in the period 1990-2014 is 0.027. If we assume time periods that are longer than one year, entrants represent a higher share in the total number of establishments and in employment. When we solve the model nonlinearly, we calibrate other parameter values using additional information on product-level dynamics.

By equation (40), with $\bar{d}=0.047, \exp \left(\bar{g}_{Y}\right) /(1+\bar{R})=0.986$, and $\bar{s}_{e}=0.027$, we obtain $\bar{v}=1.15$. By equation (39), we obtain $\frac{\bar{P}_{r t} \bar{x}_{e}}{\left(1+\tau_{y}\right) \bar{Y}_{t}}=0.031$, so $\bar{i}_{r}=\frac{\bar{P}_{r t}\left(\bar{x}_{e}+\bar{x}_{c}+\bar{x}_{m}\right)}{\left(1+\tau_{y}\right) \bar{Y}_{t}}=$ $0.061+0.031=0.093$. The fiscal cost on innovation spending, $E / Y$, in the initial BGP is given by $0.03 \times \bar{i}_{r}=0.0028$. The ratio $\bar{x}_{e} / \bar{Y}_{r}$, which is required to calculate $\Theta_{e}$ in equation (36), is equal to $0.032 / 0.093=0.34$.

Business stealing Based on the derivation of equation (86) in Appendix B, the expression in square brackets in equation (36) can be written as

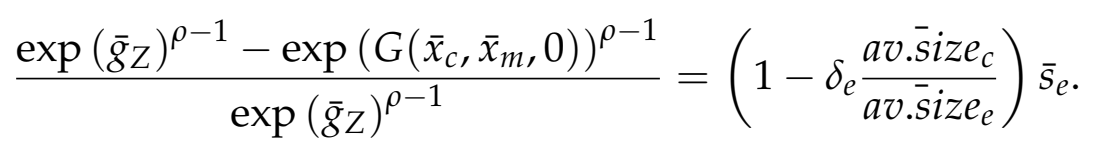

We consider two parameterizations of the extent of business stealing for entering firms. First, we set $\delta_{e}=0$, so that the expression in square brackets in equation (36) is equal to $\bar{s}_{e}=0.027$. Second, we let $\delta_{e}>0$, and choose $G\left(\bar{x}_{c}, \bar{x}_{m}, 0\right)$ so that $\left.\left(\bar{g}_{Z}-G\left(\bar{x}_{c}, \bar{x}_{m}, 0\right)\right) / \bar{g}_{Z}\right)=$

\footnotetext{
${ }^{28}$ This value of production subsidy is set so that $\left(1-\tau_{\text {corp }}\right)\left(\left(1+\tau_{y}\right) \frac{\alpha}{\mu} \overline{\bar{y}}-d_{k}\right)=\alpha \frac{\bar{y}}{\bar{k}}-d_{k}=\bar{R}$.
} 


\begin{tabular}{|c|c|c|c|}
\hline \multicolumn{2}{|l|}{ Shares in firms' output, $Y \times\left(1+\tau_{y}\right)$} & \multicolumn{2}{|l|}{ Parameters } \\
\hline Production labor compensation, $W L_{p}$ & 0.655 & Elasticity of substitution, $\rho$ & 4 \\
\hline Physical capital compensation, $R_{k} K$ & 0.218 & Markup, $\mu$ & 1.146 \\
\hline Variable profits, $\Pi=\left(1+\tau_{y}\right) Y-W L_{p}-R_{k} K$ & 0.127 & Physical capital share in costs, $\alpha$ & 0.25 \\
\hline Innovation investments by incumbents, $P_{r}\left(x_{c}+x_{m}\right)$ & 0.061 & Intertemporal spillovers, $\phi$ & -1.6 or 0.99 \\
\hline Dividends, $\left(1-\tau_{\text {corp }}\right) \Pi-P_{r}\left(\left(1-\tau_{c}\right) x_{c}+\left(1-\tau_{m}\right) x_{m}\right)$ & 0.047 & Capital depreciation rate, $d_{k}$ & 0.055 \\
\hline Innovation investments by entrants, $P_{r} x_{e}$ & 0.031 & Interest rate, $\bar{R}$ & 0.04 \\
\hline Innovation intensity, $P_{r}\left(x_{c}+x_{m}+x_{e}\right)=P_{r} Y_{r}$ & 0.093 & Intertemporal substitution, $\gamma$ & 1 \\
\hline \multirow[t]{3}{*}{ Implied allocation of labor, $L_{p} / L$} & 0.876 & Labor growth rate, $\bar{g}_{L}$ & 0.007 \\
\hline & & Scientific progress growth, $\bar{g}_{A_{r}}$ & 0.029 or -0.006 \\
\hline & & Business stealing by entrants, $\delta_{e}$ & 0 or 0.20 \\
\hline Policies in initial BGP & & Other targets & \\
\hline Innovation subsidies, $\tau_{c}=\tau_{m}=\tau_{e}$ & 0.03 & Output growth rate, $\bar{g}_{Y}$ & 0.025 \\
\hline Output subsidy, $\tau_{y}$ & 0.24 & Employment share of entrants, $\bar{s}_{e}$ & 0.027 \\
\hline Corporate profit tax rate, $\tau_{\text {corp }}$ & 0.16 & Growth contribution of entrants, $\frac{\bar{g} Z-G\left(\bar{x}_{c}, \bar{x}_{m}, 0\right)}{\bar{g} Z}$ & 0.257 \\
\hline \multicolumn{4}{|l|}{ Other model outcomes } \\
\hline Aggregate productivity growth, $\bar{g}_{Z}$ & 0.014 & Value incumbents relative to $\bar{Y}\left(1+\tau_{y}\right)$ & 1.16 \\
\hline Discount factor, $\tilde{\beta}$ & 0.986 & Term $\frac{\exp \left(\bar{g}_{Z}\right)^{\rho-1}-\exp \left(G\left(\bar{x}_{c}, \bar{x}_{m}, 0\right)\right)^{\rho-1}}{\exp \left(\bar{\sigma}_{\bar{z}}\right)^{\rho-1}}$ & 0.027 or 0.01 \\
\hline Consumption/output, $\bar{C} / \bar{Y}$ & 0.789 & Impact elasticity entry, $\Theta_{e}$ & 0.026 or 0.010 \\
\hline
\end{tabular}

Table 2: Baseline parameters, targets, and outcomes

0.257, which corresponds to estimates of the portion of annual trend productivity growth due to entry in Akcigit and Kerr (2010). Given our estimate of $\bar{g}_{Z}=0.014$ and $\rho=4$, we obtain $G\left(\bar{x}_{c}, \bar{x}_{m}, 0\right)=0.01$ and the expression in square brackets in equation (36) is equal to 0.011 . Given our measure $\frac{a^{\bar{s} s i z e_{c}}}{a^{v} \overline{s i z e_{e}}}=3$ discussed below, our parameterization implies $\delta_{e}=0.20$.

\section{C.3 Calibration of additional parameters to solve nonlinear transition dynamics}

In the previous section, we described how we assign values to the parameters determining the elasticities required to evaluate the aggregate implications of a change in innovation policies. We now discuss how we assign remaining parameter values to solve for all BGP variables and to solve the transition dynamics of the model nonlinearly and globally (in which we do not impose that $\Theta$ is at its upper bound of $\Theta_{e}$ in response to proportional policy changes).

In Section C. 2 we described how we choose the value of $\delta_{e}$. Here we impose $\delta_{m}=\delta_{e}$. 
Moreover, we specify

$$
\begin{gathered}
h\left(x_{m}\right)=h_{1} x_{m}^{h_{2}} \\
\zeta\left(x_{c}\right)=\zeta_{0}+\zeta_{1} x_{c}^{\zeta_{2}}
\end{gathered}
$$

where $h_{1}>0, \zeta_{1}>0,0<h_{2}<1$, and $0<\zeta_{2}<1$. The parameters that need to be assigned are $\left\{\delta_{0}, \eta_{e}, \eta_{m}, h_{1}, h_{2}, \zeta_{0}, \zeta_{1}, \zeta_{2}\right\}$.

Suppose we have data on the growth rate of the measure of products $g_{M t}=\log \left(M_{t+1} / M_{t}\right)$, as well as data on the fraction of products that are continuing products in incumbent firms $f_{c t+1}$, the fraction of products that are new to incumbent firms measured as the sum of those that are new to society and stolen $f_{m t+1}$, and the fraction of products that are produced in entering firms measured as the sum of those that are new to society and stolen $f_{e t+1}=1-f_{c t+1}-f_{m t+1}$. Suppose we also have data on the aggregate size of continuing products in incumbent firms $s_{c t+1}$, the aggregate size of products that are new to incumbent firms measured as the sum of those that are new products and those that are stolen $s_{m t+1}$, and the aggregate size of products that are new to entering firms measured as the sum of those that are new products and those that are stolen $s_{e t+1}=1-s_{c t+1}-s_{m t+1}$. The average size of continuing products in continuing firms, new products in incumbent firms, and new products in entering firms is denoted by avsize $e_{c t+1}=\frac{s_{c t+1}}{f_{c t+1}}$, avsize $_{m t+1}=$ $\frac{s_{m t+1}}{f_{m t+1}}$ and $a_{v s i z e_{e t+1}}=\frac{s_{e t+1}}{f_{e t+1}}$, respectively. Time averages of these variables are denoted with a bar.

We calibrate $\delta_{0}, \eta_{e}, \eta_{m}$ and the initial BGP values of $h\left(\bar{x}_{m}\right), \zeta\left(\bar{x}_{c}\right), \bar{x}_{e}$ to satisfy the following equations:

$$
\begin{gathered}
h\left(\bar{x}_{m}\right)=\bar{f}_{m} \exp \left(\bar{g}_{M}\right) \\
\bar{x}_{e}=\bar{f}_{e} \exp \left(\bar{g}_{M}\right) \\
\zeta\left(\bar{x}_{c}\right)=\operatorname{avsize}_{c} \frac{\exp \left((\rho-1) \bar{g}_{Z}\right)}{\exp \left(\bar{g}_{M}\right)} \\
\eta_{m}=\operatorname{avsize}_{m} \frac{\exp \left((\rho-1) \bar{g}_{Z}\right)}{\exp \left(\bar{g}_{M}\right)} \\
\eta_{e}=\operatorname{avsize} e_{e} \frac{\exp \left((\rho-1) \bar{g}_{Z}\right)}{\exp \left(\bar{g}_{M}\right)} \\
\delta_{0}=1-\delta_{m} h\left(\bar{x}_{m}\right)-\delta_{e} \bar{x}_{e}-\bar{f}_{c} \exp \left(\bar{g}_{M}\right) .
\end{gathered}
$$

Given initial policy ratios, $\left(\frac{1-\bar{\tau}_{c}}{1-\bar{\tau}_{e}}\right)$ and $\left(\frac{1-\bar{\tau}_{c}}{1-\bar{\tau}_{m}}\right)$, we calibrate $\zeta^{\prime}\left(\bar{x}_{c}\right)$ and $h^{\prime}\left(\bar{x}_{m}\right)$ using equations (64) and (65).

In order to calibrate the parameters $h_{1}, h_{2}, \zeta_{1}$, and $\zeta_{2}$, we must know the values of $\bar{x}_{c}$ 
and $\bar{x}_{m}$. Note that our calibration procedure uses as an input a measure of $\left(\bar{x}_{c}+\bar{x}_{m}\right) / \bar{Y}_{r}$ and implies a value of $\bar{x}_{e} / \bar{Y}_{r}$, but does not pin down $\bar{x}_{c}$ and $\bar{x}_{m}$ separately. To determine the value of $\bar{x}_{c}$, we use the following logic. The contribution of investment in acquiring products each period to firm value must be nonnegative. That is, on a BGP, we must have $\bar{v}$ at least as large as the value that the firm would obtain if it were to set investment into acquiring new products equal to zero in every period. Given the assumption that $h(0)=0$, this alternative value of incumbent firms on a BGP is given by

$$
\tilde{v}=\left[1-\frac{\exp \left(\bar{g}_{Y}\right)}{1+\bar{R}} \bar{s}_{c}\right]^{-1}\left[\left(1-\tau_{c o r p}\right)\left(\frac{\mu-1}{\mu}\right)-\left(1-\bar{\tau}_{c}\right) \frac{\bar{P}_{r t} \bar{x}_{c}}{\left(1+\bar{\tau}_{y}\right) \bar{Y}_{t}}\right] .
$$

If $\tau_{c}=\tau_{m}$, then

$$
\bar{v}=\left[1-\frac{\exp \left(\bar{g}_{Y}\right)}{1+\bar{R}}\left(\bar{s}_{c}+\bar{s}_{m}\right)\right]^{-1}\left[\left(1-\tau_{c o r p}\right)\left(\frac{\mu-1}{\mu}\right)-\left(1-\bar{\tau}_{c}\right) \frac{\bar{P}_{r t}\left(\bar{x}_{c}+\bar{x}_{m}\right)}{\left(1+\bar{\tau}_{y}\right) \bar{Y}_{t}}\right] .
$$

The requirement that $\tilde{v} \leq \bar{v}$ implies that the research expenditures of incumbents on improving continuing products relative to value added must lie between the bounds

$$
\begin{gathered}
\frac{\bar{P}_{r t}\left(\bar{x}_{c}+\bar{x}_{m}\right)}{\left(1+\bar{\tau}_{y}\right) \bar{Y}_{t}} \geq \frac{\bar{P}_{r t} \bar{x}_{c}}{\left(1+\bar{\tau}_{y}\right) \bar{Y}_{t}} \geq \\
\frac{1-\frac{\exp \left(\bar{g}_{Y}\right)}{1+\bar{R}} \bar{s}_{c}}{1-\frac{\exp \left(\bar{g}_{Y}\right)}{1+\bar{R}}\left(1-\bar{s}_{e}\right)} \frac{\bar{P}_{r t}\left(\bar{x}_{c}+\bar{x}_{m}\right)}{\left(1+\bar{\tau}_{y}\right) \bar{Y}_{t}}-\frac{\frac{\exp \left(\bar{g}_{Y}\right)}{1+\bar{R}} \bar{s}_{m}}{1-\frac{\exp \left(\bar{g}_{Y}\right)}{1+\bar{R}}\left(1-\bar{s}_{e}\right)} \frac{\left(1-\tau_{c o r p}\right)}{\left(1-\bar{\tau}_{c}\right)}\left(\frac{\mu-1}{\mu}\right) .
\end{gathered}
$$

In our calibration, we set $\frac{\bar{P}_{r t} \bar{x}_{c}}{\left(1+\bar{\tau}_{y}\right) \bar{Y}_{t}}$ in the middle point between the two bounds. Given values of $\bar{x}_{m}, h\left(\bar{x}_{m}\right)$, and $h^{\prime}\left(\bar{x}_{m}\right)$, we determine the values of $h_{0}$ and $h_{1}$. Given values of $\bar{x}_{c}, \zeta\left(\bar{x}_{c}\right)$, and $\zeta^{\prime}\left(\bar{x}_{c}\right)$ (which are assigned as described above, independently of $\zeta_{2}$ ) and a value of $0<\zeta_{2}<1$, we determine the values of $\zeta_{0}$ and $\zeta_{1}$. For the policy exercises in which we do not set $\Theta$ at its upper bound of $\Theta_{e}$ (which is independent of $\zeta_{2}$ ), we set $\zeta_{2}$ halfway between its two bounds, that is, $\zeta_{2}=0.5$. This assumed value of $\zeta_{2}$ implies that, with business stealing, $\Theta=0.0093<0.0102=\Theta_{e}$ when considering proportional policy changes. ${ }^{29}$

We use LBD data to measure the necessary statistics to implement this calibration procedure. Specifically, we measure $\bar{g}_{M}=0.01$ as the annual growth rate in the number of establishments (averaged between 1990 and 2014), $\bar{f}_{e}=0.0775$ as the fraction of establishments in the data that are new and are owned by new firms, $\bar{f}_{m}=0.0227$ as the fraction

\footnotetext{
${ }^{29}$ If we set $\zeta_{2}=0.05$, close to its lower bound, then $\Theta=0.0098$.
} 
of establishments that are new and are owned by firms that are not new, and $\bar{f}_{c}=0.9$ as the fraction of establishments that are not new. The employment shares of these three categories of establishments are $\bar{s}_{e}=0.027, \bar{s}_{m}=0.025$, and $\bar{s}_{c}=0.948$. Our results are very similar if we calibrate the model using the statistics implied in Garcia-Macia et al. (2016).

\section{C.4 Solving the model}

Given parameter values assigned as described above, here we provide a summary of the steps to solve the model's BGP and transition dynamics assuming that the equilibrium allocations are interior (one needs to verify that the conjectured equilibrium that is obtained is interior). ${ }^{30}$

BGP The economy starts on an original BGP corresponding to policies $\bar{\tau}_{c}, \bar{\tau}_{m}, \bar{\tau}_{e}$, and $\bar{\tau}_{y}$. We normalize the level of scientific progress to be $A_{r t}=1$ at $t=0$. This gives $A_{r t}=$ $\exp \left(t \bar{g}_{A r}\right)$. We normalize the population to be $L_{t}=1$ at $t=0$. This gives $L_{t}=\exp \left(t \bar{g}_{L}\right)$. We take as given parameters and observed growth rates of aggregate output and labor $\bar{g} Y$ and $g_{L}$.

Let $l_{p t}=L_{p t} / L_{t}$ and $l_{r t}=L_{r t} / L_{t}$. These variables are constant at $\bar{l}_{p}$ and $\bar{l}_{r}$ on the initial BGP. Let $k_{t}=K_{t} / \exp \left(t \bar{g}_{Y}\right)$. This variable is constant at $\bar{k}$ on the initial BGP. Let $v_{t}=V_{t} /\left(\left(1+\bar{\tau}_{y}\right) Y_{t}\right)$ and $p_{r t}=P_{r t} /\left(\left(1+\bar{\tau}_{y}\right) Y_{t}\right)$. Both of these variables are constant on a BGP at $\bar{v}$ and $\bar{p}_{r}$. Let $z_{t}=Z_{t} / \exp \left(t \bar{g}_{Z}\right)$ where we solve for the BGP value $\bar{g}_{Z}$ below. Let $\bar{z}$ denote the BGP value of this variable. Let $y_{t}=Y_{t} / \exp \left(t \bar{g}_{Y}\right)$ where we calibrate the BGP value $\bar{g}_{Y}$. Let $\bar{y}$ denote the BGP value of this variable. Let $c_{t}=C_{t} / \exp \left(t \bar{g}_{Y}\right)$. Let $\bar{c}$ denote the BGP value of this variable. The BGP equations to be solved for the value of the state variables $Z_{0}$ and $K_{0}$ are as follows.

Growth rates $\bar{g}_{Z}, \bar{g}_{A r}$ :

$$
\begin{aligned}
& \bar{g}_{Z}=(1-\alpha)\left(\bar{g}_{Y}-\bar{g}_{L}\right) \\
& \bar{g}_{A r}=(1-\phi) \bar{g}_{Z}-\bar{g}_{L}
\end{aligned}
$$

Interest rate and rental rate of physical capital $\bar{R}$ and $\bar{R}_{k}$ :

$$
1+\bar{R}=\exp \left(\gamma\left(\bar{g}_{Y}-\bar{g}_{L}\right)\right) / \beta
$$

\footnotetext{
${ }^{30}$ The Matlab codes that we use to solve the model numerically (linearly and nonlinearly) are available at www.econ.ucla.edu/arielb/innovpolicycodes.zip.
} 


$$
\bar{R}=\left(1-\tau_{\text {corp }}\right)\left(\bar{R}_{k}-d_{k}\right)
$$

Innovative investment $\bar{x}_{c}, \bar{x}_{m}, \bar{x}_{e}$, and $\bar{Y}_{r}$ :

$$
\begin{gathered}
\frac{1-\bar{\tau}_{c}}{1-\bar{\tau}_{e}} \eta_{e}=\left(1-\delta_{0}-\delta_{m} h\left(\bar{x}_{m}\right)-\delta_{e} \bar{x}_{e}\right) \zeta^{\prime}\left(\bar{x}_{c}\right) \\
\frac{1-\bar{\tau}_{m}}{1-\bar{\tau}_{e}} \eta_{e}=\eta_{m} h^{\prime}\left(\bar{x}_{m}\right) \\
\bar{g}_{Z}=\frac{1}{\rho-1} \log \left(\left(1-\delta_{0}-\delta_{m} h\left(\bar{x}_{m}\right)-\delta_{e} \bar{x}_{e}\right) \zeta\left(\bar{x}_{c}\right)+\eta_{m} h\left(\bar{x}_{m}\right)+\eta_{e} \bar{x}_{e}\right) \\
\bar{x}_{c}+\bar{x}_{m}+\bar{x}_{e}=\bar{Y}_{r}
\end{gathered}
$$

Employment share of entering firms, value of intangible capital, price of the research good $\bar{s}_{e}$, $\bar{v}$ and $\bar{p}_{r}$ :

$$
\begin{gathered}
\bar{s}_{e}=\frac{\eta_{e} \bar{x}_{e}}{\exp \left((\rho-1) \bar{g}_{Z}\right)} \\
\bar{v}=\frac{\left[\left(1-\tau_{c o r p}\right) \frac{\mu-1}{\mu}-\bar{p}_{r}\left(\left(1-\bar{\tau}_{c}\right) \bar{x}_{c}+\left(1-\bar{\tau}_{m}\right) \bar{x}_{m}\right)\right]}{1-\frac{\exp \left(\bar{g}_{Y}\right)}{1+\bar{R}}\left(1-\bar{s}_{e}\right)} \\
\left(1-\bar{\tau}_{e}\right) \bar{p}_{r} \bar{x}_{e}=\bar{s}_{e} \frac{\exp \left(\bar{g}_{Y}\right)}{1+\bar{R}} \bar{v}
\end{gathered}
$$

Note that by combining the last two expressions, we can rewrite $\bar{v}$ as

$$
\bar{v}=\frac{\left[\left(1-\tau_{\text {corp }}\right) \frac{\mu-1}{\mu}-\bar{p}_{r}\left(\left(1-\bar{\tau}_{c}\right) \bar{x}_{c}+\left(1-\bar{\tau}_{m}\right) \bar{x}_{m}+\left(1-\bar{\tau}_{e}\right) \bar{x}_{e}\right)\right]}{1-\frac{\exp (\overline{\bar{g}})}{1+\bar{R}}}
$$

Innovation intensity and allocation of labor $\bar{i}_{r}, \bar{l}_{p}, \bar{l}_{r}$ :

$$
\begin{gathered}
\bar{i}_{r}=\bar{p}_{r} \bar{Y}_{r} \\
\frac{\bar{l}_{p}}{\bar{l}_{r}}=\frac{1-\alpha}{\mu} \frac{1}{\bar{i}_{r}} \\
\bar{l}_{p}+\bar{l}_{r}=1
\end{gathered}
$$


Levels of aggregate productivity $\bar{z}$ :

$$
\bar{Y}_{r}=\bar{z}^{\phi-1} \bar{l}_{r}
$$

Output, consumption, and capital stock $\bar{y}, \bar{c}$ and $\bar{k}$ :

$$
\begin{gathered}
\bar{R}_{k}=\left(1+\tau_{y}\right) \frac{\alpha}{\mu} \overline{\bar{k}} \\
\bar{y}=\bar{z} \bar{k}^{\alpha} \bar{l}_{p}^{1-\alpha} \\
\bar{c}=\bar{y}-\left(\exp \left(\bar{g}_{Y}\right)+\left(1-d_{k}\right)\right) \bar{k}
\end{gathered}
$$

New BGP We consider a permanent change in innovation policies from $\bar{\tau}_{c}, \bar{\tau}_{m}, \bar{\tau}_{e}$ to $\bar{\tau}_{c}^{\prime}, \bar{\tau}_{m}^{\prime}, \bar{\tau}_{e}^{\prime}$ that is unanticipated and starts in period $t=0$. Thus, the economy starts in period $t=0$ with the state variables $A_{r 0}=L_{0}=1$, and $\bar{Z}_{0}, \bar{K}_{0}$ solved for above. The economy follows a transition path to a new BGP. We can use the same procedure as above to compute the new BGP, which we denote with primes. The terminal condition we will use when we solve for the transition dynamics is that we end up at the new BGP allocation.

Transition dynamics The two states of the model are $z_{t}$ and $k_{t}$. Given $z_{0}, k_{0}$, we wish to solve for a sequence $\left\{z_{t+1}, k_{t+1}\right\}_{0}^{T}$, as well as the remaining intra-period variables that satisfy the Euler equations and the terminal conditions that $z_{t}, k_{t}$ converges to the new BGP $\bar{z}^{\prime}, \bar{k}^{\prime}$.

Let $Y_{t}$ denote the vector of intra-period variables:

$$
Y_{t}=\left(x_{c t}, x_{m t}, x_{e t}, Y_{r t}, l_{r t}, l_{p t}, i_{r t}, p_{r t}, y_{t}, c_{t}\right)
$$

We first show how we solve for $Y_{t}$, given $\left\{z_{t}, z_{t+1}, k_{t}, k_{t+1}\right\}$. Specifically, we solve for $\left(x_{c t}, x_{m t}, x_{e t}, Y_{r t}, l_{r t}, l_{p t}, i_{r t}, p_{r t}\right)$ given $\left(z_{t}, z_{t+1}\right)$. We then solve for $\left(y_{t}, c_{t}\right)$ given $\left(k_{t}, k_{t+1}\right)$.

Allocation of innovative investment $x_{c t}, x_{m t}, x_{e t}, Y_{r t}$ (assuming that the allocation is interior):

$\log z_{t+1}-\log z_{t}+\bar{g}_{z}=\frac{1}{\rho-1} \log \left(\left(1-\delta_{0}-\delta_{m} h\left(x_{m t}\right)-\delta_{e} x_{e t}\right) \zeta\left(x_{c t}\right)+\eta_{m} h\left(x_{m t}\right)+\eta_{e} x_{e t}\right)$ 


$$
\begin{gathered}
\left.\frac{1-\bar{\tau}_{c}}{1-\bar{\tau}_{e}} \eta_{e}=\left(1-\delta_{0}-\delta_{m} h\left(x_{m t}\right)-\delta_{e} x_{e t}\right)\right) \zeta^{\prime}\left(x_{c t}\right) \\
\frac{1-\bar{\tau}_{m}}{1-\bar{\tau}_{e}} \eta_{e}=\eta_{m} h^{\prime}\left(x_{m t}\right) \\
x_{c t}+x_{m t}+x_{e t}=Y_{r t}
\end{gathered}
$$

Allocation of labor $l_{r t}, l_{p t}$ :

$$
\begin{gathered}
Y_{r t}=z_{t}^{\phi-1} l_{r t} \\
l_{p t}+l_{r t}=1
\end{gathered}
$$

Price of the research and innovation intensity $i_{r t}, p_{r t}$ :

$$
\begin{gathered}
\frac{l_{p t}}{l_{r t}}=\frac{1-\alpha}{\mu} \frac{1}{i_{r t}} \\
i_{r t}=p_{r t} Y_{r t}
\end{gathered}
$$

Output and consumption $y_{t}, c_{t}$ :

$$
\begin{gathered}
y_{t}=z_{t} k_{t}^{\alpha} l_{p t}^{1-\alpha} \\
c_{t}=y_{t}+\left(1-d_{k}\right) k_{t}-\exp \left(\bar{g}_{Y}\right) k_{t+1}
\end{gathered}
$$

We now consider the Euler equations that must be satisfied.

Standard physical capital Euler equation:

$$
\begin{gathered}
R_{t}=\left(1-\tau_{\text {corp }}\right)\left(\left(1+\tau_{y}\right) \frac{\alpha}{\mu} \frac{y_{t+1}}{k_{t+1}}-d_{k}\right) \\
1=\left(1+R_{t}\right) \tilde{\beta} \exp \left(-\bar{g}_{Y}\right)\left(\frac{c_{t+1}}{c_{t}}\right)^{-\gamma}
\end{gathered}
$$

Value function and zero profit at entry condition:

$$
v_{t}=\left(1-\tau_{\text {corp }}\right) \frac{\mu-1}{\mu}-p_{r t}\left(\left(1-\tau_{c}\right) x_{c t}+\left(1-\tau_{m}\right) x_{m t}\right)+
$$




$$
\left.\frac{\exp \left(\bar{g}_{Y}-(\rho-1) \bar{g}_{Z}\right)}{1+R_{t}} v_{t+1}\left(\frac{y_{t+1}}{y_{t}}\right)\left(\frac{z_{t}}{z_{t+1}}\right)^{\rho-1}\left[\left(1-\delta_{0}-\delta_{m} h\left(x_{m t}\right)-\delta_{e} x_{e t}\right)\right) \zeta\left(x_{c t}\right)+\eta_{m} h\left(x_{m t}\right)\right]
$$

and

$$
\left(1-\tau_{e t}\right) p_{r t}=\eta_{e} \frac{\exp \left(\bar{g}_{Y}-(\rho-1) \bar{g}_{Z}\right)}{1+R_{t}} v_{t+1}\left(\frac{y_{t+1}}{y_{t}}\right)\left(\frac{z_{t}}{z_{t+1}}\right)^{\rho-1}
$$

Let

$$
X_{t}=\left(z_{t}, k_{t}, v_{t-1}\right)
$$

denote the vector of state variables extended with the lagged value of $v_{t}$. If we specify the triple $X_{t}, X_{t+1}, X_{t+2}$, we can solve for $Y_{t}$ and $Y_{t+1}$, and we calculate the Euler equations above. We then solve for the path of $\left\{X_{t}, Y_{t}\right\}$ using standard linear or nonlinear methods.

Solving transition taking as given a path of innovation intensities or research labor We now consider the problem of finding innovation policies to implement an equilibrium with a pre-specified path of the allocation of labor to research $\left\{l_{r t}\right\}$ or, equivalently given equation (98), a path for the innovation intensity of the economy $\left\{i_{r t}\right\}$. We begin with an analysis of our simple model in which only entering firms invest in innovation. We then extend the analysis to include investment by incumbent firms. We impose that the sequence $\left\{l_{r t}\right\}$ converges to a constant value $\bar{l}_{r}^{\prime}$ associated with the new BGP.

Given $z_{0}, k_{0}$, consider a given path of the allocation of research labor $\left\{l_{r t}\right\}$ (or, similarly, the innovation intensity of the economy $\left\{i_{r t}\right\}$ ). Assume that a given level of the tax $\tau_{\text {corp }}$ is fixed. We solve for the implied allocation and the sequence of entry subsidies that implement this allocation as an equilibrium as follows.

Equations (92), (95), (96), (97), (98), and (99) are used recursively to construct the implied sequences in the transition for $\left\{z_{t+1}, x_{e t}, Y_{r t}, l_{p t}, i_{r t}, p_{r t}\right\}$. The equilibrium sequences of consumption, output, physical capital and the real interest rate $c_{t}, y_{t}, k_{t+1}, R_{t}$ in the transition are given as the solutions to equations (100), (101), (102), and (103) together with the terminal condition that the capital stock converge to its new BGP value $\lim _{t \rightarrow \infty} k_{t+1}=\bar{k}^{\prime}$. These equations are those equations characterizing equilibrium in the growth model with time-varying exogenous supply of production labor $l_{p t}$ and aggregate productivity $z_{t}$.

Solving equation (104) recursively, the value of a product of size one relative to output $v_{t}$ is given by

$$
v_{t}=\left[d_{t}+\sum_{k=1}^{\infty} d_{t+k}\left(\frac{y_{t+k}}{y_{t}}\right)\left(\frac{z_{t}}{z_{t+k}}\right)^{\rho-1} \exp \left(\bar{g}_{Y}-(\rho-1) \bar{g}_{Z}\right)^{k} \prod_{j=0}^{k-1} \frac{1-\delta_{c t+j}}{1+R_{t+j}}\right]
$$


where $1-\delta_{c t}=1-\delta_{0}-\delta_{e} x_{e t}$ and $d_{t}=\left(1-\tau_{c o r p}\right) \frac{\mu-1}{\mu}$. The sequence of innovation policies $\left\{\tau_{e t}\right\}$ that implement this allocation as an equilibrium is then given from equation (105).

Observe that when we extend this result to the model with innovative investment by incumbents, we can no longer uniquely identify the feasible allocation corresponding to a given path of the allocation of labor to research $\left\{l_{r t}\right\}$. Instead, we must specify a rule for interior investment by incumbents $x_{c t}$ and $x_{m t}$ as a function of $Y_{r t}$ that allows for $x_{e t}$ strictly positive. One such rule would be to specify that $x_{c t} / Y_{r t}$ and $x_{m t} / Y_{r t}$ are constant fractions that sum to less than one. Then, from equation (95), we can solve for an interior value of $x_{e t}$. With such a rule for allocating innovative investment across firms, we can repeat the procedure for finding innovation policies that implement the implied allocation as an equilibrium as follows.

Again equations (92), (95), (96), (97), (98), and (99) and our rule for allocating innovative investment by incumbents are used recursively to construct the implied sequences in the transition for $\left\{z_{t+1}, x_{c t}, x_{m t}, x_{e t}, Y_{r t}, l_{p t}, i_{r t}, p_{r t}\right\}$. The equilibrium sequences of consumption, output, physical capital, and the real interest rate $c_{t}, y_{t}, k_{t+1}, R_{t}$ in the transition are given as the solutions to equations (100), (101), (102), and (103) together with the terminal condition that the capital stock converge to its new BGP value $\lim _{t \rightarrow \infty} k_{t+1}=\bar{k}^{\prime}$.

The problem of finding policies to implement this allocation as an equilibrium is somewhat more complex than is the case in the simple model. We can use equations (93) and (94) to find the required values of $\left(1-\tau_{c t}\right) /\left(1-\tau_{e t}\right)$ and $\left(1-\tau_{m t}\right) /\left(1-\tau_{e t}\right)$ by plugging the allocation into the right-hand side of these equations. We then have to solve for the entire sequence of entry subsidies $\left\{\tau_{e t}\right\}$ as follows. The dividend to an incumbent product is now

$$
d_{t}=\left(1-\tau_{c o r p}\right) \frac{\mu-1}{\mu}-\left(1-\tau_{e t}\right) p_{r t}\left(\frac{1-\tau_{c t}}{1-\tau_{e t}} x_{c t}+\frac{1-\tau_{m t}}{1-\tau_{e t}} x_{m t}\right) .
$$

The value of a product of size one relative to output $v_{t}$ is given as above, using this expression for dividends and with $1-\delta_{c t}$ now including business stealing by incumbent firms. The sequence of entry subsidies that implements this allocation as an equilibrium is then given by the solution to equation (105).

Alternatively to specifying interior paths for $x_{c t} / Y_{r t}$ and $x_{m t} / Y_{r t}$, we can specify timevarying policy ratios $\frac{1-\tau_{c t}}{1-\tau_{e t}}$ and $\frac{1-\tau_{m t}}{1-\tau_{e t}}$, and solve for $x_{c t}, x_{m t}$, and $x_{e t}$ using equations (95), (93), and (94). At this point, we must verify that the solution to this system of equations implies allocations of innovative investment that are interior. After solving for a timevarying path of $\left\{\tau_{e t}\right\}$ as described above, we calculate $\left\{\tau_{c t}, \tau_{m t}\right\}$ given the innovation policy ratios. 


\section{C.5 Additional numerical results}

In this section, we report additional details and figures for our innovation policy counterfactuals considered in Section 7. We first consider our baseline proportional policy changes. We then consider nonproportional policy changes. Finally, we consider proportional policy changes that are accompanied by annual exogenous productivity shocks.

Figures 1 and 2 display, for each of our four specifications, the transition dynamics (solving the model fully nonlinearly) of aggregate productivity and output in the first 100 and 20 years, respectively, after the proportional policy change that increases research labor permanently by $10 \%$. Figure 3 displays the 20-year transition dynamics of fiscal expenditures $E / Y$ and the innovation subsidy rate $\tau_{e t}$ that produces the $10 \%$ permanent increase in research labor. Recall that, with uniform innovation policies, the fiscal cost of these policies in terms of the change in $E / Y$ from the initial BGP to the new BGP required to induce a given change in the innovation intensity of the economy is given as in Proposition 4 . In Figure 3 we see that the increase in innovation subsidies in the early phase of the transition is smaller than in the new BGP, especially with low intertemporal knowledge spillovers $\phi$. With low $\phi$, the price of the research good is expected to rise quickly during the transition, so that (due to intertemporal substitution) innovation subsidies do not have to be as large in order to induce the same increase in total expenditures.

Figure 4 compares the path of aggregate productivity and output calculated using the log-linear approximation (as in Table 1) and the nonlinear solution method. The small differences between the linear and nonlinear solutions (which vanish in the new BGP) result in very small differences in welfare. For example, with high $\phi$ and no business stealing (in which the differences between the solutions in the first 100 years are the largest in Figure 4), the consumption equivalent changes in welfare are very similar: $20.96 \%$ when solving the model nonlinearly and $20.08 \%$ when solving the model via linear approximation.

We next consider nonproportional changes in innovation subsidies, which satisfy restriction (32). Specifically, we solve for the dynamics of innovation subsidies for entrants, $\tau_{e t}$, such that research labor increases by $10 \%$ permanently and both $\frac{1-\tau_{c t}}{1-\tau_{e t}}$ and $\frac{1-\tau_{m t}}{1-\tau_{e t}}$ fall from 1 to 0.95 . That is, innovation investments by incumbents are disproportionately subsidized relative to innovation investments by entrants.

We first assume that there is no business stealing. Figure 5 displays the transition dynamics of aggregate productivity and output in the first 100 years when solving the model via linearization (around the initial BGP) and nonlinearly. Given that the initial BGP allocation of innovative investments is conditionally efficient, Proposition 5 applies. Up to a first-order approximation, the transition dynamics of aggregate productivity and output only depend on the aggregate change in research labor and are the same for proportional 
and nonproportional policy changes (so that the transition dynamics coincide with those displayed in Figure 4 under the linearized solution). Figure 5 shows that the difference between the linearized (using the expressions referenced in Proposition 5) and nonlinear transition dynamics are quite small. With $\phi=-1.6$, the resulting change in welfare is $2.6 \%$ based on the linearized solution and $2.5 \%$ based on the nonlinearized solution. With $\phi=0.96$, the resulting change in welfare is $20.1 \%$ based on the linearized solution and $20.6 \%$ based on the nonlinearized solution.

We next assume that there is business stealing. In this case, the initial BGP allocation of innovative investment is not conditionally efficient, so Proposition 5 does not apply. Since policy changes are nonproportional, Proposition 7 does not apply either. However, in this case we can apply Proposition 6, which provides a first-order approximation around the new BGP. Figure 6 displays the transition dynamics of aggregate productivity and output in the first 100 years, in the presence of business stealing, when solving the model via linearization (as indicated in Proposition 6) and nonlinearly. In this case, there are additional output gains from reallocating innovative investment from entrants to incumbent firms (since $\Theta_{c}$ and $\Theta_{m}$ are larger than $\Theta_{e}$ ). The welfare gains when solving the model nonlinearly are $5.4 \%$ with low $\phi$ and $16.2 \%$ with high $\phi$ (versus $1.7 \%$ and $6.9 \%$, respectively, when considering a proportional policy change). The differences between the linearized and nonlinear transition dynamics are quite modest given the large policy change that we consider. With $\phi=-1.6$, the resulting change in welfare is $5.2 \%$ based on the linearized solution and $5.4 \%$ based on the nonlinearized solution. With $\phi=0.96$, the resulting change in welfare is $14.7 \%$ based on the linearized solution and $16.2 \%$ based on the nonlinearized solution.

Our results in Section 7 suggest that it would be hard to verify whether innovation policies yield large output and welfare gains using medium-term data on the response of aggregates to changes in innovation policies. We illustrate this point in Figure 7. In that figure, we show results obtained from simulating the response of aggregates in our model (with and without business stealing, with low and high $\phi$ ) to our baseline proportional increase in innovation subsidies in an extended version of our model with Hicks-neutral AR1 productivity shocks with a persistence of 0.9 and an annual standard deviation of 0.018. We introduce these shocks as a proxy for business cycle shocks around the BGP. We show histograms generated from 3,000 simulations of the log-linearized model for the first 20 years of the transition. The units on the horizontal axis show the log of the ratio of detrended output (in the upper panels) and productivity (in the lower panels) at the end of the 20th year of transition to initial output or productivity. The vertical axis shows the frequency of the corresponding outcome for output or productivity. The red 
bars show results for the model with low intertemporal knowledge spillovers $\phi$, and the blue bars show the results with high spillovers $\phi$. We can observe in each panel that the distribution represented by the blue bars is slightly to the right of that represented by the red bars. But it is also clear in each panel that, using either output or productivity, it would be very hard to distinguish the degree of intertemporal knowledge spillovers (and, hence, the long-term effects from this innovation subsidy) in aggregate time series data even if we had the benefit of a true policy experiment.
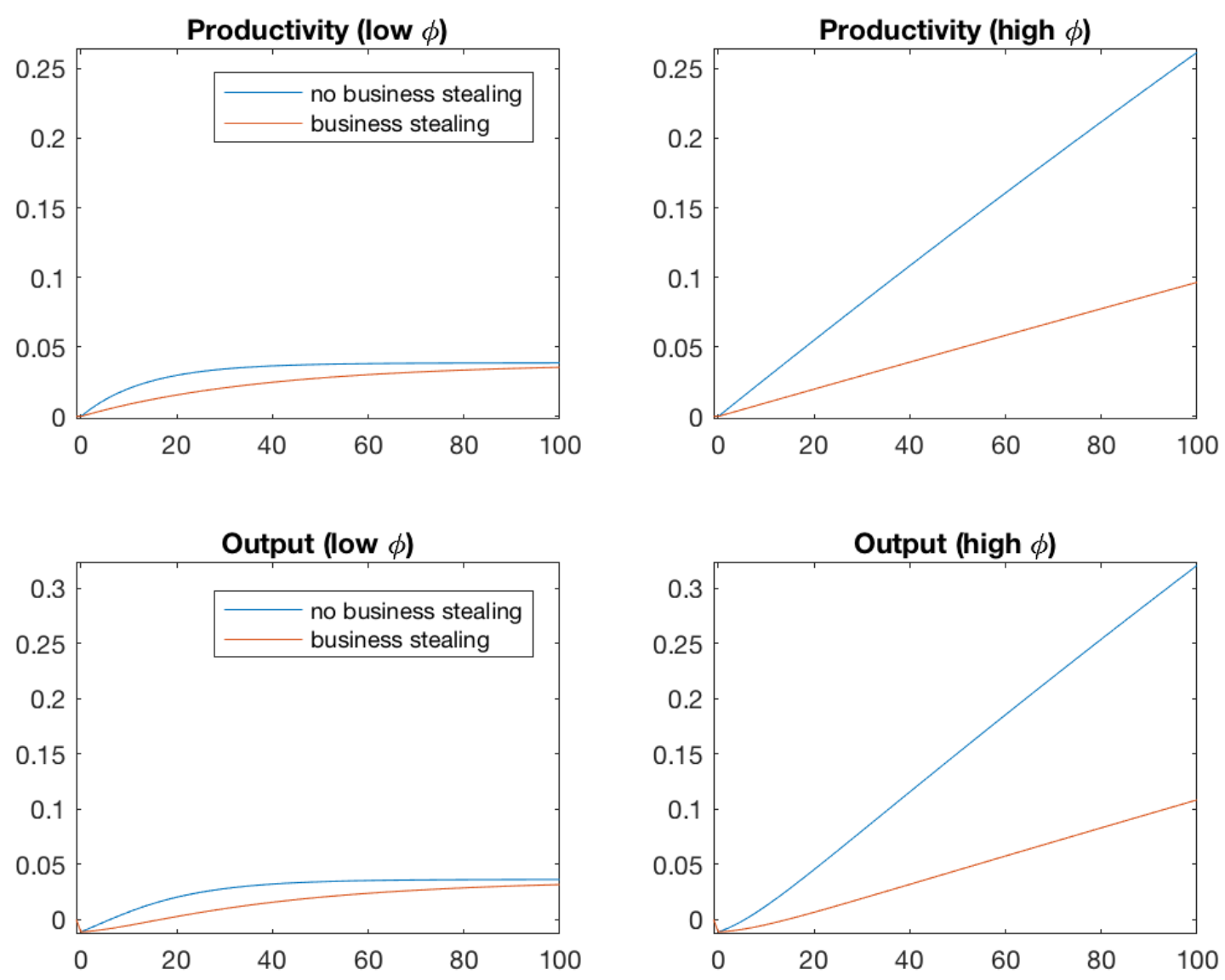

Figure 1: 100-year transition dynamics to a 10\% permanent increase in research labor via proportional innovation policies, nonlinear solution 

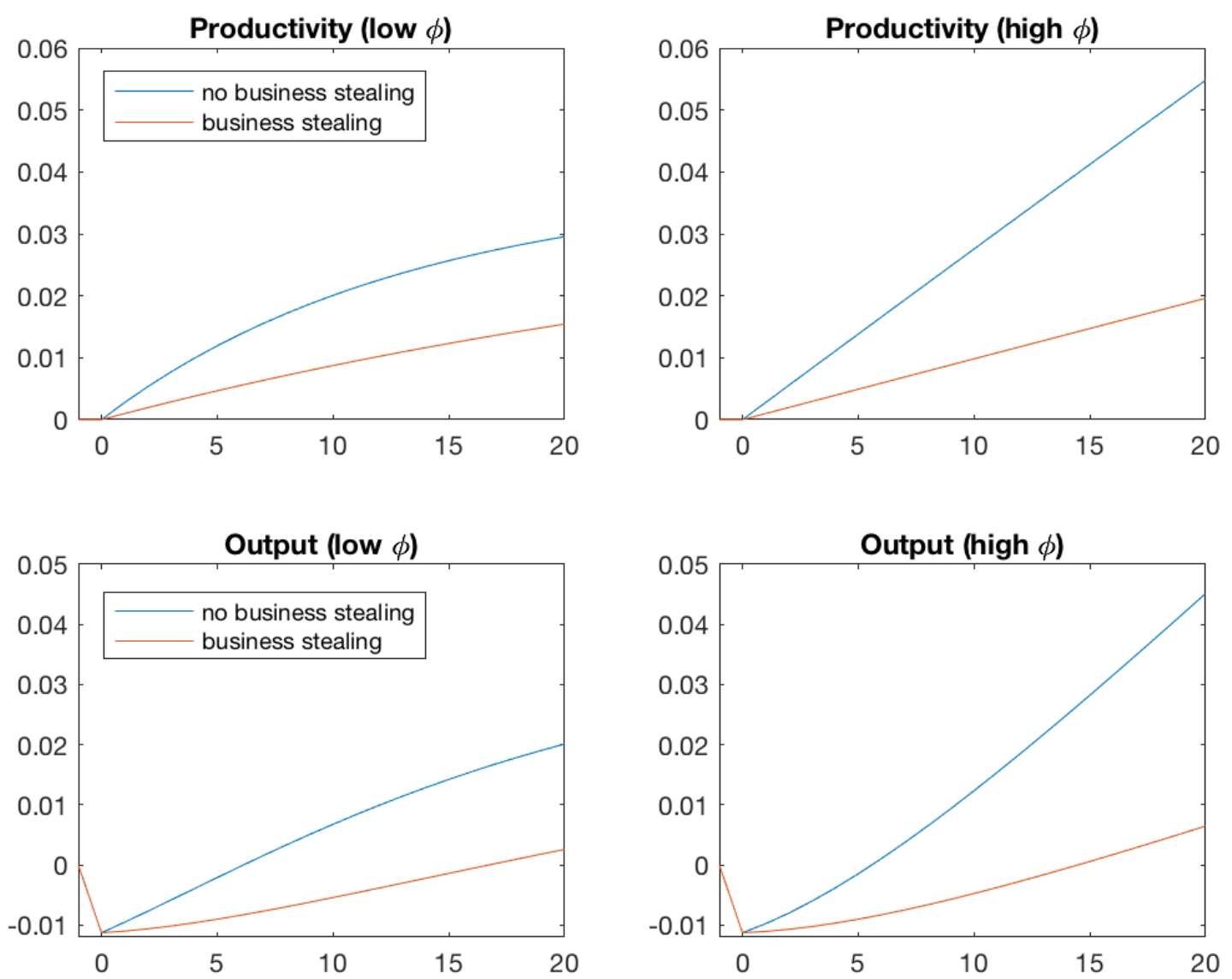

Figure 2: 20-year transition dynamics to a 10\% permanent increase in research labor via proportional innovation policies, nonlinear solution 

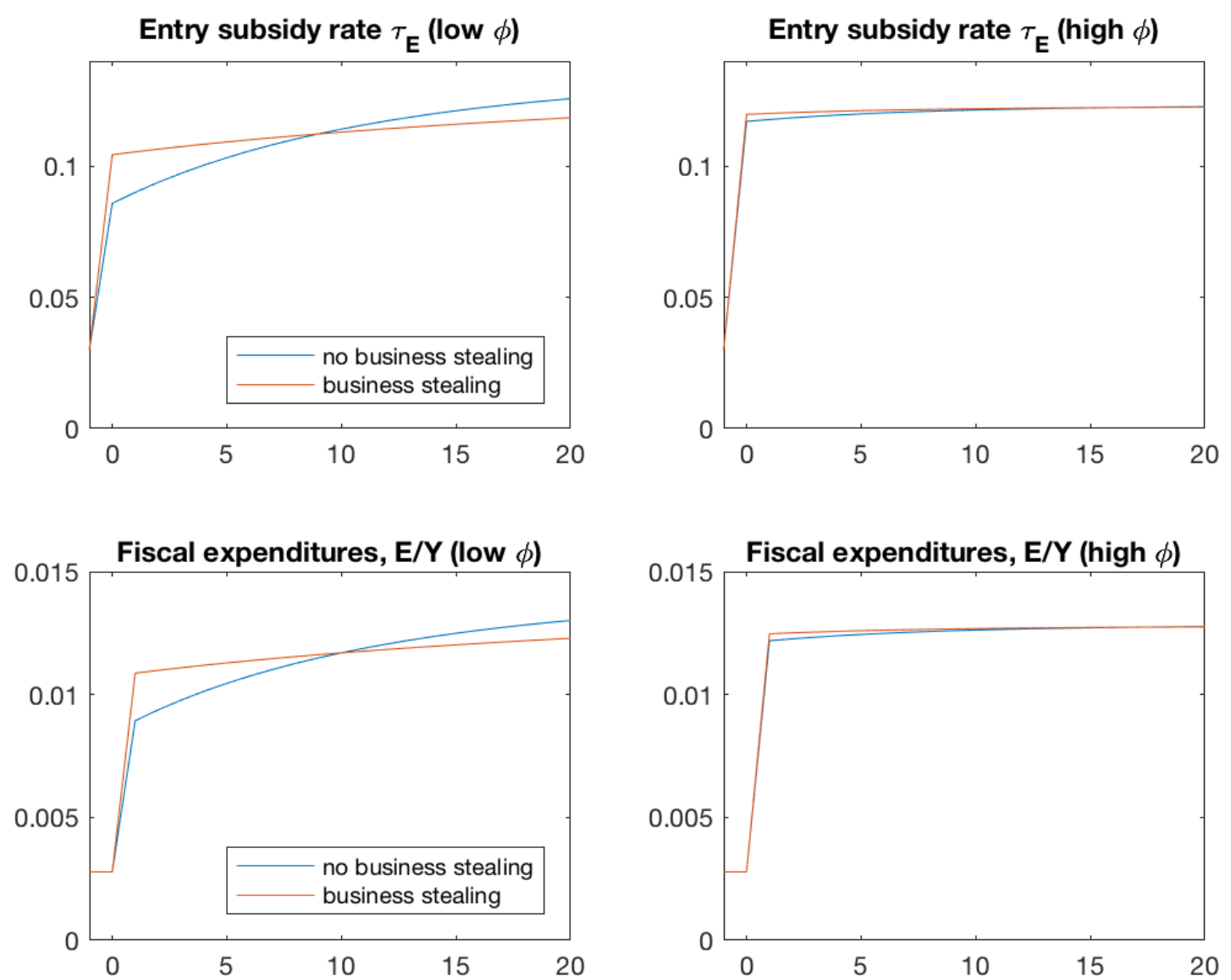

Figure 3: Fiscal expenditures and innovation subsidy rate, 20-year transition dynamics to a $10 \%$ permanent increase in research labor via proportional innovation policies, nonlinear solution 

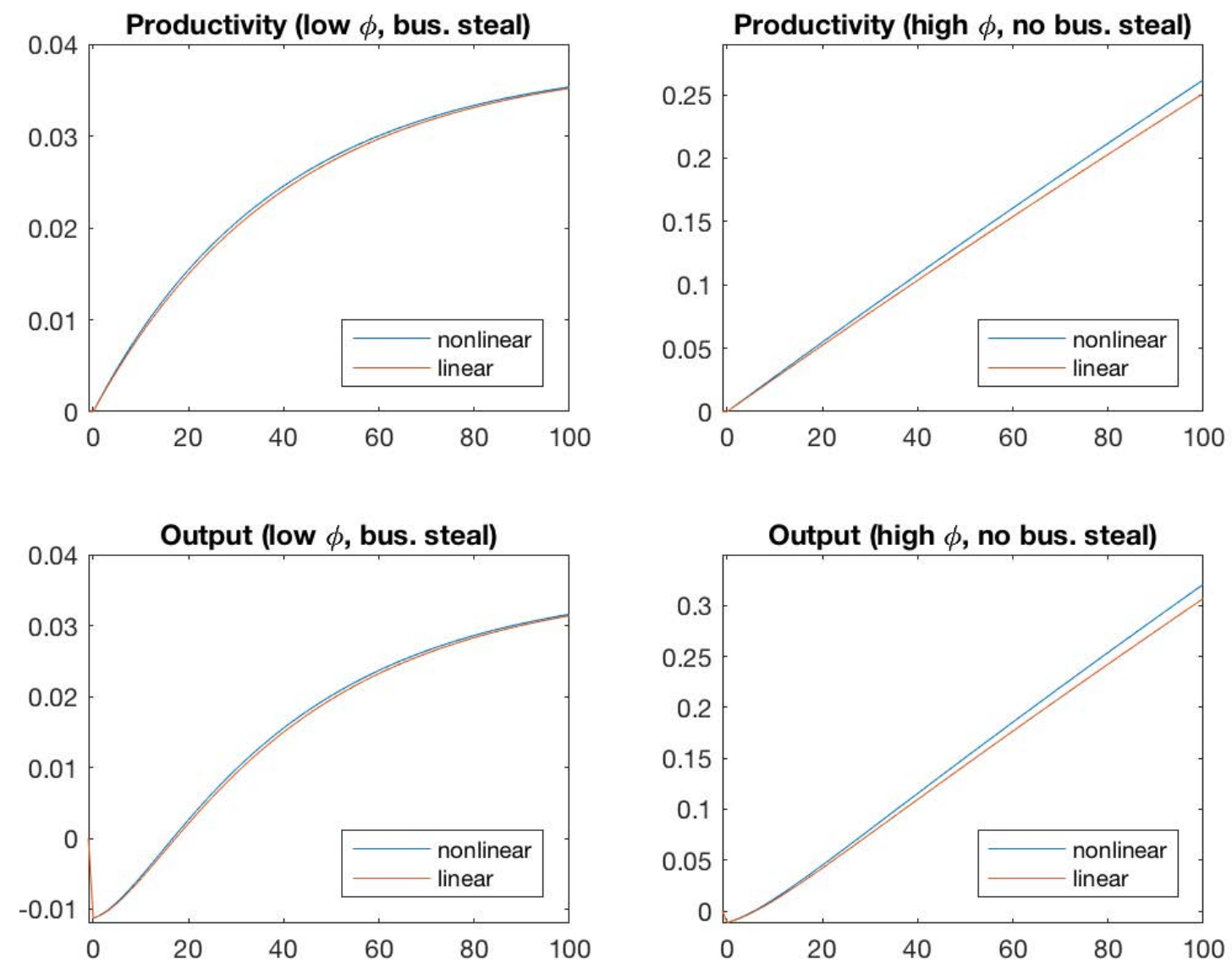

Figure 4: 100-year transition dynamics to a $10 \%$ permanent increase in research labor via proportional innovation policies, nonlinear versus linear solution 

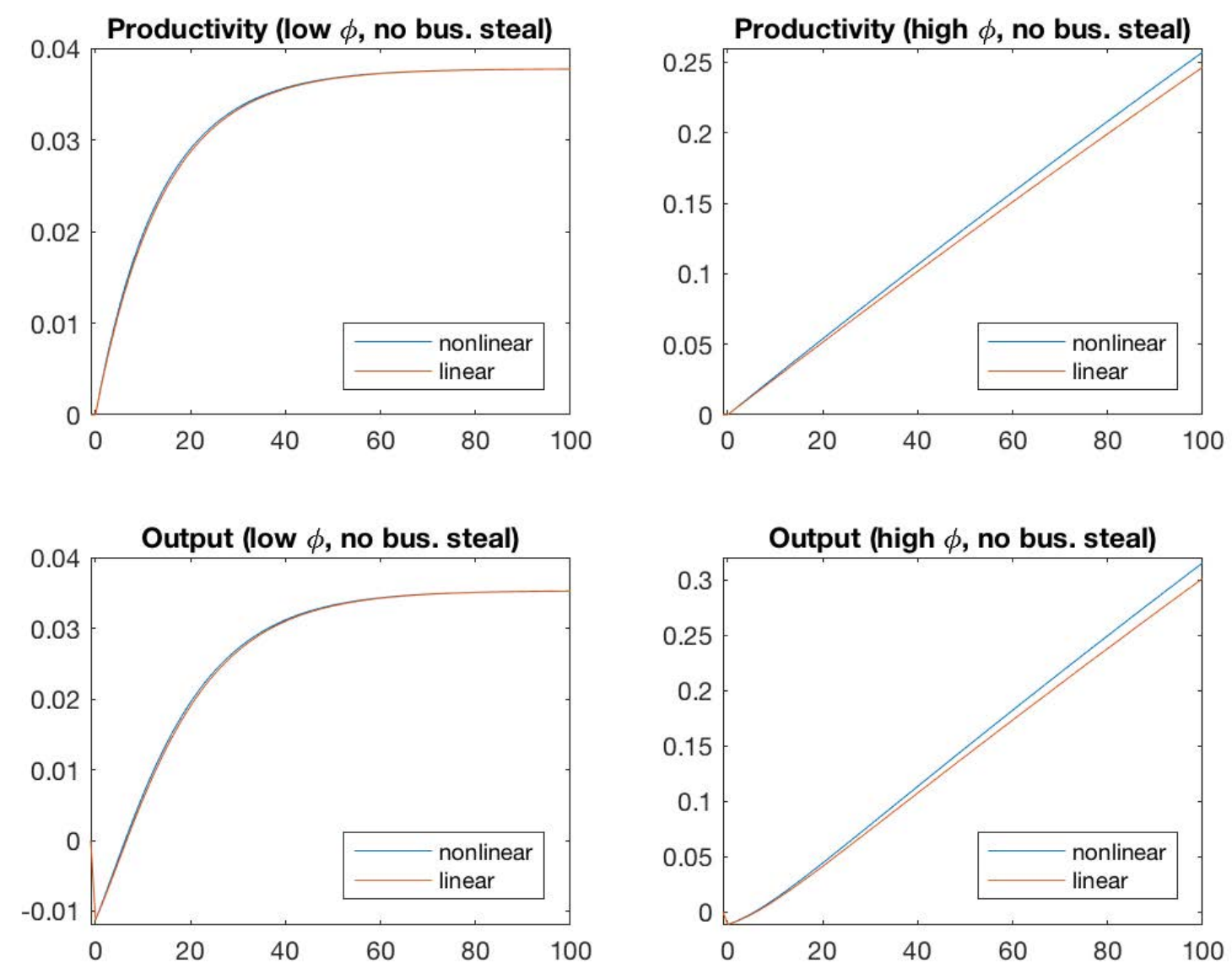

Figure 5: 100-year transition dynamics to a $10 \%$ permanent increase in research labor via nonproportional innovation policies, no business stealing, nonlinear versus linear solution 

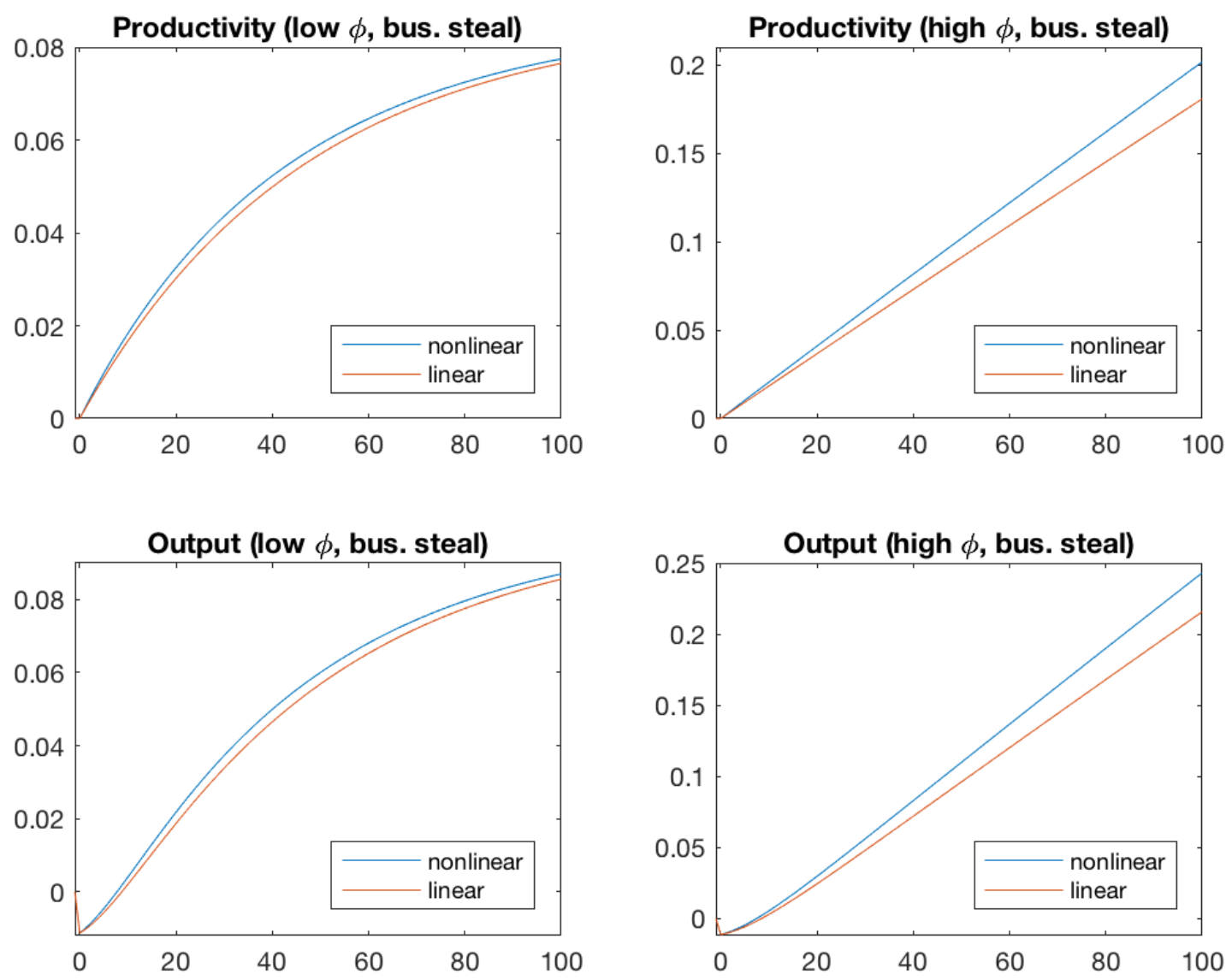

Figure 6: 100-year transition dynamics to a 10\% permanent increase in research labor via nonproportional innovation policies, with business stealing, nonlinear versus linear solution 

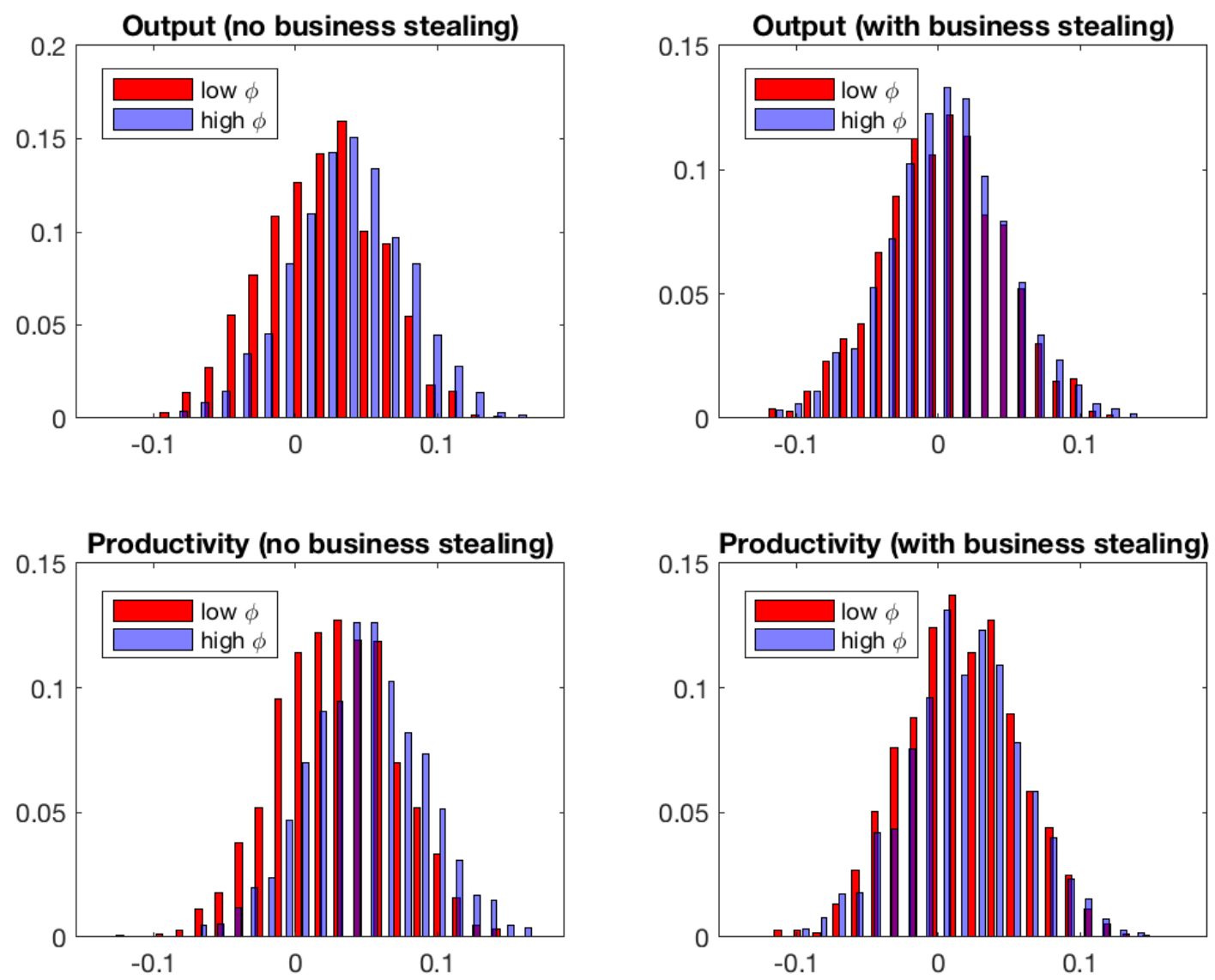

Figure 7: Histogram of 20-year increase in aggregate output and productivity to a permanent $10 \%$ increase in research labor, including productivity shocks

\section{Discussion of models not nested in our framework}

As discussed in Section 4.4, our model nests several influential models in the literature on firms' innovative investments and aggregate growth. In constructing our model, we rely on three key assumptions in deriving our analytical results: (i) the markup $\mu$ is constant across products and time, (ii) the costs and benefits of innovative investments by incumbent firms scale with firm size, and (iii) all incumbent firms share the same technologies for innovative investment. Some recent papers in the literature examine models of firms' investments in innovation in which one or more of these key assumptions do not hold. We discuss some of these alternative model specifications here and the extent to which our results may be applied to these models.

Consider first our assumption that markups $\mu$ are constant across intermediate goods 
and time. We rely on this assumption to derive the formula (6) for aggregate productivity that plays a central role in our derivation of our analytical results. If we consider an alternative model in which both productivity indices $z$ and markups $\mu$ on intermediate goods had support on a grid, and if we let $M_{t}\left(z_{n}, \mu_{j}\right)$ denote the measure of intermediate goods with productivity index $z_{n}$ and markup $\mu_{j}$, then aggregate productivity $Z_{t}$ would be given by

$$
Z_{t}=\frac{\left(\sum_{n} \sum_{j} z_{n}^{\rho-1} \mu_{j}^{1-\rho} M_{t}\left(z_{n}, \mu_{j}\right)\right)^{\rho /(\rho-1)}}{\sum_{n} \sum_{j} z_{n}{ }^{\rho-1} \mu_{j}^{-\rho} M_{t}\left(z_{n}, \mu_{j}\right)} .
$$

In general, then, in a model in which markups vary across intermediate goods, one must keep track of the evolution of the joint distribution of productivity indices $z$ and markups $\mu$ across products to compute the evolution of aggregate productivity. ${ }^{31}$

Peters (2016) presents a model that emphasizes the interaction of firms' investments in innovation and their markups. He introduces a Neo-Schumpeterian model in which incumbent firms invest to improve their own products, and entering and incumbent firms invest to acquire new products. An incumbent firm that innovates on its own product charges a higher markup on its product relative to an entering firm or an incumbent firm acquiring a new product. As a result of this assumption, the joint distribution of markups and productivity indices across products varies over time. Hence, there is no simple ana$\log$ to the equation (28) we derive in Lemma 3 linking aggregate innovative investments by firms and aggregate productivity growth. Instead, one must keep track of the evolution of the measure $M_{t}(z, \mu)$ to compute the dynamics of aggregate productivity implied by his model. Innovation policy interacts with competition policy in that investments in innovation by entrants and incumbent firms seeking to acquire new products have an additional impact on the growth of aggregate productivity that arises from the impact of this type of innovation on the portion of products sold at a low markup.

Consider next our assumption that the costs and benefits of innovative investments scale with firm size. This assumption is key to our derivation of equation (28) in Lemma 3 linking aggregate innovative investments by firms and aggregate productivity growth. Akcigit and Kerr (2010) estimate an alternative model of firms' investments in innovation and firm dynamics in which investments by incumbent firms in acquiring new products do not scale proportionally with firm size. In general, in a model of this kind, one must

\footnotetext{
${ }^{31}$ If the distribution of markups across products is independent of the productivity index of the product and if the marginal distribution of markups is constant over time, then the terms $\sum_{j} \mu_{j}^{1-\rho} M_{t}\left(z_{n}, \mu_{j}\right)$ and $\sum_{j} \mu_{j}^{-\rho} M_{t}\left(z_{n}, \mu_{j}\right)$ do not vary with $z_{n}$ or with $t$. In this case, the formula above for aggregate productivity reduces to our formula (6) times a constant. In this case, we can extend our analytical results to cover a model with markups that vary across intermediate goods.
} 
keep track of the distribution of incumbent firms by size to compute the transition dynamics of aggregate productivity implied by the model. In Appendix E.4, we analyze a version of our model in which investments to acquire new products do not scale up one to one with firm size, but instead scale up with the number of products that the firm has (this specification of our model is nested in the generalized model of Akcigit and Kerr 2010). We discuss the extent to which we can extend our analytical results and measurement procedure to this alternative model.

Finally, consider our assumption that all incumbent firms share the same technologies for innovative investment. Lentz and Mortensen (2008), Lentz and Mortensen (2016), and Luttmer (2011) present examples of a Neo-Schumpeterian model (in the first two papers) and an expanding varieties model (in the third paper) in which different types of incumbent firms have different technologies for innovating. To nest these models in our framework, we would index the parameter $\eta_{m}$ and the functions $h(\cdot)$ and $\zeta(\cdot)$ characterizing the investment technologies for incumbent firms to acquire new products and to improve their own products respectively by a firm "type" $i$. The evolution of aggregate productivity in these models is then a function of the measure of intermediate goods produced by firms of each type together with the aggregate investments $x_{m}^{i}$ and $x_{c}^{i}$ of incumbent firms of each type. To compute the transition dynamics of aggregate productivity implied by these models, one would have to keep track of the evolution of the distribution of intermediate goods produced by each type of firm.

\section{E Variations of baseline model}

\section{E.1 Occupation choice}

Suppose that workers each period draw a productivity $a$ to work in the research sector, where $a$ is drawn from a cumulative distribution function $F(a)$ that is Pareto with minimum 1 and slope coefficient $\chi>1$. There are two wages, $W_{p t}$ and $W_{r t}$. For the marginal agent,

$$
\bar{a}_{t} W_{r t}=W_{p t} .
$$

Given that the minimum value of $a$ is 1 , any interior equilibrium with positive production requires $W_{r t} \leq W_{p t}$. The aggregate supplies of production and research labor (relative to the total labor force, which grows exogenously) are

$$
l_{p t}=F\left(\bar{a}_{t}\right)=1-\bar{a}_{t}^{-\chi}
$$




$$
l_{r t}=\int_{\bar{a}_{t}}^{\infty} a f(a) d a=\frac{\chi}{\chi-1} \bar{a}_{t}^{1-\chi}
$$

The ratio of labor $l_{r t} / l_{p t}$ and the ratio of wages $W_{r t} / W_{p t}$ are determined by

$$
\begin{gathered}
\frac{W_{r t} l_{r t}}{W_{p t} l_{p t}}=\frac{\mu}{(1-\alpha)} i_{r t} \\
\frac{l_{r t}}{l_{p t}}=\frac{\chi}{\chi-1} \frac{\left(\frac{W_{p t}}{W_{r t}}\right)^{1-\chi}}{1-\left(\frac{W_{p t}}{W_{r t}}\right)^{-\chi}} .
\end{gathered}
$$

These two equations replace equation (13) in our baseline model to solve for $l_{r t} / l_{p t}$ as a function of $i_{r t}$. Note that as $\chi$ goes to infinity, $W_{r t} / W_{p t}$ must converge to 1 in order for $l_{r t} / l_{p t}$ to be finite. The elasticity of $l_{r t}$ with respect to $i_{r t}$ is

$$
\left(\log l_{r t}^{\prime}-\log \bar{l}_{r}\right)=\frac{(\chi-1)}{(\chi-1)\left(1+\frac{\bar{W}_{r} \bar{l}_{r}}{\bar{W}_{p} \bar{l}_{p}}\right)+1}\left(\log i_{r t}^{\prime}-\log \bar{i}_{r}\right)
$$

When $\chi$ converges to 1 (high worker heterogeneity), the elasticity of $l_{r t}$ with respect to $i_{r t}$ converges to 0 . When $\chi$ converges to infinity (no worker heterogeneity), this elasticity converges to $\bar{l}_{p}$, as in our baseline model.

\section{E.2 Goods and labor used as inputs in research}

We consider an extension in which research production uses both labor and the consumption good, as in the lab-equipment model of Rivera-Batiz and Romer (1991), and discuss the central changes to our analytic results. Specifically, the production of the research good is given by

$$
Y_{r t}=A_{r t} Z_{t}^{\phi-1} L_{r t}^{\lambda} X_{t}^{1-\lambda}
$$

and the resource constraint of the final consumption good is

$$
C_{t}+K_{t+1}-\left(1-d_{k}\right) K_{t}+X_{t}=Y_{t}
$$

Given this production technology, the BGP growth rate of aggregate productivity is given by $\bar{g}_{Z}=\frac{\bar{g}_{A_{r}}+\bar{g}_{L}}{1-\tilde{\phi}}$, where $\tilde{\phi}=\phi+\frac{1-\lambda}{1-\alpha}$. The condition for semi-endogenous growth is $\tilde{\phi}<1$ (equality for endogenous growth). 
Revenues from the production of the research good are divided as follows:

$$
W_{t} L_{r t}=\lambda P_{r t} Y_{r t}, \text { and } X_{t}=(1-\lambda) P_{r t} Y_{r t} .
$$

The analog to equation (13), relating the allocation of labor between production and research to the innovation intensity, is

$$
l_{r t}=\frac{i_{r t}}{i_{r t}+\frac{(1-\alpha)}{\mu \lambda}} \text { and } l_{p t}=1-l_{r t}
$$

where $i_{r t} \equiv P_{r t} Y_{r t} /\left(\left(1+\tau_{y}\right) Y_{t}\right)$. Our analytical results need to be modified for two reasons. First, for a given share of production labor in output $(1-\alpha) / \mu$, the elasticity of research labor $l_{r t}$ with respect to the innovation intensity of the economy $i_{r t}$ is decreasing in $\lambda$. A higher share of goods in production of the research good (lower $\lambda$ ) increases the sensitivity of $l_{r t}$ with respect to $i_{r t}$.

Second, by equations (5), (106), (107), and $R_{k t}=\left(1+\tau_{y}\right) \frac{\alpha}{\mu} \frac{Y_{t}}{K_{t}}$, we have

$$
Y_{r t}=\kappa A_{r t} Z_{t}^{\tilde{\phi}-1}\left(\frac{K_{t}}{Y_{t}}\right)^{\frac{\alpha(1-\lambda)}{1-\alpha}} L_{r t}
$$

where $\kappa$ is a constant, so

$\log Y_{r t}^{\prime}-\log \bar{Y}_{r}=\left(\log l_{r t}^{\prime}-\log \bar{l}_{r}\right)-(1-\tilde{\phi})\left(\log Z_{t}^{\prime}-\log \bar{Z}_{t}\right)-\frac{(1-\lambda) \alpha}{1-\alpha}\left(\log R_{k t}^{\prime}-\log \bar{R}_{k}\right)$.

Long-run changes in aggregate productivity are given as in equation (14) in Proposition 1 where $\tilde{\phi}$ replaces $\phi$. A lower value of $\lambda$ increases $\tilde{\phi}$ and the associated long-term productivity gains from a given increase in research labor. Following the same steps as in the proof of Proposition 2, we obtain the analog of equation (17) for the new path for aggregate productivity, up to a first-order approximation:

$$
\log Z_{t+1}^{\prime}-\log \bar{Z}_{t+1} \approx \sum_{j=0}^{t}\left[\Gamma_{j}\left(\log l_{r t-j}^{\prime}-\log \bar{l}_{r}\right)-\frac{(1-\lambda) \alpha}{1-\alpha}\left(\log R_{k j}^{\prime}-\log \bar{R}_{k}\right)\right],
$$

where the decay coefficients are given as in equation (18) with $\tilde{\phi}$ replacing $\phi$. The second term on the right-hand side reflects the change in research output $Y_{r t}$ that results when $\lambda<1$ from changes in the capital-output ratio. This second term is equal to zero once the economy converges to the new long-run BGP. The dynamics of aggregate output are given as in Corollary 1. 


\section{E.3 Klette and Kortum (2004) specification}

Here we briefly describe our analytic results in a version of our model that follows Klette and Kortum (2004) more closely in assuming a unitary elasticity of substitution between intermediate goods, $\rho=1$. With $\rho=1$, we abstract from growth in the measure of intermediate goods and from innovation by incumbents to improve their own goods.

Specifically, every product that is new to an incumbent firm or an entrant firm is stolen from another incumbent firm (that is, $\delta_{m}=\delta_{e}=1$ ). We normalize the constant total measure of products to $1, M_{t}=1$. Output of the final good is

$$
\log Y_{t}=\sum_{z} \log \left(y_{t}(z)\right) M_{t}(z)
$$

For each intermediate good, the markup is fixed at $\mu$ (determined by the productivity distance between the incumbent producer and a latent competitor). The size of each product (in terms of revenues or input use relative to the total) is $s_{t}(z)=1 / M_{t}=1$. Substituting the production function (3) into equation (109), and given that the ratio of physical capital to production labor is independent of $z$, aggregate output in equilibrium is

$$
Y_{t}=Z_{t}\left(K_{t}\right)^{\alpha}\left(L_{p t}\right)^{1-\alpha}
$$

where

$$
Z_{t}=\exp \left(\sum_{z} z M_{t}(z)\right)
$$

With constant markups, variable profits of each product are given by $\frac{\mu-1}{\mu}\left(1+\tau_{y}\right) Y_{t}$. Given that variable profits are independent of $z$, firms have no incentive to use the technology $\zeta($.$) to invest in improvements of the products they own. Without loss of gener-$ ality, we set $x_{c t}=0$ and $\zeta(0)=1$.

An incumbent firm that owns the right to produce a product with productivity $z$ possesses the technology to acquire new goods by investing $x_{m t}(z)$ units of the research good to displace with probability $h\left(x_{m t}(z)\right)$ a product drawn at random from the entire distribution and start producing at $t+1$ with a productivity index $z^{\prime}$ that is a step $\Delta_{s}>0$ higher than the stolen product. ${ }^{32}$ Similarly, entrants can invest 1 unit of the research good

\footnotetext{
${ }^{32}$ Klette and Kortum (2004) consider an extension of their model in which firms differ permanently in terms of the size of their step sizes (and markups) on the products they own. With $\rho=1$, markup heterogeneity does not affect aggregate productivity. Since the cost of innovation also scales up with step size (or equivalently, the probability of success falls with step size), all firms choose the same innovation investment per product.
} 
to displace and improve by $\Delta_{S}$ a product drawn randomly from the entire distribution. ${ }^{33}$

We conjecture (and verify below) that incumbents' investments are independent of $z$, so $x_{m t}(z)=x_{m t}$. A firm that owns the rights to produce $n$ products at time $t$ invests a total of $x_{m t} \times n$ units of the research to acquire in expectation $h\left(x_{m t}\right) \times n$ new products (the expectation of a binomial distribution with parameters $h\left(x_{m t}\right)$ and $n$ ). Note that this innovative technology for incumbents can be equivalently described (as in Klette and Kortum 2004) as an investment of $c\left(I_{t} / n\right) \times n$ to acquire $I_{t} \times n$ products in expectation, where $c(\cdot)$ is increasing and convex. To map these two technologies, we set $I_{t}=h\left(x_{m t}\right)$ and $c\left(I_{t} / n\right)=x_{m t}$.

The measure of incumbent products that are displaced and improved is $h\left(x_{m t}\right) \times 1+$ $x_{e t}$, and the $G$ function mapping aggregate investment levels to productivity growth is

$$
G\left(x_{m t}, x_{e t}\right)=\left(h\left(x_{m t}\right)+x_{e t}\right) \Delta_{s}
$$

Impact elasticities are

$$
\begin{gathered}
\Theta_{m} \equiv G_{m}\left(\bar{x}_{m}, \bar{x}_{e}\right) \bar{Y}_{r}=h^{\prime}\left(\bar{x}_{m}\right) \Delta_{s} \bar{Y}_{r} \\
\Theta_{e} \equiv G_{e}\left(\bar{x}_{m}, \bar{x}_{e}\right) \bar{Y}_{r}=\Delta_{s} \bar{Y}_{r} .
\end{gathered}
$$

Note that $\Theta_{e}$ can also be written as

$$
\Theta_{e}=\Delta_{s} \bar{x}_{e} \frac{\bar{Y}_{r}}{\bar{x}_{e}}=\left(\bar{g}_{Z}-G\left(\bar{x}_{m}, 0\right)\right) \frac{\bar{Y}_{r}}{\bar{x}_{e}}
$$

which corresponds to the upper bound in equation (37). If the equilibrium allocation of innovative investment is conditionally efficient (i.e., $h^{\prime}\left(\bar{x}_{m}\right)=1$, so that $\Theta_{m}=\Theta_{e}$ ), then the impact elasticity $\Theta$ (for any perturbation to $x_{m t}$ and $x_{e t}$ ) has an upper bound as given in equation (26) with $G(0)=0$. Hence, $\Theta \leq \bar{g}_{Z}$.

The value of a firm that owns the rights to produce $n$ products (independently of their productivity) is equal to $V_{t} n$, with

$$
V_{t}=\max _{x_{m} \geq 0} \frac{\mu-1}{\mu}\left(1+\tau_{y}\right) Y_{t}-\left(1-\tau_{m t}\right) P_{r t} x_{m}+\frac{1}{1+R_{t}}\left(1-\delta_{c t}+h\left(x_{m}\right)\right) V_{t+1},
$$

where the displacement probability of each product, $\delta_{c t}$, is taken as given by the firm and, in equilibrium, is equal to $\delta_{c t}=h\left(x_{m t}\right)+x_{e t}$. The first-order condition of this profit

\footnotetext{
${ }^{33}$ In our baseline model, we have assumed that innovations associated with product $z$ displace other products with productivity $z$, whereas here (as well as in Klette and Kortum 2004) we have assumed that displaced products are drawn randomly from the entire distribution (see also Appendix E.4). When $\rho=1$, these two assumptions have identical aggregate implications since size is independent of $z$.
} 
maximization implies that $x_{m t}(z)=x_{m t}$ with

$$
\left(1-\tau_{m t}\right) P_{r t} \geq \frac{1}{1+R_{t}} h^{\prime}\left(x_{m t}\right) V_{t+1}
$$

confirming that $x_{m t}$ is independent of $z$. The free entry condition is

$$
\left(1-\tau_{e t}\right) P_{r t} \geq \frac{1}{1+R_{t}} V_{t+1}
$$

The equilibrium allocation of innovative investment is conditionally efficient $\left(h^{\prime}\left(\bar{x}_{m}\right)=\right.$ 1) if and only if innovation policies are uniform $\left(\tau_{m t}=\tau_{e t}\right)$.

Finally, we show how we can measure $\frac{\bar{P}_{r t} \bar{x}_{e}}{\left(1+\tau_{y}\right) \bar{Y}_{t}}$, which is required to calculate $\Theta_{e}$ in equation (110). Defining $v_{t}=V_{t} /\left(\left(1+\tau_{y}\right) Y_{t}\right)$ and using the fact that, with $\rho=1$ and $g_{M t}=0, s_{e t+1}=f_{e t+1}=x_{e t}$, we have from equation (113),

$$
\frac{\bar{P}_{r t} \bar{x}_{e}}{\left(1+\tau_{y}\right) \bar{Y}_{t}}=\frac{\exp \left(\bar{g}_{Y}\right)}{1+\bar{R}} \frac{\bar{v} \bar{s}_{e}}{\left(1-\tau_{e}\right)}
$$

where by equation (111),

$$
\bar{v}=\frac{\left[\frac{\mu-1}{\mu}-\left(1-\bar{\tau}_{m}\right) \frac{\bar{P}_{r t} \bar{x}_{m}}{\left(1+\tau_{y}\right) \bar{Y}_{t}}\right]}{1-\frac{\exp \left(\bar{g}_{Y}\right)}{1+\bar{R}}\left(1-\bar{s}_{e}\right)},
$$

which is analogous to equation (90) in the baseline model.

\section{E.4 Alternative specification of incumbent technology to acquire new products}

In this section, we consider a specification of the investment technology for incumbent firms to acquire new products (which is nested in the generalized model of Akcigit and Kerr 2010) in which investments to acquire new products do not scale up one to one with firm size, but instead scale up with the number of products that the firm has. These two specifications are equivalent when $\rho=1$, as discussed in Section E.3.

We assume that a firm with a product with productivity $z$ has a technology to acquire a new product with probability $h\left(x_{m t}(z) M_{t}\right)$ (as opposed to $h\left(x_{m t}(z) / s_{t}(z)\right)$ in our baseline model). With probability $\delta_{m}$ it displaces a product drawn at random from the entire distribution (as opposed to displacing a product with productivity $z$ ), so that the displaced product has productivity index $z$ at time $t$ with $\mathbb{E} z^{\rho-1}=Z_{t}^{\rho-1} / M_{t}$. The 
incumbent firm that stole this product can produce it at $t+1$ with a new productivity index $z^{\prime}$ such that the expected value of the term $z^{\prime \rho-1}$ is equal to $\mathbb{E} z^{\prime \rho-1}=\eta_{m s} Z_{t}^{\rho-1} / M_{t}$ (instead of $\eta_{m s} z^{\rho-1}$ in the baseline model), with $\eta_{m s}>1$. With complementary probability $1-\delta_{m}$ the newly acquired product is new to society, with productivity index $z^{\prime}$ drawn from a distribution such that the expected value of the term $z^{\prime \rho-1}$ is equal to $\mathbb{E} z^{\prime \rho-1}=\eta_{m n} Z_{t}^{\rho-1} / M_{t}$ (instead of $\eta_{m n} z^{\rho-1}$ in the baseline model), with $\eta_{m n}>0$. We define $\eta_{m}=\delta_{m} \eta_{m s}+\left(1-\delta_{m}\right) \eta_{m n}$. The investment technologies of entrants and of incumbent firms to improve continuing products remain unchanged.

We conjecture (and verify below) that the level of investment by incumbent firms in acquiring new products is independent of the productivity index $z$ of the product with which this investment is associated. So, $x_{m t}(z)=x_{m t} / M_{t}$ (instead of $x_{m t}(z)=s_{t}(z) x_{m t}$ in the baseline model). We also conjecture that investments by incumbent firms in improving their continuing products scale up with the size of the product with which this investment is associated, as in the baseline model. With $x_{m t}(z)=x_{m t} / M_{t}$ and $x_{c t}(z)=$ $x_{c t} s_{t}(z)$, a firm that owns the right to produce $n$ products with productivities $\left\{z_{1}, \ldots, z_{n}\right\}$ has size $s_{t}=\sum_{i=1}^{n} s_{t}\left(z_{i}\right)$ and spends a total $r_{t}=s_{t}\left(x_{c t}+\frac{x_{m t}}{M} \frac{n}{s_{t}}\right)$ on the research good. Assuming a positive cross-firm correlation between firm size $s_{t}$ and average product size $s_{t} / n$, this alternative specification generates a negative correlation between firm size $s_{t}$ and innovation intensity $\frac{r_{t}}{s_{t}}=x_{c t}+\frac{x_{m t}}{M} \frac{n}{s_{t}}$. Similarly, since small firms have products with a lower average $z$, their investments in acquiring new products produce mean reversion in the average value of $z$ (since the new $z$ 's they acquire are drawn from the entire distribution and not from products with productivity $z$ as in the baseline model), implying higher growth relative to firms with a higher average value of $z{ }^{34}$ In what follows, we discuss how our analytic results are affected under the modified technology.

Incumbent firms acquire in the aggregate a measure $h\left(x_{m t}\right) M_{t}$ new products - a measure $\delta_{m} h\left(x_{m t}\right) M_{t}$ are stolen from other incumbent firms and complementary measure $\left(1-\delta_{m}\right) h\left(x_{m t}\right) M_{t}$ are new to society. The average value of $z^{\prime \rho-1}$ across all newly acquired products in incumbent firms at $t+1$ is $\eta_{m} \frac{Z_{t}^{\rho-1}}{M_{t}}$. With $x_{c t}(z)=s_{t}(z) x_{c t}$, and following the logic of the proof of Lemma 3, we obtain the same law of motion for aggregate productivity (28) and resource constraint of the research good (27) as in our baseline model. Therefore, $\Theta_{c}, \Theta_{m}$ and $\Theta_{e}$ are given as in equations (66)-(68) as well as equation (36) in

\footnotetext{
${ }^{34}$ To match the quantitative magnitude of these effects, Akcigit and Kerr (2010) argue that investments by incumbent firms to acquire new products scale moderately slower than the number of products in the firm. As a result, the relationship between aggregate productivity growth and aggregate innovative investment in their estimated model is a function of the firm size distribution. Thus, in order to assess the impact of innovation policies on the dynamics of aggregate productivity, one would have to solve their model fully numerically.
} 
our baseline model.

We now verify our conjecture that in equilibrium, firms choose $x_{m t}(z)=x_{m t} / M_{t}$ and $x_{c t}(z)=s_{t}(z) x_{c t}$. Under this conjecture, the value of a continuing product with productivity index $z$ for an incumbent firm is given by $V_{t}(z)+U_{t}$ where $V_{t}(z)$ denotes the discounted present value for an incumbent firm of the dividends associated with a product with productivity $z$ at time $t$, and $U_{t}$ denotes the value for an incumbent firm of this product in facilitating further acquisition of products (which, in contrast to our baseline model, is independent of $z$ ). The value of a firm that owns the technology to produce $n$ products with productivities $\left\{z_{1}, \ldots, z_{n}\right\}$ is equal to

$$
V_{t}(z) \sum_{i=1}^{n} s_{t}\left(z_{i}\right)+U_{t} n
$$

Specifically, $V_{t}(z)=s_{t}(z) V_{t}$ with

$$
V_{t}=\max _{x_{c} \geq 0}\left(1+\tau_{y}\right) \frac{\mu-1}{\mu} Y_{t}-\left(1-\tau_{c t}\right) P_{r t} x_{c}+\frac{1}{1+R_{t}} V_{t+1}\left(1-\delta_{c t}\right) \zeta\left(x_{c}\right) \frac{Z_{t}^{\rho-1}}{Z_{t+1}^{\rho-1}}
$$

and

$U_{t}=\max _{x_{m} \geq 0}-\left(1-\tau_{m t}\right) P_{r t} x_{m}+\frac{1}{1+R_{t}}\left(h\left(x_{m} M_{t}\right) V_{t+1} \eta_{m} \frac{Z_{t}^{\rho-1}}{M_{t} Z_{t+1}^{\rho-1}}+\left(1-\delta_{c t}+h\left(x_{m} M_{t}\right)\right) U_{t+1}\right)$

The first-order condition of the incumbent firm's profit maximization problem (114) with respect to $x_{c}$ implies that $x_{c t}(z)=s_{t}(z) x_{c t}$ with

$$
\left(1-\tau_{c t}\right) P_{r t} \geq \frac{1}{1+R_{t}} V_{t+1}\left(1-\delta_{c t}\right) \zeta^{\prime}\left(x_{c t}\right) \frac{Z_{t}^{\rho-1}}{Z_{t+1}^{\rho-1}}
$$

and the first-order condition of the incumbent firm's profit maximization problem (115) with respect to $x_{m}$ implies that $x_{m t}(z)=x_{m t} / M_{t}$ with

$$
\left(1-\tau_{m t}\right) P_{r t} \geq \frac{1}{1+R_{t}} h^{\prime}\left(x_{m t}\right)\left(V_{t+1} \eta_{m} \frac{Z_{t}^{\rho-1}}{Z_{t+1}^{\rho-1}}+U_{t+1} M_{t}\right)
$$

The free entry condition is

$$
\left(1-\tau_{e t}\right) P_{r t} \geq \frac{1}{1+R_{t}}\left(V_{t+1} \eta_{e} \frac{Z_{t}^{\rho-1}}{Z_{t+1}^{\rho-1}}+U_{t+1} M_{t}\right)
$$


These first-order conditions are equalities if $x_{c t}, x_{m t}>0$.

Defining $v_{t}=V_{t} /\left(\left(1+\tau_{y}\right) Y_{t}\right)$ and $u_{t}=U_{t} M_{t} /\left(\left(1+\tau_{y}\right) Y_{t}\right)$, and assuming an interior equilibrium, we can rewrite this system of equations as

$$
\begin{gathered}
\frac{\left(1-\tau_{c t}\right) P_{r t}}{\left(1-\tau_{y}\right) Y_{t}}=\frac{Y_{t+1} / Y_{t}}{1+R_{t}} v_{t+1}\left(1-\delta_{c t}\right) \zeta^{\prime}\left(x_{c t}\right) \frac{Z_{t}^{\rho-1}}{Z_{t+1}^{\rho-1}} \\
\frac{\left(1-\tau_{m t}\right) P_{r t}}{\left(1-\tau_{y}\right) Y_{t}}=\frac{Y_{t+1} / Y_{t}}{1+R_{t}} h^{\prime}\left(x_{m t}\right)\left(v_{t+1} \eta_{m} \frac{Z_{t}^{\rho-1}}{Z_{t+1}^{\rho-1}}+u_{t+1} \frac{M_{t}}{M_{t+1}}\right) \\
\frac{\left(1-\tau_{e t}\right) P_{r t}}{\left(1-\tau_{y}\right) Y_{t}}=\frac{Y_{t+1} / Y_{t}}{1+R_{t}}\left(v_{t+1} \eta_{e} \frac{Z_{t}^{\rho-1}}{Z_{t+1}^{\rho-1}}+u_{t+1} \frac{M_{t}}{M_{t+1}}\right) \\
v_{t}=\frac{\mu-1}{\mu}-\frac{\left(1-\tau_{c t}\right) P_{r t} x_{c t}}{\left(1-\tau_{y}\right) Y_{t}}+\frac{Y_{t+1} / Y_{t}}{1+R_{t}} v_{t+1}\left(1-\delta_{c t}\right) \zeta\left(x_{c t}\right) \frac{Z_{t}^{\rho-1}}{Z_{t+1}^{\rho-1}} \\
u_{t}=-\frac{\left(1-\tau_{m t}\right) P_{r t} x_{m t}}{\left(1+\tau_{y}\right) Y_{t}}+\frac{Y_{t+1} / Y_{t}}{1+R_{t}}\left(h\left(x_{m t}\right) v_{t+1} \eta_{m} \frac{Z_{t}^{\rho-1}}{Z_{t+1}^{\rho-1}}+\left(1-\delta_{c t}+h\left(x_{m t}\right)\right) u_{t+1} \frac{M_{t}}{M_{t+1}}\right)
\end{gathered}
$$

Recall that in the baseline model, if new innovation policies satisfy condition (32), for a given value of $Y_{r t}$ we are able to solve for $x_{c t}, x_{m t}$, and $x_{e t}$ as a static system of equations using equations (64), (65), and the resource constraint (27). In contrast, in this alternative model specification, we must also solve for $v_{t+1}$ and $u_{t+1}$, unless $x_{c t}$ is fixed exogenously $\left(x_{c t}=\bar{x}_{c}\right)$ and $\eta_{m}=\eta_{e}$. In this case, $x_{m t}$ and $x_{e t}$ can be solved using the two following static equations:

$$
\frac{1-\tau_{m t}}{1-\tau_{e t}}=h^{\prime}\left(x_{m t}\right) \text { and } \bar{x}_{c}+x_{m t}+x_{e t}=Y_{r t},
$$

without requiring to solve for $v_{t+1}$ and $u_{t+1}$.

In the BGP, $x_{c t}=\bar{x}_{c}, x_{m t}=\bar{x}_{m}, x_{e t}=\bar{x}_{e}, v_{t}=\bar{v}$, and $u_{t}=\bar{u}$. The first-order conditions (119), (121) in the BGP are

$$
\begin{gathered}
\frac{\left(1-\tau_{c}\right) \bar{P}_{r t}}{\left(1+\tau_{y}\right) \bar{Y}_{t}}=\frac{\exp \left(\bar{g}_{Y}-(\rho-1) \bar{g}_{Z}\right)}{1+\bar{R}} \bar{v}\left(1-\bar{\delta}_{c}\right) \zeta^{\prime}\left(\bar{x}_{c}\right) \\
\frac{\left(1-\tau_{m}\right) \bar{P}_{r t}}{\left(1+\tau_{y}\right) \bar{Y}_{t}}=\frac{\exp \left(\bar{g}_{Y}-(\rho-1) \bar{g}_{Z}\right)}{1+\bar{R}} h^{\prime}\left(\bar{x}_{m}\right)\left(\bar{v} \eta_{m}+\bar{u} \exp \left((\rho-1) \bar{g}_{Z}-\bar{g}_{M}\right)\right) \\
\frac{\left(1-\tau_{e}\right) \bar{P}_{r t}}{\left(1+\tau_{y}\right) \bar{Y}_{t}}=\frac{\exp \left(\bar{g}_{Y}-(\rho-1) \bar{g}_{Z}\right)}{1+\bar{R}}\left(\bar{v} \eta_{e}+\bar{u} \exp \left((\rho-1) \bar{g}_{Z}-\bar{g}_{M}\right)\right),
\end{gathered}
$$


where $\bar{v}$ and $\bar{u}$ satisfy

$$
\begin{gathered}
\bar{v}=\frac{\mu-1}{\mu}-\frac{\left(1-\tau_{c}\right) \bar{P}_{r t}}{\left(1+\tau_{y}\right) \bar{Y}_{t}}+\frac{\exp \left(\bar{g}_{Y}-(\rho-1) \bar{g}_{Z}\right)}{1+\bar{R}} \bar{v}\left(1-\bar{\delta}_{c}\right) \zeta\left(\bar{x}_{c}\right) \\
\bar{u}=-\frac{\left(1-\tau_{m}\right) \bar{P}_{r t}}{\left(1+\tau_{y}\right) \bar{Y}_{t}} \bar{x}_{m}+\frac{\exp \left(\bar{g} Y-(\rho-1) \bar{g}_{Z}\right)}{1+\bar{R}}\left(h\left(x_{m t}\right) \eta_{m} \bar{v}+\left(1-\bar{\delta}_{c}+h\left(\bar{x}_{m}\right)\right) \bar{u} \exp \left((\rho-1) \bar{g}_{Z}-\bar{g}_{M}\right)\right) .
\end{gathered}
$$

In equilibrium, it must be that $\bar{v} \geq 0$ and $\bar{u} \geq 0$.

Using equations (122), (123), and (124), $\Theta_{c}, \Theta_{m}$ and $\Theta_{e}$ can be expressed as

$$
\begin{gathered}
\Theta_{c}=\left[\frac{1-\tau_{c}}{\rho-1}\right]\left[\frac{1+\bar{R}}{\exp \left(\bar{g}_{Y}\right)}\right] \frac{\bar{i}_{r}}{\bar{v}} \\
\Theta_{m}=\left[\frac{1-\tau_{m}}{\rho-1}\right]\left[1-\delta_{m} \frac{\zeta\left(\bar{x}_{c}\right)}{\eta_{m}}\right]\left[\frac{1+\bar{R}}{\exp \left(\bar{g}_{Y}\right)}\right] \frac{\bar{i}_{r}}{\bar{v}} \frac{1}{\left[1+\frac{\bar{u}}{\bar{v} \eta_{m}} \exp \left((\rho-1) \bar{g}_{Z}-\bar{g}_{M}\right)\right]} \\
\Theta_{e}=\left[\frac{1-\tau_{e}}{\rho-1}\right]\left[1-\delta_{e} \frac{\zeta\left(\bar{x}_{c}\right)}{\eta_{e}}\right]\left[\frac{1+\bar{R}}{\exp \left(\bar{g}_{Y}\right)}\right] \frac{\bar{i}_{r}}{\bar{v}} \frac{1}{\left[1+\frac{\bar{u}}{\bar{v} \eta_{e}} \exp \left((\rho-1) \bar{g}_{Z}-\bar{g}_{M}\right)\right]},
\end{gathered}
$$

where $\frac{\zeta\left(\bar{x}_{c}\right)}{\eta_{m}}=\frac{\operatorname{avsize}_{c}}{\operatorname{avsize}_{m}}, \frac{\zeta\left(\bar{x}_{c}\right)}{\eta_{e}}=\frac{\text { avsize }_{c}}{\text { avsize }_{e}}, \eta_{m} \exp \left(\bar{g}_{M}-(\rho-1) \bar{g}_{Z}\right)=\operatorname{avsize}_{m}$ and $\eta_{e} \exp \left(\bar{g}_{M}-\right.$ $\left.(\rho-1) \bar{g}_{Z}\right)=$ avsize $_{e}$ as in our baseline model. These expressions coincide with expressions 86, (87) and (88) in our baseline model with the exception of the added terms $\left[1+\frac{\bar{u}}{\bar{v} \times a v \overline{s i z e} e_{m}}\right]^{-1}$ and $\left[1+\frac{\bar{u}}{\bar{v} \times a v \overline{s i z e} e_{e}}\right]^{-1}$ in $\Theta_{m}$ and $\Theta_{e}$. The ranking of impact elasticities is equal to that in our baseline specification. Lemma 4 providing conditions under which the equilibrium allocation of innovative investment on the initial BGP is conditionally efficient holds, except that in case (i) there is an additional requirement that $\overline{\bar{u}} \rightarrow 0$.

We now describe how we infer the value of $\frac{\bar{P}_{r t} \bar{x}_{e}}{\bar{Y}_{t}}$, which we use to measure $\Theta_{e}$ in equation (36) (and which is also used to measure the remaining impact elasticities). By the free entry condition (124),

$$
\frac{\bar{P}_{r t} \bar{x}_{e}}{\left(1+\tau_{y}\right) \bar{Y}_{t}}=\frac{\exp (\bar{g} Y)}{1+\bar{R}} \frac{\bar{v} \bar{s}_{e}}{\left(1-\tau_{e}\right)}\left(1+\frac{\bar{u}}{\bar{v} \times \operatorname{avsize}_{e}}\right)
$$

where $\bar{s}_{e}$ and avsize $_{e}$ can be measured as described in Appendix C.3. Combining equations (125) and (126), we obtain

$$
\bar{v}\left(1+\frac{\bar{u}}{\bar{v}}\right)=\frac{\mu-1}{\mu}-\frac{\left(1-\tau_{c}\right) \bar{P}_{r t}\left(\bar{x}_{c}+\bar{x}_{m}\right)}{\left(1+\tau_{y}\right) \bar{Y}_{t}}+\frac{\exp (\bar{g} Y)}{1+\bar{R}} \bar{v}\left(1-\bar{s}_{e}\right)\left[1+\frac{\bar{u}}{\bar{v} \times \operatorname{avsize}_{c m}}\right]
$$


where

$$
\operatorname{avsize}_{c m}=\frac{\left(1-\bar{s}_{e}\right)}{\left(1-\bar{f}_{e}\right)}
$$

Given a value of $\bar{u} / \bar{v}$ and measures of $\bar{s}_{e}$, avsize $\bar{s}_{c m}$, and $\frac{\bar{P}_{r t}\left(\bar{x}_{c}+\bar{x}_{m}\right)}{\left(1+\tau_{y}\right) \bar{Y}_{t}}$, we use equation (127) to calculate $\bar{v}$ and $\frac{\bar{P}_{r t} \bar{x}_{e}}{\left(1+\tau_{y}\right) \bar{Y}_{t}}$, with which we can then calculate all impact elasticities.

While the ratio $\bar{u} / \bar{v}$ cannot be inferred directly, we can bound it as follows. Equation (125) provides an upper bound for $\bar{v} /(\bar{v}+\bar{u})$ (since $\left.\bar{x}_{c} \geq 0\right)$, and equation (126) provides a lower bound for $\bar{v} /(\bar{v}+\bar{u})$ (since $\left.\bar{x}_{m} \geq 0\right)$. Given $\bar{v} /(\bar{v}+\bar{u})$, we can pin down the value of $\bar{x}_{c}$ relative to $\bar{x}_{m}$.

Finally, note that using equations (124), (125), and (126), the total value of incumbent firms relative to output in the BGP is given by

$$
\bar{v}+\bar{u}=\frac{1}{\left(1-\frac{\exp \left(\bar{g}_{\bar{\gamma}}\right)}{1+\bar{R}}\right)}\left[\frac{\mu-1}{\mu}-\frac{\bar{P}_{r t}}{\left(1+\tau_{y}\right) \bar{Y}_{t}}\left(\left(1-\tau_{c}\right) \bar{x}_{c}+\left(1-\tau_{m}\right) \bar{x}_{m}+\left(1-\tau_{e}\right) \bar{x}_{e}\right)\right],
$$

which coincides with the expression (91) for $\bar{v}$ in our baseline model. 